Development of a Current

Collection Loss Management

System

for SDI Homopolar Power

Supplies

Annual Progress Report \#1 Covering the Period September 30, 1986

to September 30, 1987

Preparec for

U. S. Dept. of Energy

San Francisco Operations Office

1333 Broadway

Oakland, CA 94612

Under Contract No. DE-AC03-86SF 16518

G.0. No. SF-11856-CE

by

William F. Hannan III, Principal Investigator

Technical Contributors: D. W. Brown, D. Pavlik, E. S. Ortoli, A. Patterson, and G. T. Mallick

Westinghouse Electric Corporation

Research and Development Center

Pittsburgh, PA 15235 
Development of a Current

Collection Loss Management System

for SDI Homopolar Power

Supplies

Annual Progress Report \#1 Covering the Period September 30, 1986 to September 30, 1987

Prepared for

U. S. Dept. of Energy

San Francisco Operations Ofice

1333 Broadway

Oakland, CA 94612

Under Contract No. DE-AC03-86SF16518

G.0. No. SF-11856-CE

by

William F. Hannan III, Principal Investigator

Technical Contributors: D. W. Brown, D. Pavlik, E. S. Ortoli, A. Patterson, and G. T. Mallick

Westinghouse Electric Corporation

Research and Development Center

Pittsburgh, PA 15235

\section{DISCLAIMER}

This report was prepared as an account of work sponsored by an agency of the United States Government. Neither the United States Government nor any agency thtreof, nor any of their employees, makes any warranty, express or implied, or assumes any legal liability or responsibility for the accuracy, completeness, or usefulness of any information, apparatus, product, or process disclosed, or represents that its use would not infringe privately owned rights. Reference herein to any specific commercial product, process, or service by trade name, trademark, manufacturer, or otherwise does not necessarily constitute or imply its endorsement, recommendation, or favoring by the United States Government or any agency thereof. The views and opinions of authors expressed herein do not necessarily state or reflect those of the United States Government or any agency thereof. 
Written by: W.F. Hammen W. W. Hannan, III Electromechanical Applications

Reviewed by: $\frac{\text { Pewen } L 1 / 2}{0}$ 0. S. Taylor, Manager Electromechanical Applications

Reviewed by: Cokbeyne C. J. Heyne, Manager Electromechanical Systems

Approved by: F.J. Thompsere F. T. Thompson, Manager Bngineering Technology Division

Westinghouse Electric Corporation Research and Development Center 1310 Beulah Road

Pittsburgh, Pennsylvania 15235 


\section{TABLE OF CONTENTS}

EXECUTTVE SUMMARY............................ iv

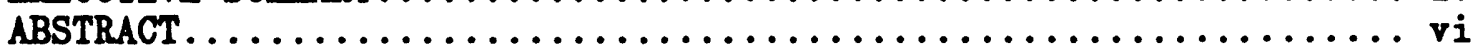

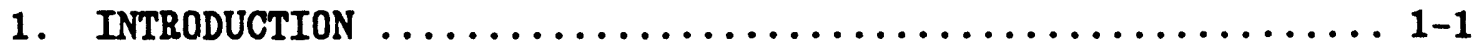

1.1 BACKGROUND ................................... 1-

1.1 .1 Homopolar Porer Supply ......................... 1-1

1.1 .2 Current Collection Technology .................... 1-3

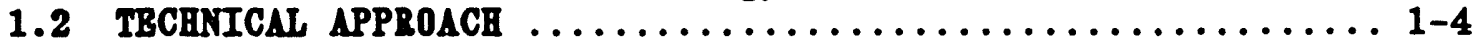

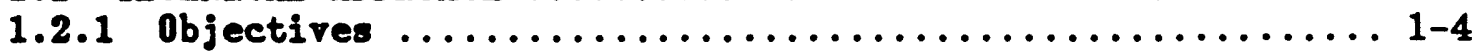

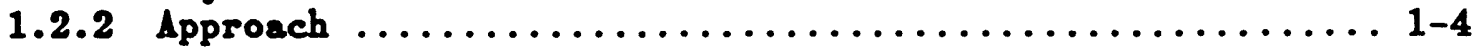

1.2 .3 Gool $\ldots \ldots \ldots \ldots \ldots \ldots \ldots \ldots \ldots \ldots \ldots \ldots \ldots \ldots \ldots \ldots \ldots \ldots$.

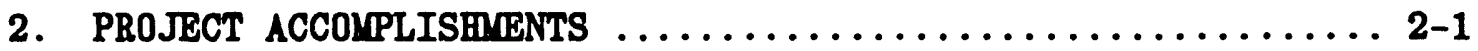

2.1 CRYOGENIC CURRENT COLLECTION TBST RIG .............. 2-1

2.1.1 Background of Cryogenic Testing .................. 2-1

2.1.2 Cryogenic Test Rig Design ...................... 2-1

2.1.3 Cryogenic Test Rig Status .................... 2-7

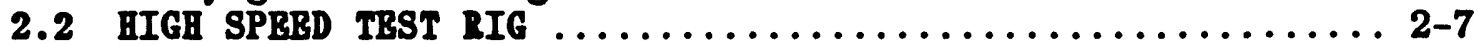

2.2.1 Background of High Speed Test Rig $\ldots \ldots \ldots \ldots \ldots \ldots \ldots \ldots$ 2-7

2.2.2 High Speed Test Rig Blectrical Design .............. 2-8

2.2.3 High Speed Test Rig Yechanical Design ............... 2-10

2.3 TBST DATA ACQUISITION SYSTEY ................... 2-10

2.3.1 Specifications for Data Acquisition System, High

Current Brush Bxperiment ......................... 2-10

2.3.2 Data Aequisition Systen for Current Collection

Bxperiment ............................... 2-14

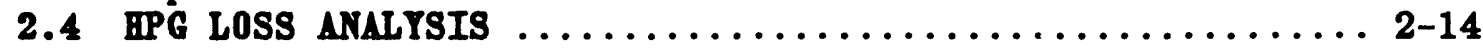

2.5 HOYOPOLAR YACHINB APPLICATION STUDY $\ldots \ldots \ldots \ldots \ldots \ldots \ldots \ldots$ 2-17

2.5.1 Background................................ 2-17

2.5.2 Conclusions and Recommendations............... 2-21

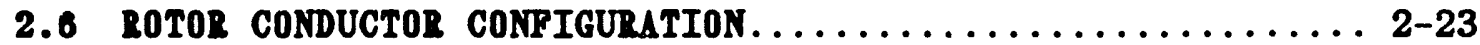

2.6.1 Rotor Stress............................. 2-23

2.6.2 Heat Transfer........................... 2-23

2.7 SHUNT-BRUSH DIPFUSION BOND................... 2-24

3. SCHEDULE/STATUS . ........................

4. FUTURE EFFORTS. .......................... 4-1

4.1 Test Progran.............................. 4-1

4.2 Detailed Loss Analysis......................... 4-1

4.3 Develop Detailed Design of Brush/Collector Concept........ 4-1

4.4 Prototype Current Collection System - Construction and

Test.................................44-2 


\section{TABLE OF CONTENTS (CONT'D)}

$\underline{\text { Page }}$

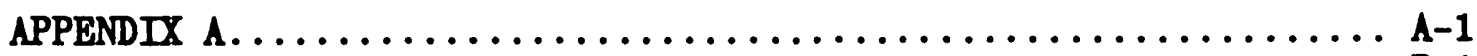
APPENDIX B. $\ldots \ldots \ldots \ldots \ldots \ldots \ldots \ldots \ldots \ldots \ldots \ldots \ldots \ldots, \mathrm{B}-1$ 


\section{LIST OF FIGURES}

$\underline{\text { Page }}$

Figure 1.1 - High power density homopolar generator.......... 1-2

Figure 2.1 - Slip-ring cross section liquid nitrogen-cooled test rig. .......................... 2-2

Figure 2.2 - Slip-ring assembly - liquid nitrogen-cooled test rig. ......................... 2-4

Figure 2.3 - Liquid nitrogen-cooled current collection test rig. ........................... 2-5

Figure 2.4 - Liquid nitrogen-cooled slip-ring. ........... 2-6

Figure 2.5 - Cross section - high speed (200 m/s) current collection test rig. ..................... 2-9

Figure 2.6 - Stator Eleld winding - high speed test rig. ..... 2-11

Figure 2.7 - Rotor parts as of September 1987. Note large copper cylinder shrunk onto the steel cylinder. .. 2-12

Figure 2.8 - Data acquisition system for the high speed test rig. ............................ 2-15

Figure 2.9 - Boundary conditions on surface are expressed as limits on radial currents over outer surface and condition of no axial currents from ends of conductor. ............................ 2-16

Figure 2.10 - Surface plot showing radial current injected at cylindrical surface................... 2-18

Figure 2.11 - Ideal drum type homopolar motor............ 2-19

Figure 2.12 - Micrograph of the interface between the \#359 $\mathrm{Cu}-\mathrm{C}$ and copper.....................26

Figure 2.13 - Nicrograph of the interface between the \#933 $\mathrm{Cu}-\mathrm{C}$ and copper.......................27

Figure 3.1 - Current collection program-schedule........... 3-1 


\section{EXECUTIVE SUMMARY}

Various weapons systems under consideration for the Strategic Defense Initiative (SDI) will require large amounts of electrical power (hundreds of megawatts). A large portion of that electrical power is dc, depending upon the particular application. This program supports the development of enabling technologies for large dc power supplies for SDI, specifically the homopolar generator.

An example of one such weapons system to be identified is the neutral particle beam (NPB). NPB is the application chosen for analysis and comparison in this program. RF power generation is the major consumer ( $90 \%$ ) of NPB burst mode power. It also occupies a major portion of the platform mass (up to 60\%). Since RF generation comprises the largest component of power consumption, it is important to develop efficient, lightweight power supplies to operate them.

Four specific areas have been identified which are considered "enabling technologies" necessary to construct spaceborne homopolar power supplies. These areas are as follows:

- Steady-state operation of current collectors at cryogenic temperatures

- Rejection of the immense heat flux occurring at the slip ring surface

- Identification of all appropriate loss mechanisms

- Modeling of the underlying electromagnetics of high powered homopolar devices

Work done on this contract has advanced and will continue to advance the state of the art in high powered space power supplies. Specific accomplishments are as follows:

- Construction of the first high current density current collection test rig to demonstrate operation at cryogenic temperatures. 
- Identification of pool boiling of available cryogenic fuel in the centripetal field of the rotor conductor as adequate to reject the large heat fluxes required.

- Identification of a significant loss mechanism driven by a "skin effect" shown to develop in high velocity current collectors utilizing monolithic brushes.

- Creation of an electromagnetic model to optimize air-cored homopolar machines. A significant, surprising result of this study demonstrates that such machines are optimized at operational magnetic fields of $\sim 2$ tesla, which is much lower than previously assumed.

- Tradeoff analysis shows that air-cored homopolars can achieve power densities of $80 \mathrm{~kW} / \mathrm{kg}$ at a power level of 50 $M W$, and with an efficiency of $97 \%$. This performance satisfies the weight and power goals desired for such devices.

Work remaining in the second year of this contract will demonstrate low speed, high current density, cryogenic operation of a current collector utilizing the cryogenic test rig. High speed, high current density operation of a current collector will be demonstrated utilizing the high speed $(200 \mathrm{~m} / \mathrm{s})$ test rig. Knowledge gained under these tests will be used to construct and demonstrate a continuouslyoperating current collection system operating at $12 \mathrm{kA} / \mathrm{cm}^{2}$ and at 200 $\mathrm{m} / \mathrm{s}$ rubbing velocity, with a packing factor greater than 0.2 .

Significant progress has been made toward developing the enabling technologies needed to operate high powered homopolar power supplies in the space environment. 


\begin{abstract}
High speed, high power density current collection systems have been identified as an enabling technology required to construct homopolar power supplies to meet SDI missions. This work is part of a three-year effort directed towards the analysis, experimental verification, and prototype construction of a current collection system designed to operate continuously at $2 \mathrm{kA} / \mathrm{cm}^{2}$, at a rubbing speed of $200 \mathrm{~m} / \mathrm{s}$, and with acceptable losses in a space environment. To date, no system has achieved these conditions simultaneously.

This is the annual report covering the first year period of performance on DOE contract DE-ACO3-86SF16518.

Major areas covered include design and construction of a cryogenically-cooled brush test rig, design of a high speed brush test rig, loss analysis of the current collection system, and an application study which defines the air core homopolar construction necessary to achieve the goal of $80-90 \mathrm{~kW} / \mathrm{kg}$ generator power density.
\end{abstract}




\section{INTRODUCTION}

\subsection{BACKGROUND}

\subsubsection{Homopolar Power Supply}

Homopolar machines have been used for sver a cecade as reliable high current pulsed power supplies for Electromagnetic Launchers (EML), resistance welding, and metal compaction. In the 1970s, several ironcored homopolar machines were built as power supplies for laboratory EML systems. Although these machines satisfactorily performed their functions, their power density was $10 \mathrm{w}(<10 \mathrm{~kW} / \mathrm{kg})$ and they could produce only one short-duration pulse every several hours. The movement of these power supplies to space requires a new approach with high power density, acceptable efficiency, and the capability of essentially steady operation for rapid fire. One new approach is an air core homopolar employing cryogenically-cooled coils (hyperconducting or superconducting).

The voltage developed by a homopolar machine is proportional to the machine active length, the magnetic field intensity, and the rotor tip speed. Iron-cored machines are limited to a magnetic field strength of about 2.0 tesla; the rotor tip speed is limited by the strength of the ferromagnetic material in the rotor. In an air-cored machine, for the same active length, fields of as high as 6 tesla and possibly higher can be achieved and rotor tip speeds can be increased through the use of unique rotor designs and high strength, light weight materials. A section $0:$ an air core drum type homopolar is shown in Figure 1.1. The drux type configuration was chosen because it produces higher power density and generated voltage than other configurations, based on a study in which Westinghouse was a principal contributor. The machine in Figure 1.1 represents a module consisting of two counter-rotating rotors 


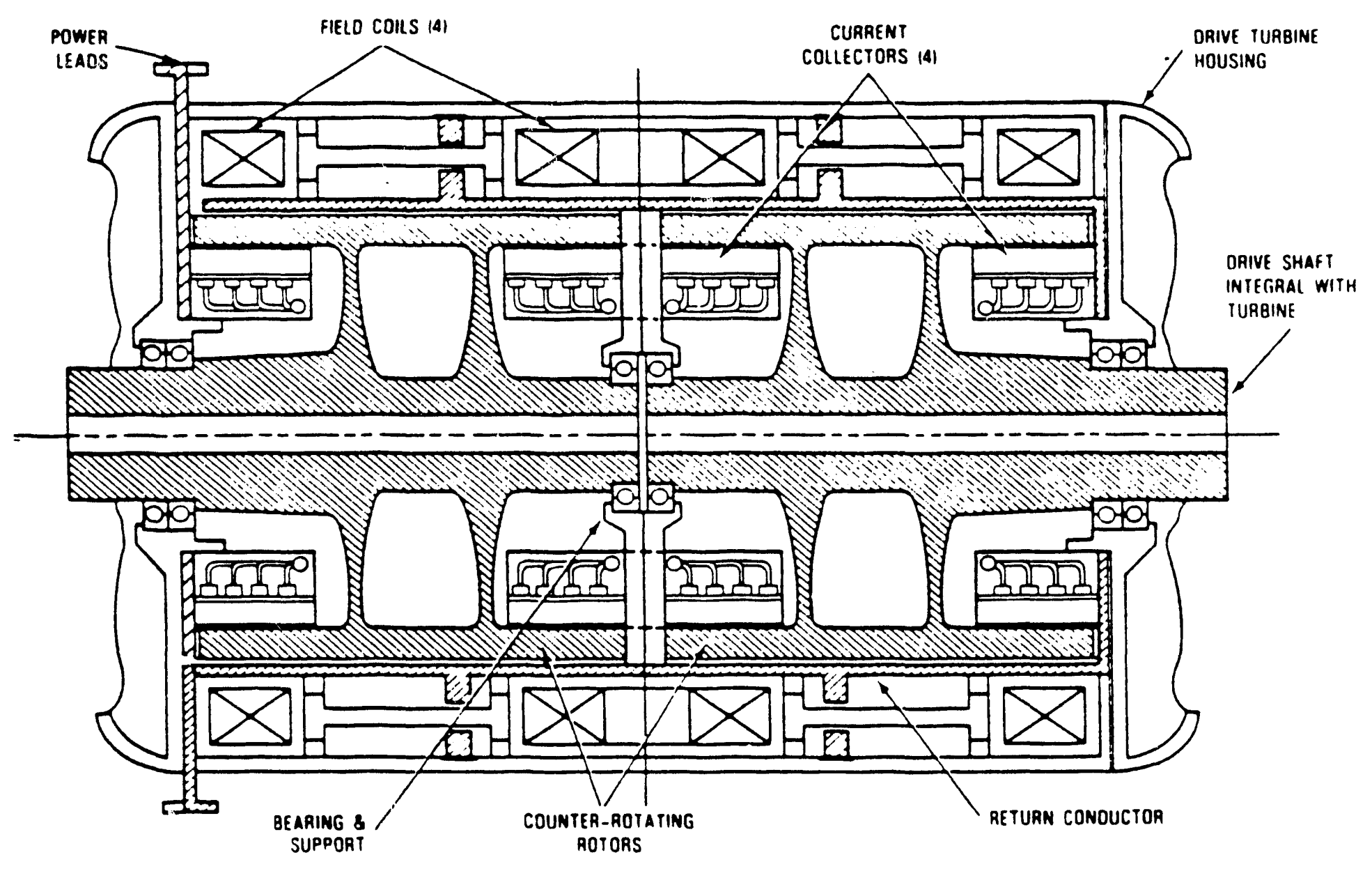

Figure 1.1 - High power density homopolar generator. 
designed to eliminate any net torque on the space vehicle foundation. These modules can be connected in series or parallel to achieve the voltage or current required. Using this approach, the power densities required for SDI $(80-90 \mathrm{~kW} / \mathrm{kg})$ can be achieved. The success of this approach is dependent on the development of a current collection system that will: (1) function in the machine, (2) operate in the environment, (3) pass current at a high density $\left(2 \mathrm{kA} / \mathrm{cm}^{2}\right)$ and high rubbing speed $(200 \mathrm{~m} / \mathrm{s})$ continuously, (4) have acceptable losses, and (5) operate near the temperature of the coolants available (possibly liquid hydrogen or liquid oxygen). Such a current collection system is not yet available.

\subsubsection{Current Collection Technology}

Significant advancements in conventional electrical brush contacts have resulted from research and development programs, such as those at the Westinghouse R\&D Center, during the past forty years. Within the past ten years, advanced machine and device applications have been identified which require brush current densities for continuous duty 10 to 50 times higher and for intermittent or pulsed duty up to 5,000 times higher than for the highest conventional sliding brush contact system. Through intensive R\&D effort, achievement of these brush-ring contact, high current density goals has been demonstrated with laboratory test apparatus and with actual prototype machines and devices. The high contact current densities are achieved by employing selected brush and ring (or rail) materials, unique brush configurations, conventional to special cooling, and controlled ambient gas/vapor environments.

Although current collection systems have been developed for various applications requiring high current density, high speed, and steady-state operation, a single system has yet to be developed which meets all of these requirements simultaneously. In this context, steady-state operation (in terms of temperature rise) is acknowledged to be reached in 30 to 300 seconds. This void in the technology presents a significant challenge to machine applications which require operating times in the order of minutes. 


\subsection{TECHNICAL APPROACH}

\subsubsection{Objectives}

The objective of this program is to produce a current collection. system that will function as part of an air core homopolar power supply designed to operate in space. The current collection system will be designed to meet certain specific technical goals including: continuous oneration at high current density $\left(2 \mathrm{kA} / \mathrm{cm}^{2}\right)$, high rubbing speed $(200 \mathrm{~m} / \mathrm{s})$ in a high local magnetic field (2 to $6 \mathrm{~T}$ ) with acceptable losses and wear associated with the extreme reliability demanded of space equipment.

\subsubsection{Approach}

The current collection system will be developed by the program. The program consists of two parallol parts: (1) the development of a cryogenic brush slip-ring combination, and (2) the development of a cooling system that is capable of continuously removing the losses generated. The results will be incorporated into the design of a current collection system capable of operating in an air-cored homopolar power supply for continuous operation in space. In the third year of the project, a prototype current collection system will be fabricated and tested to confirm its operational characteristics.

\subsubsection{Goal}

The program goal is to analyze, design, build, and test a continuously operating ( $>30 \mathrm{~s}$ ) current collection system with a $200 \mathrm{~m} / \mathrm{s}$ rubbing velocity, $2 \mathrm{kA} / \mathrm{cm}^{2}$ current density in the current collector and with a 0.2 packing factor.

Packing factor is defined as the ratio of the gross rubbing area of the current collector divided by the area of the rotor swept by the current collector.

Additional goals of the program are to demonstrate analytically that such a current collection system will operate in the expected magnetic fields occurring in such a high powered device, and that 
homopolar power supplies meeting power densities of $80-90 \mathrm{~kW} / \mathrm{kg}$ are practical utilizing such systems. 


\section{PROJECT ACCOMPLISHMENTS}

\subsection{CRYOGENIC CURRENT COLLECTION TEST RIG}

\subsubsection{Background of Cryogenic Testing}

Heat rejection from space-based homopolar power supplies will. be accomplished utilizing liquid hydrogen which will then fuel the prime mover.

Utilization of a cryogenic fluid to cool the current collection system will impose operational temperatures much lower than ever experienced in high speed, high power density current collection devices.

Conventional sliding contacts rely upon establishing a thin, conductive film to provide a suitably conductive, lubricated interface. Such films are normally formed of graphite present in conventional brushes acting in the presence of water vapor or certain hydrocarbon vapors. With the exclusion of such vapors from a conventional brush, the graphite film becomes abrasive, and rapid wear results.

Special brushes utilized for high altitude or extreme cold have been developed to allow the formation of conductive films under adverse conditions. These brush materials have special additives, such as lithium flouride, which assist in film formation.

The initial testing conducted in this program will be conducted with commercially-available, high altitude brush grades purihased from the Stackpole Carbon Company.

The cryogen that will be used for testing will be liquid nitrogen.

\subsubsection{Cryogenic Test Rig Design}

The design of the cryogenically-cooled slip-ring is shown in

Figure 2.1. In operation, liquid nitrogen is fed on axis into the inner 


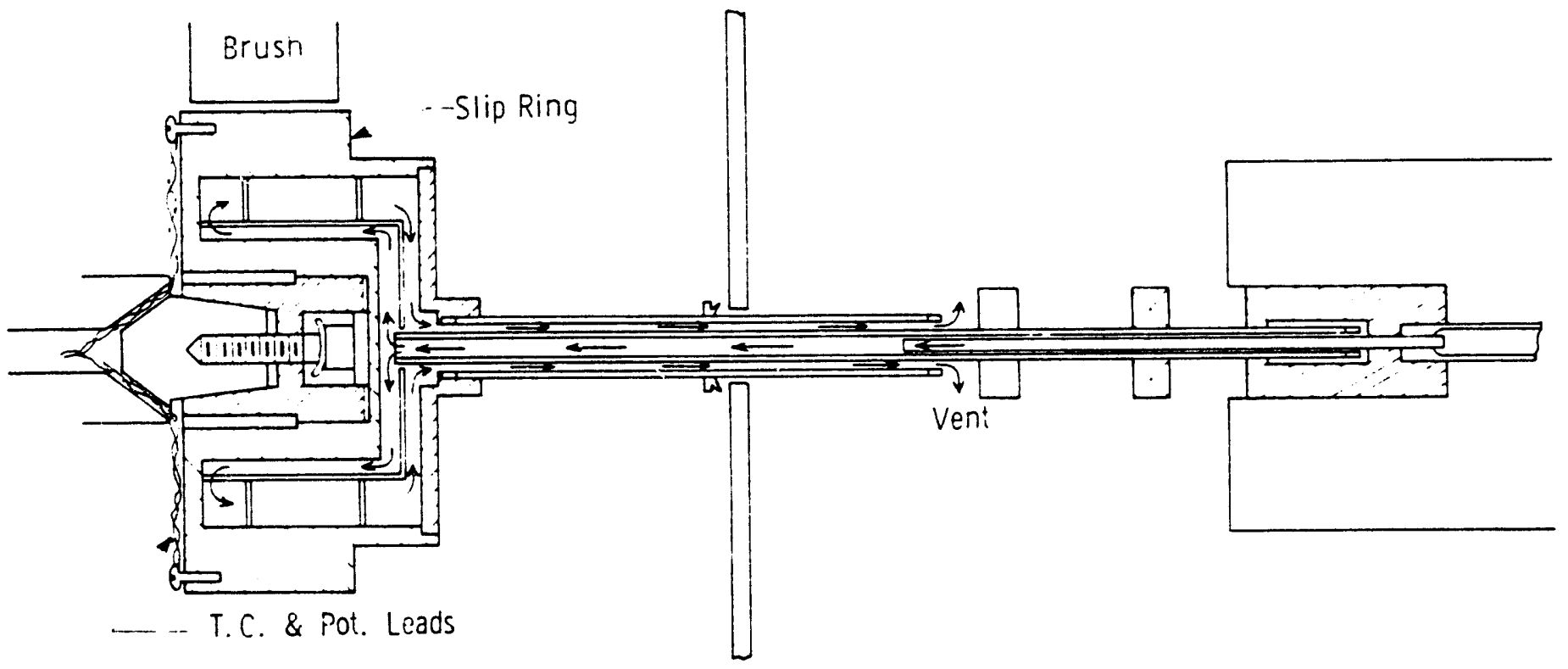

Figure 2.1 - Slip-ring cross section liquid nitrogen-cooled test rig. 
chamber of the slip-ring. From there it flows off axis into a baffle which directs the stream towards the far end of the chamber, where the stream again is diverted, into the outer chamber and reversed. When the outer chamber fills, the overflow is vented through a tube which is coaxial to the inlet bayonet. The cryogen flow initially will be controlled by a manual hand valve. Two thermocouples have been placed diametrically on the rear surface of the slip-ring, near its outer diameter. Two potential leads have been similarly connected.

The cryogenic operating temperature of the slip-ring necessitated shaft replacement by one made of 304 stainless steel., eliminating the possibility of low temperature embrittlement. An instrumentation lead access hole was drilled the length of the shaft, allowing the thermocouples and potential leads to be connected to an instrumentation slip-ring assembly connected to the other end of the shaft.

Figure 2.2 shows the completed shaft assembly, slip-ring assembly, seals, and couplings.

The slip-ring test rig has been reassembled. The test rig is shown in Figures 2.3 and 2.4. Provisions have been made to continuously monitor those parameters deemed necessary for analyzing the assigned tasks. These are as listed:

Drive motor power

Drive motor speed (series connected to slip-ring)

Brush current

Brush/slip-ring potential

Brush temperature

Slip-ring temperature

Chamber gas temperature

Chamber gas pressure

Cryogen flow rate 


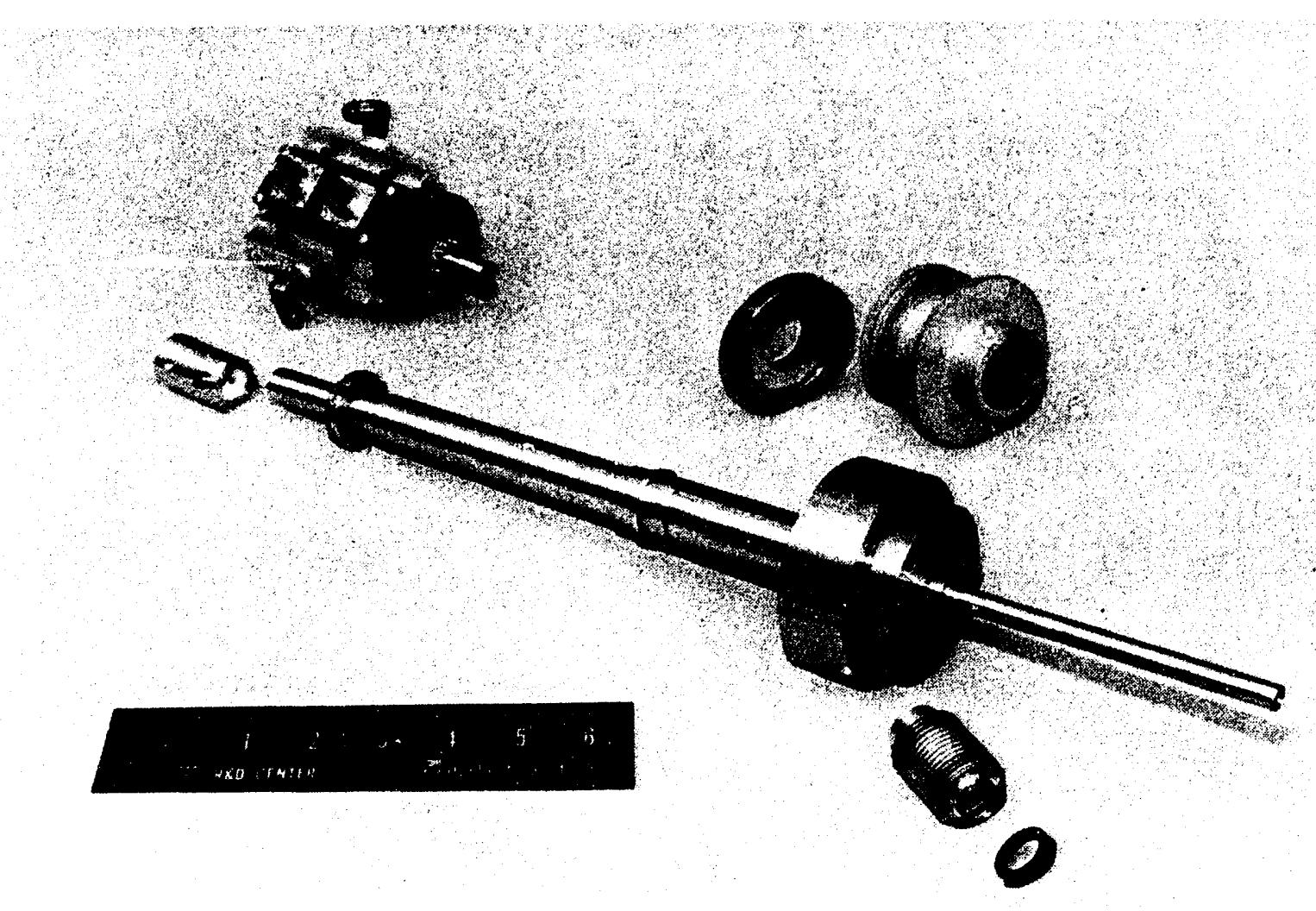

Figure 2.2 - Slip-ring assembly - liquid nitrogen-cooled test rig. 


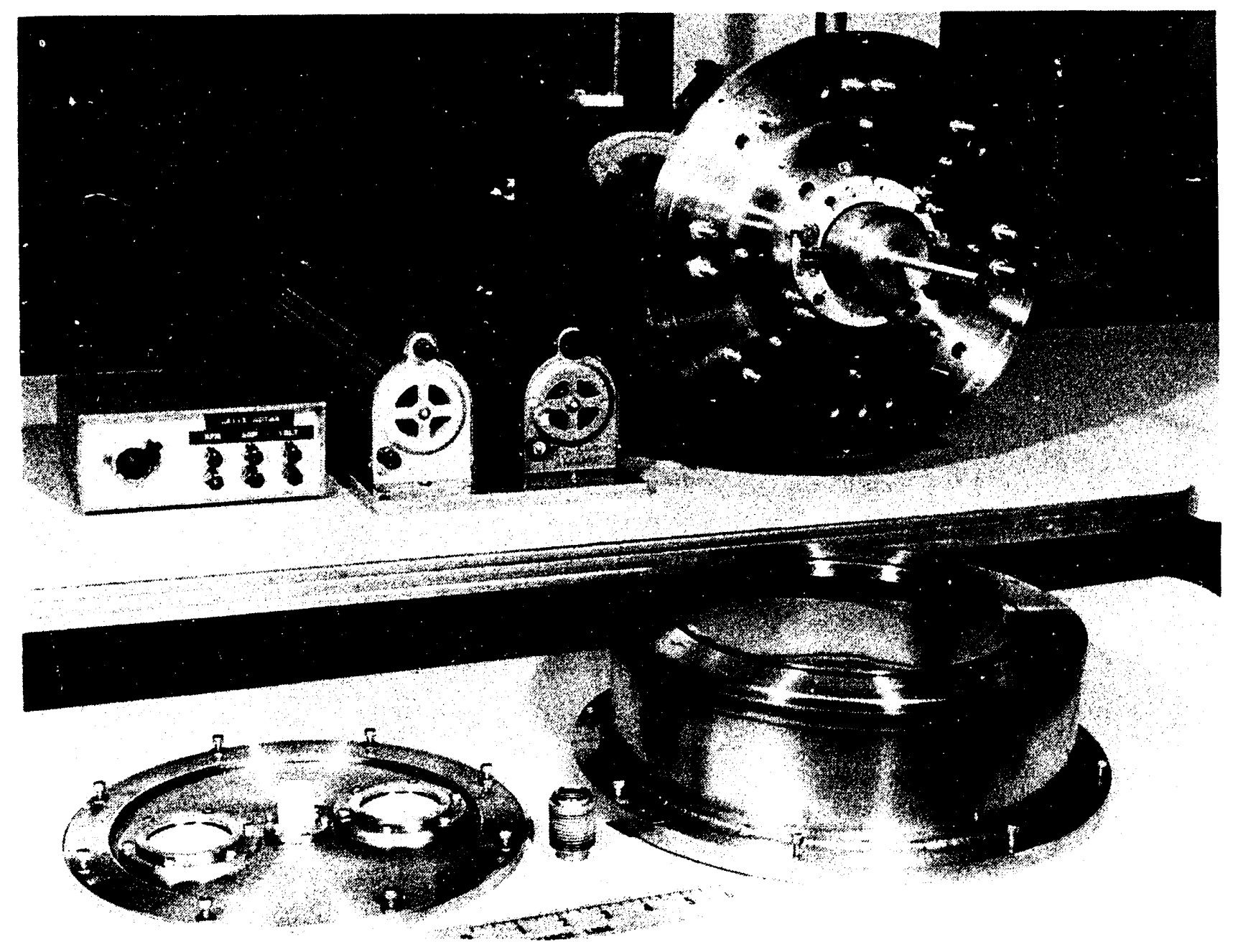

Figure 2.3 - Liquid nitrogen-cooled current collection test rig. 


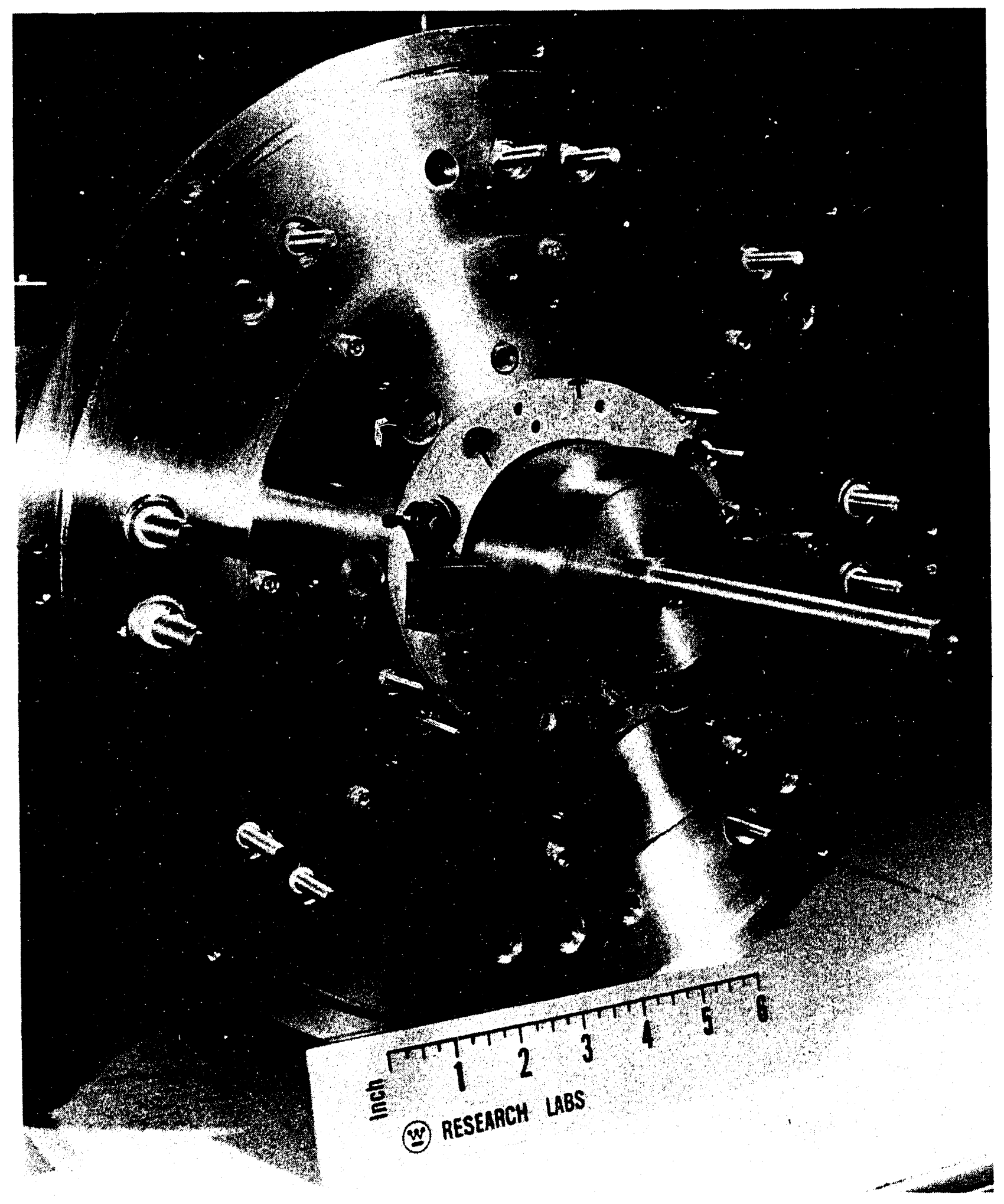

Figure 2.4 - Liquid nitrogen-cooled slip-ring. 


\subsubsection{Cryogenic Test Rig Status}

The test rig was $90 \%$ assembled when the funding allotted for FY-87 was exhausted. Testing will occur approximately two to three weeks after the program restarts and a technician is acquired.

\subsection{HIGH SPEED TEST RIG}

\subsubsection{Background of High Speed Test Big}

High speed, high power density current collection systems are fundamentally limited by temperature rise. It is believed that wear is strongly dependent upon the temperature experienced at the rubbing interface.

In order to experimentally demonstrate the operation of a current collection system, it is necessary to duplicate the actual heat loading experienced by the slip-ring. For this reason, full "coverage" of the slip-ring with the same ratio of brush area to rotor swept area is needed. Simply testing with a brush or two per end will not thermally load the collector ring to adequately demonstrate operational temperature limits.

Due to the large current densities required, and in order to keep the size of the experimental current source to a manageable level, it is desirable to fabricate a small, high speed test rig.

The operation at high speed of a small diameter test rig requires high rotational speed. Typical mechanical methods of supplying power to a high speed rotor consist of gears or belts.

High speed gearing or belting was found to require multiple stages of rotational speed increases. They both resulted in systems that were either overly complicaten, very expensive, or required large power input just to feed the associated losses, such as bearing loss or loss due to belt slippage. High speed belting was inappropriate since the centrifugal force acting on the belt was enough to lift the belt from the rotor surface.

An attractive alternative was found in an "inside-out," 2-pole, solid armature induction motor. The 2-pole motor will be driven by a 
power supply capable of providing 3-phase power at up to $400 \mathrm{~Hz}$. A preliminary view of the high speed test rig is shown in Figure 2.5.

It should be noted that this test rig is not actively cooled.

Testing will be limited in duration by the observed temperature rise of the motor field and the rotor conductor.

\subsubsection{High Speed Test Rig Electrical Design}

An "inside-out" solid steel rotor polyphase induction motor was selected for the current collector test rig. By locating the solid steel rotor at the outer periphery of the motor and by making the appropriate choice of rotor diameter and motor poles and frequency, the test collector rings may be operated at the desired surface speed while minimizing the volume of collector ring material required. The stator winding, while concentrated in a smaller volume than in the conventional induction motor configuration, receives adequate cooling for intermittent operation of the test rig. (The stator winding has integral thermocouples for thermal monitoring.) Motor line leads and thermocouple leads are brought out through the hollow stationary "shaft" of the motor.

Motor specifications are as follows:

Nominal Rated hp

Duty

Enclosure \& Cooling

Poles

Phase

Nominal Frequency (hertz)

Volts (Line-Line)

Insulation

Speed 0 rated load \& $400 \mathrm{~Hz}$
15

Intermittent

Drip-proof/Self-ventilated

2

3

400

350

Class $\mathrm{H}$ (No silicone materials used to avoid contact contamination) $22000 \mathrm{rpm}$ (approximate)

Amperes 0 rated load \& $400 \mathrm{~Hz} 35$ (approximate) 


\section{HIGH SPEED TEST RIG}

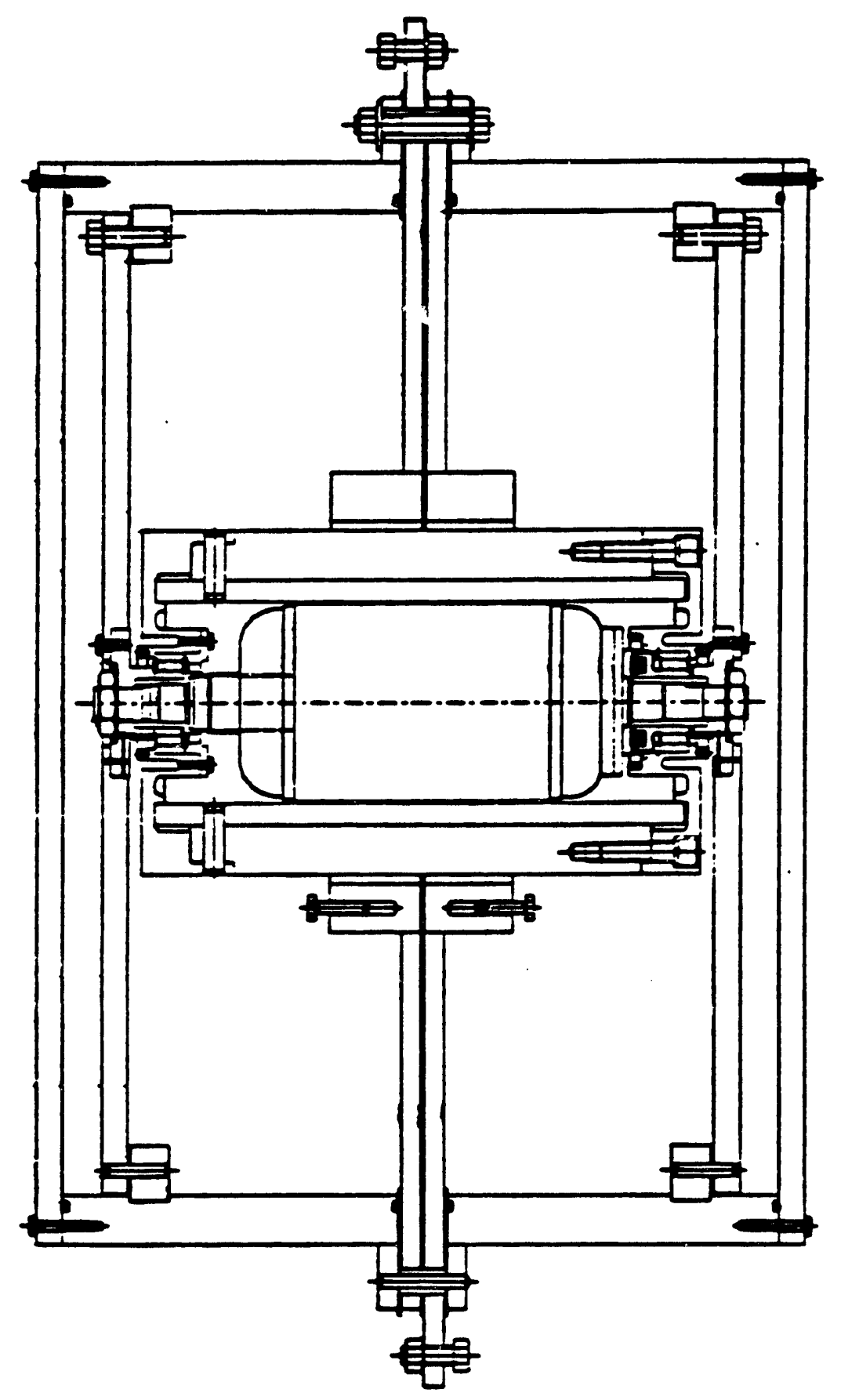

Figure 2.5 - Cross section - high speed $(200 \mathrm{~m} / \mathrm{s})$ current collection test rig. 
Stator fabrication and winding are complete. Precise motor speed and current are dependent on the actual magnetic and electrical characteristics of the steel stock used. Speed can be trimmed to the desired collector ring surface speed by use of a variable frequency power supply.

A picture of the stator winding is shown in Figure 2.6.

\subsubsection{High Speed Test Rig Yechanical Design}

The mechanical design of the high speed test rig centered upon tine rotor design. The rotor consists of a low carbon cold-drawn steel tube upon which is shrunk a chrome copper tube. The steel tube acts as the armature for the "inside-out" induction motor driven by the field winding located inside the tube. The copper cylinder becomes the hign speed current collection surface.

A picture showing the status of the rotor parts when work was suspended is presented as Figure 2.7. The two cylinders described are shown as an assembly in this picture.

The rotor cylinder is completed by endplates which accept high quality, shielded $25-\mathrm{mm}$ ball bearings capable ji operation at speeds in excess of $24,000 \mathrm{rpm}$.

Tasks remaining to complete the high speed test rig include:

- Current collector design

- Structure of high speed test rig

- Detailing of the stator

These tasks will be completed early next year.

\subsection{TEST DATA ACQUISITION SYSTEY}

2.3.1 Specifications for Data Acquisition System, High Current Brush Experiment The compiter-aided instrumentation will be designed to service two sets of brushes, the high current power supply, the motor (440 Hz) power supply, and a tachometer in the following way: 


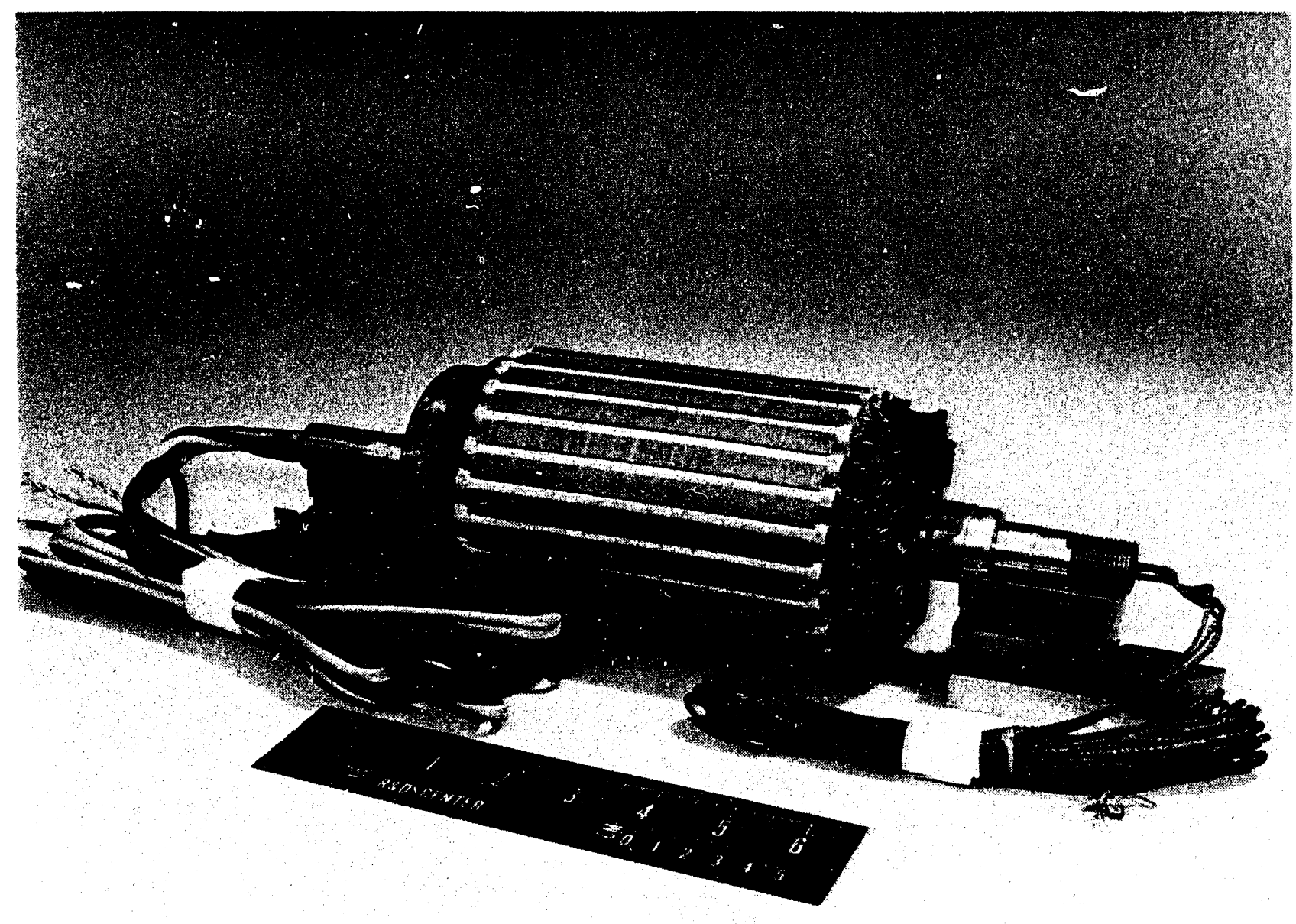

Figure 2.6 - Stator field winding - high speed test rig. 


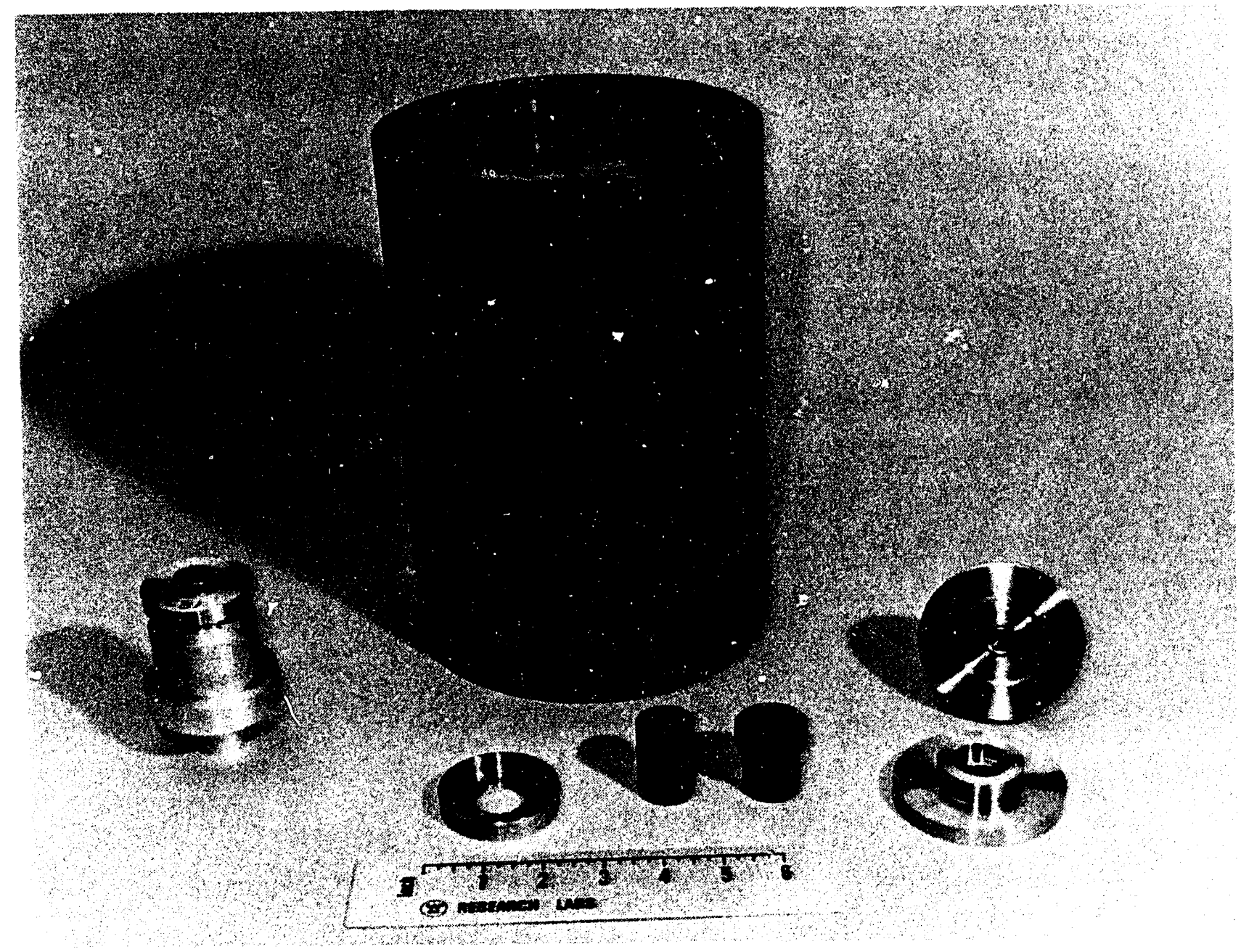

Figure 2.7 - Rotor parts as of September 1987. Note large copper cylinder shrunk onto the steel cylinder. 
The three-phase power supply will be instrumented with current transformers and voltage transducers in such a way as to produce a voltage output that is proportional to the instantaneous power input to the motor.

The net voltage produced by the high current power supply, as well as the current produced thereby, will be monitored.

Each brush set will consist of two primary current carrying brushes, and two auxiliary brushes which will be used for monitoring voltage on the drum. Each brush, regardless of type, will be provided with a copper/constantan thermocouple. The distribution of the current between the two brush sets will be monitored.

Voltage differences between each current-carrying brush, and its companion auxiliary brush will be monitored, anc the voltage difference between the auxiliary brushes will be monitored.

The data acquisition system will be capable of acquiring 32,000 dat: points at a rate of 100 points per second. These measurements will be distributed among the various transducers, but it is intended that there will be two classes, fast and slow.

The practical rate that data will be acquired on any particular fast transducer will be approximately equal to

$$
\mathrm{N} / 100 \text { (second), }
$$

where $N$ is the number of fast transducers. Thus, if there are 10 fast sensors, they will be each polled every tenth of a second.

The speed of the drum will be measured by means of an optical tachometer.

The magnetic field in the vicinity of the current in the drum may be monitored by a magnetic field sensor.

Voltage and current measurementis will be fast measurements. Power input and speed, as well as the thermocouples and magnetic field measurements, will be slow measurements. 


\subsubsection{Data Acquisition System for Current Collection Experiment}

The computerized data acquisition system consists of the following:

- IBM PC-AT personal computer with 30-MB hard drive, one 1.2-MB floppy drive, and one 360-KB drive.

- Intel Above Board memory expansion unit, to provide RAM disk with 1.2-MB capacity.

- Metrabyte DAS-8 analog input board, with 4000 channels/sec capability.

- Metrabyte EXP-16 expansion board for voltage measurements: 16 channels, each channel sampled at approximately 40-ms intervals.

- Metrabyte EXP-16 expansion board for measuring thermocouples, 16 measured at approximately one hertz.

- One channel on an EXP-16 board is dedicated to measuring rpm of the device.

A picture of the data acquisition system is shown in Figure 2.8.

\subsection{HPG LOSS ANALYSIS}

To date, no adequate analytical description of the distribution of rotor currents in the rotor conductor of a homopolar generator is available. Accurate knowledge of this phenomenon is essential to the design of homopolar power supplies operating at high power levels.

In order to define the governing physical phenomenon, an analytical model of the current collector-rotor conductor region has been constructed.

The model is based on a cylindrical conductor with prescribed boundary conditions occurring along its outside surface. The boundary conditions imposed are that current is injected radially into the conductor at prescribed areas.

Figure 2.9 shows the locations where radial current is injected into the rotor. For our test case, this bcundary condition is expressed as a double Fourier's series each containing 12 terms. A surface plot 


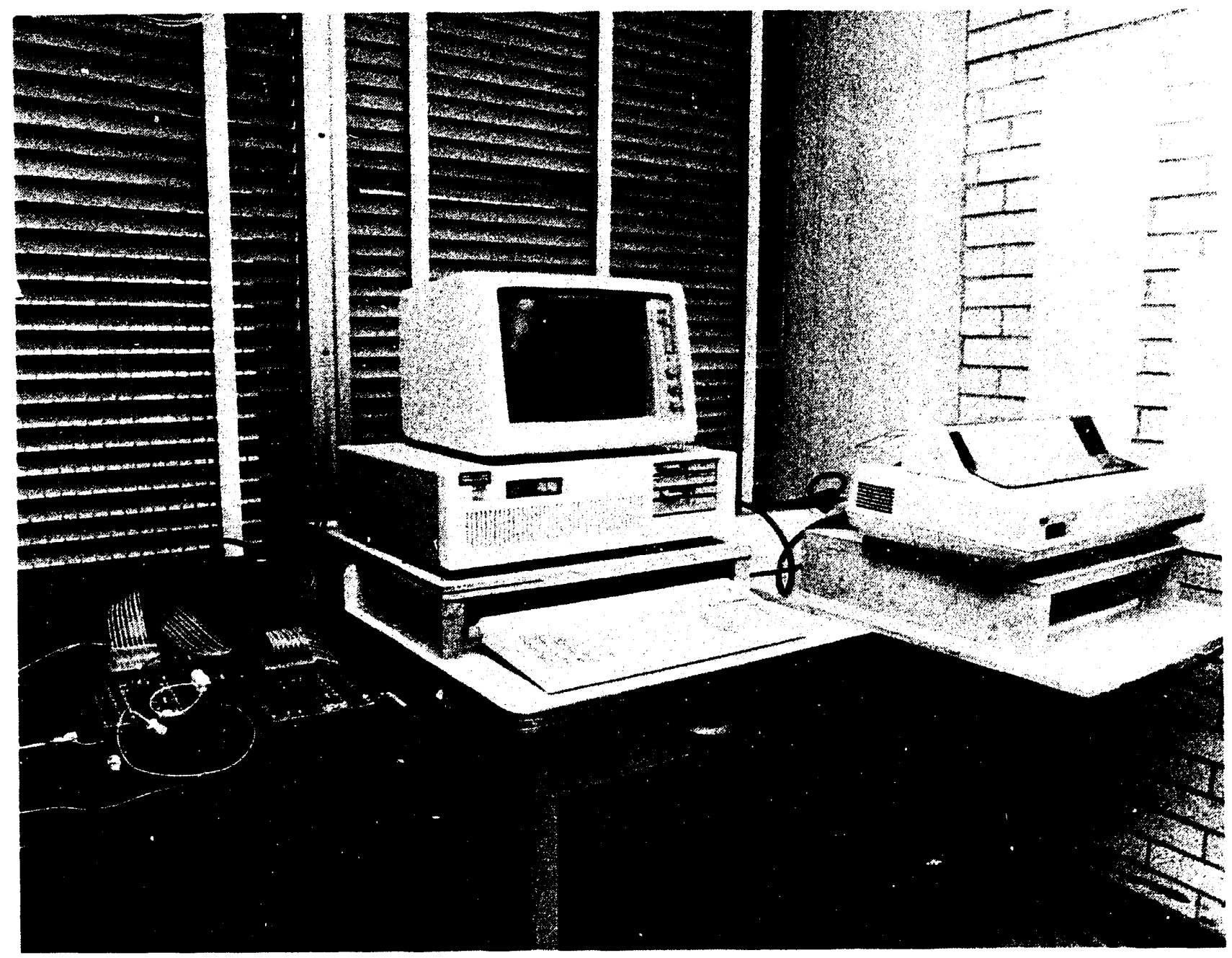

Figure 2.8 - Data acquisition system for the high speed test rig. 


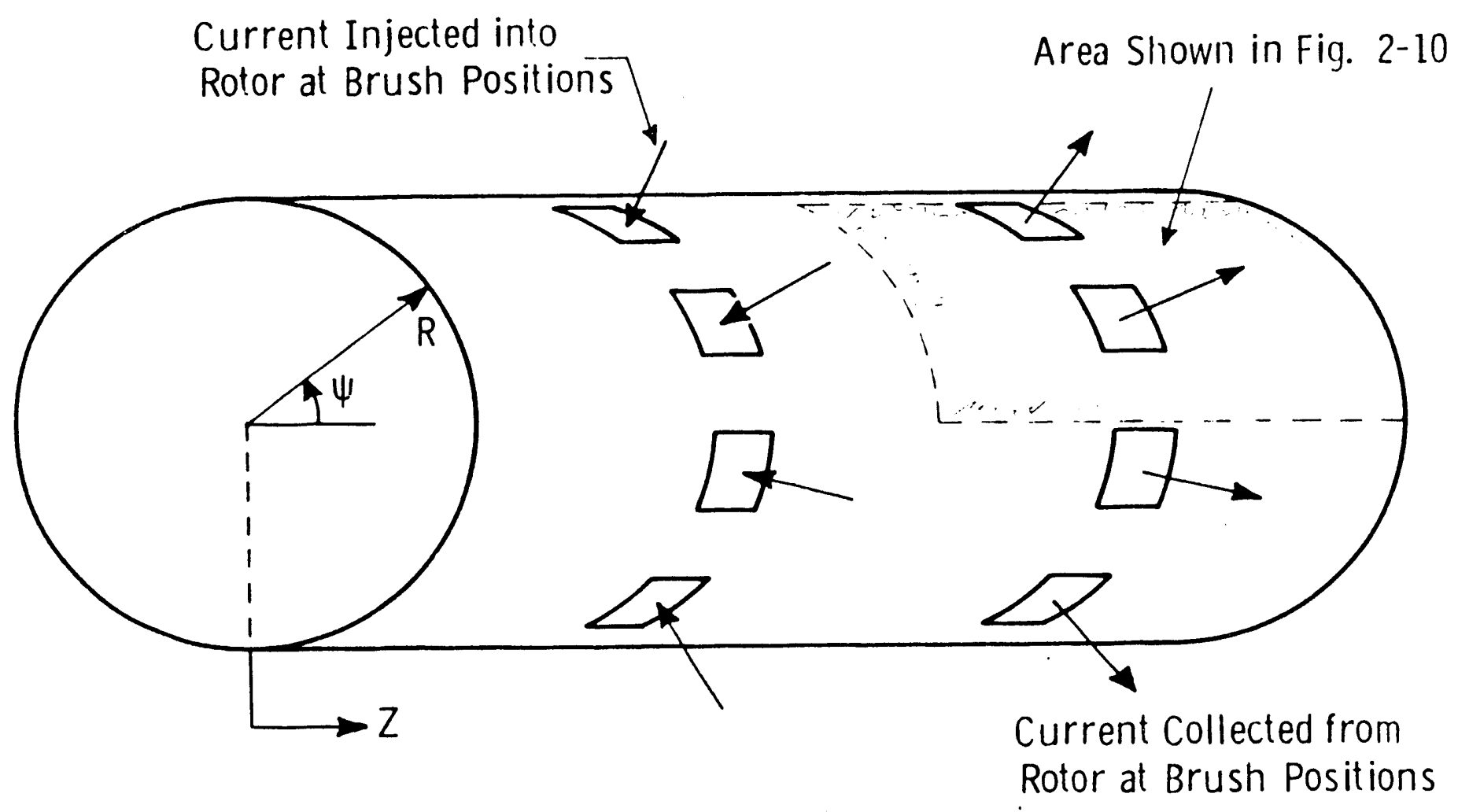

Figure 2.8 - Boundary conditions on surface are expressed as limits on radial currents over outer surface and condition of no axial currents from ends of conductor. 
depicting these conditions is shown as Figure 2.10, where elevations above the surface represents current out of the rotor.

Physical parameters were modeled after those of the 50-hp demonstration homopolar motor designed for proof of concept in homopolar drive of tracked vehicles. These motors operate at $80 \mathrm{~m} / \mathrm{s}$ rubbing speed with a 5 -in $(12.7 \mathrm{~cm})$ diameter rotor at $5-\mathrm{V}$ terminal potential. This was chosen because we have built and tested these devices, and we know their total losses to a high degree of confidence.

The model was run for a 5 -in $(12.7 \mathrm{~cm})$ diameter copper rotor conductor operating at a periferal speed of $100 \mathrm{~m} / \mathrm{s}$. Sixteen brushes were used on each end of the rotor.

Figure 2.9 represents the input boundary conditions imposed upon the model. A strong skin effect of time varying surface currents is developed. The skin depth predicted is approximately 0.040 inch. Details of the analysis can be found in Appendix A.

This model will allow assessment of current collector designs, with the result of loss minimization.

It is felt that the identification and quantification of this phenomenon represents a significant advance in the state-of-the-art. A paper summarizing this work was presented to the International Current Collection Conference held in Austin, Texas on November 17 and 18, 1987.

\subsection{HOYOPOLAR YACHINE APPLICATION STUDY}

\subsubsection{Background}

The objective of the Machine Application Study was to define a homopolar power supply which was suitable for the SDI mission requiring hundreds of megawatts of continuous dc power in the 50- to 400-V range. The major operational requirement of the system was that the power density exceed $80 \mathrm{~kW} / \mathrm{kg}$.

To define the operational and functional design requirements for the current collection system, a baseline homopolar machine concept (which met the operational goals of the SDI mission) was selected. In particular, the selection of a baseline machine quantified 


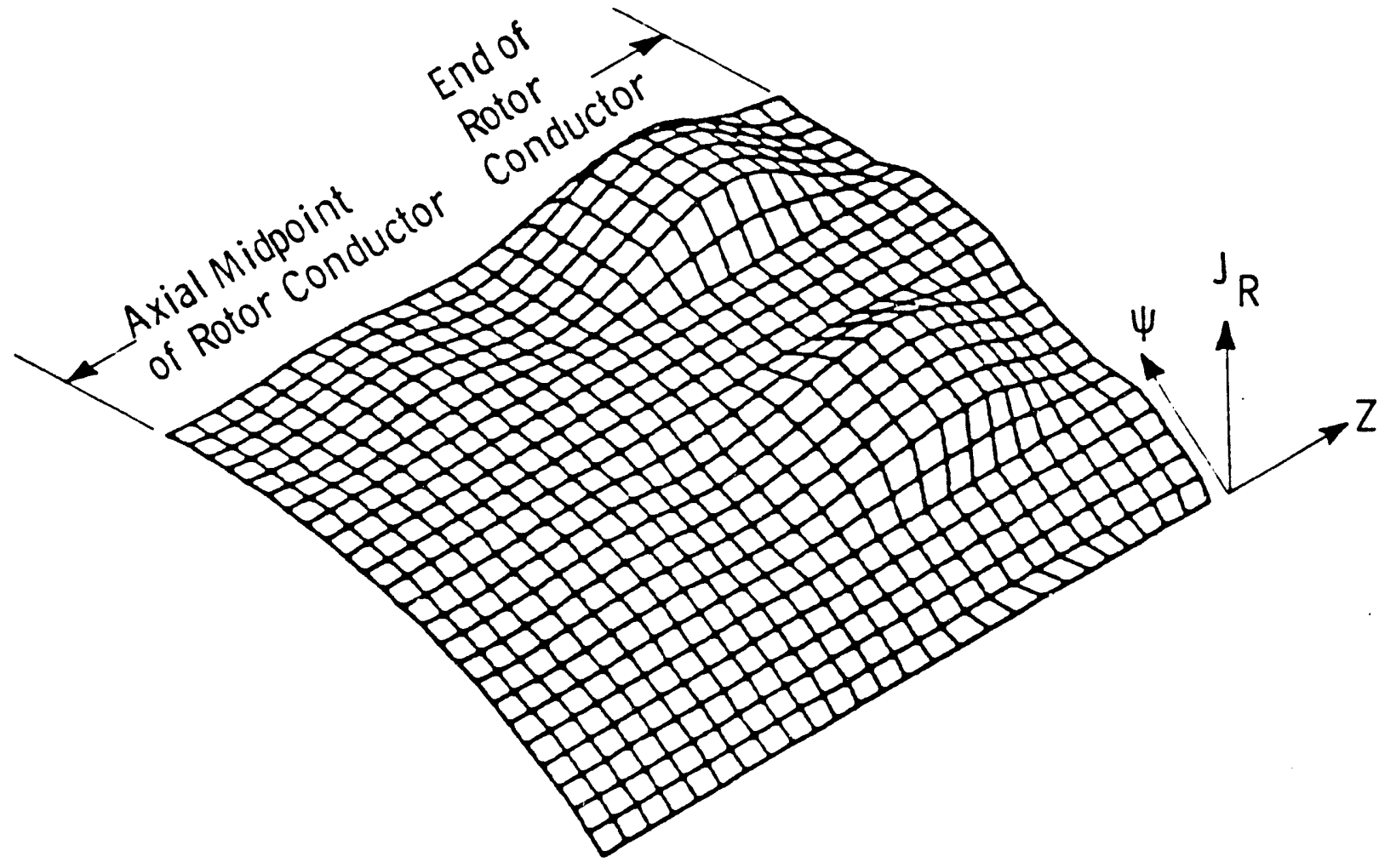

Figure 2.10 - Surface plot showing radial current injected at cylindrical surface. 


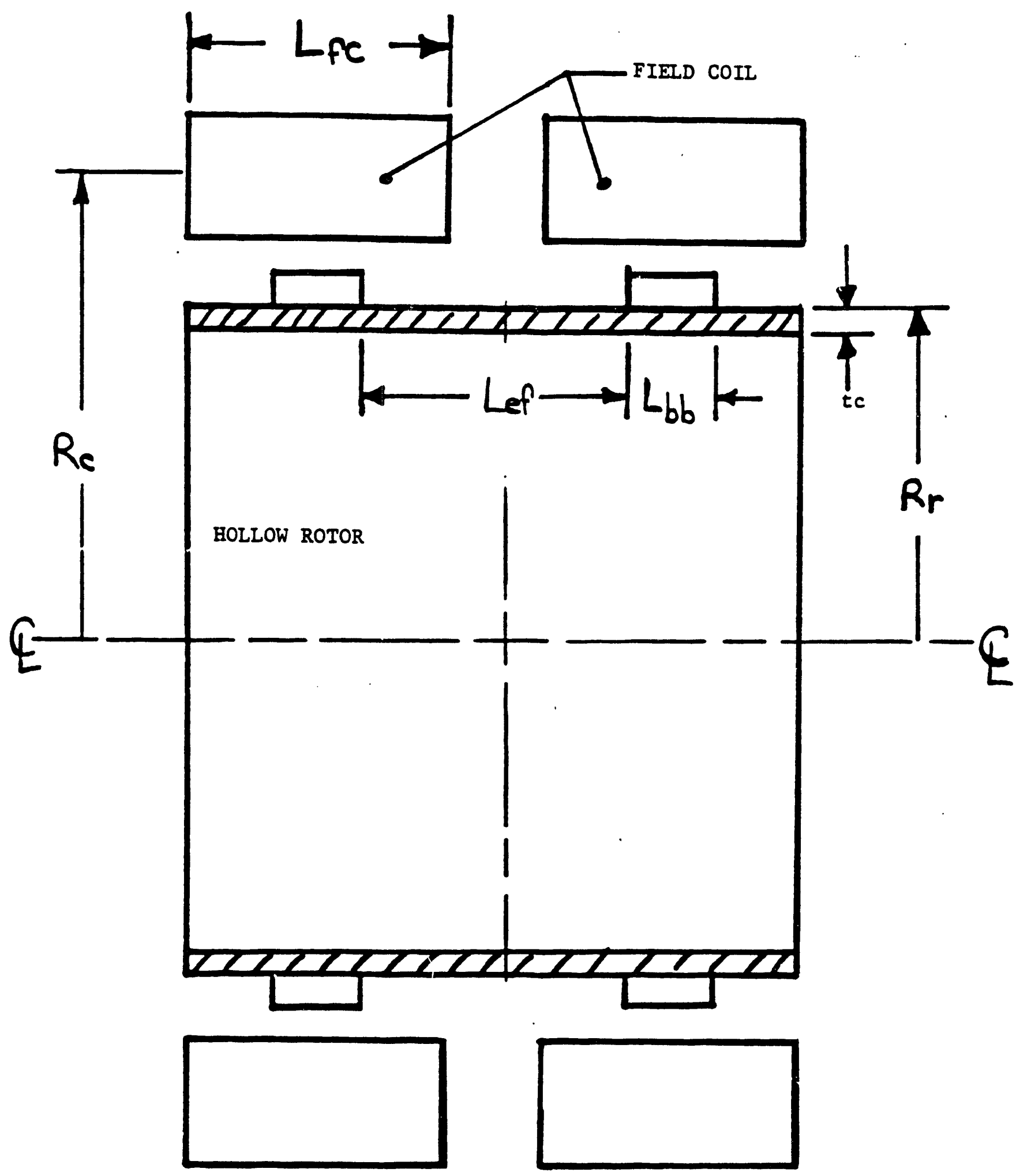

Figure 2.11 - Ideal Drum Type Homopolar Motor. 
the cooling fluids, rubbing speed, current densities, and the thermal and electromagnetic environments for the current collection system.

Two basic homopolar machine concepts were evaluated as part of the selection of a baseline machine. These were the "Iron Core" and "Air Core" machine arrangements. All concepts employed drum t.pe construction (refer to Figure 2.11) as previous studies have shown these to have the highest power density and voltage generating capability.

Although understood within the scientific community, the terms "Iron Core" and "Air Core" are somewhat misleading. Therefore a brief explanation will be included here.

"Iron Core" refers to those machines which are constructed primarily of a ferromagnetic material (i.e., iron or steel). In addition to its structural function the "iron" provides a low reluctance path for the magnetic flux created by the field winding and greatly reduces the excitation requirements on the field winding. Because of the magnetic saturation of ferromagnetic materials, operation of "Iron Core" homopolar machines at flux densities much above 2 tesla is not practical.

"Air Core" refers to those machines which are constructed primarily of nonferromagnetic materials such as stainless steel, aluminum, copper, fiber composites, etc. "Air" refers to the fact that the materials used in their construction have roughly the same magnetic permeability as air. In these machines there is no low reluctance path for the flux to follow. The flux pattern within the machine is controlled by the shape and placement of the field windings. Because the excitation requirements will in general be very high, the field coils are almost always cryogenically cooled.

Previous studies for high voltage pulsed power systems have shown that "Air Core" machines will have higher power densities than "Iron Core" designs of the same rating. This is because the structural members in "Air Core" machines need only be designed for mechanical strength and not to carry magnetic flux. The savings in the weight of the structural materials more than offsets the added weight of the larger field coil. However, these studies dealt with very high voltage 
(thousands of volts) homopolar machines which required magnetic field strengths on the order of 4 to 8 tesla. At these high magnetic field strengths there is no advantage to using ferromagnetic materials.

Because low voltage (50 to several hundred volts), high power density, high efficiency machines have not been previously investigated, a benchmark assessment of "Iron Core" technology was included as part of the application studies. The results of these studies are presented as Appendix B.

\subsubsection{Conclusions and Recommendations}

The work completed to date suggests that rather impressive power densities are obtainable using "Iron Core" technology. However, given the present limits on brush current density and rotor tip speed, the maximum obtainable power density approaches $30 \mathrm{~kW} / \mathrm{kg}$ at an efficiency of 96\%, which is short of the SDI requirements. Further increases in energy density can only be achieved by dramatically increasing the rotor tip speed and/or brush current density. It does not appear that sufficient breakthroughs in this technology can be made to make it viable for the low voltage (50 to 100 volts) SDI application.

"Iron Core" homopolar machines are not suited for the SDI mission requiring multimegawatt, low dc voltage, continuous operation, for the following reasons:

1) To meet the SDI mission requirements the machine will require cryogenic cooling. The physical properties of magnetic steels are significantly degraded at these temperatures, and interfaces between the magnetic steel rotor and stator with the cryogenic components would require significant developments in the state of the art.

2) To achieve the power density increases necessary to meet SDI goals, the brush current density and rotor tip speed limits will have to be significantly increased. Since any developments in this area apply equally well to "Air Core" technology, which already has significantly higher power 
densities, this work should be directed toward those machines as the benefits will. be greater.

3) The minimum efficiency requirement keeps the cooling requirement in line with fuel consumption. To achieve this minimum efficiency means that the friction coefficient and contact resistance will have to be significantly lowered. It also means that the homopolar machine will have to operate at less than the maximum power density point. The higher tip speed is also working against the efficiency requirement. Again, since an "Air Core" technology-based machine has an inherent advantage in terms of power density it can more readily be operated "off peak" without degrading performance below acceptable leve?.s.

Previous work has indicated that "Air Core" homopolar machines are viable for the medium voltage (several thousand volts) multimegawatt pulsed duty SDI application. The application study conducted for this program shows that they are also applicable for the low voltage continuous duty application as well. The major problem in the low voltage application will be to maintain a high power density at high efficiency. The critical factors are again rotor tip speed, contact resistance, brush friction, and operating current density.

The most significant findings of the study are:

1) The average magnetic field in the active region of "Air Core" homopolar machines (operating at maximum power density) is not an arbitrary quantity. It depends on the rotor diameter, the material thermal properties, and cooling technique employed in the design.

2) Power densities of $80 \mathrm{~kW} / \mathrm{kg}$ can be achieved with average flux densities in the active region of about 1 tesla and peak values anywhere in the magnetic circuit under 2.3 tesla.

It is recommended that the application studies be continued to determine the interrelationships between the various parameters which define the current collection system (i.e., trade off between friction 
coeficient, cooling scheme, operating current density). Further studies of alternate design concepts such as the inside out machine (field coil on the inside of the rotor), the impact of dimensional clearances, and field coil shaping should also be undertaken.

\subsection{ROTOR CONDUCTOR CONFIGURATION}

\subsubsection{Rotor Stress}

The successful design of the rotor conductor must address the following sources of stress acting upon the rotor conductor;

- Thermal Loading

- Dynamic Loading

- Fluid Pressure Loading

The rotor surface of the current collection slipping is expected to absorb large quantities of heat (estimated as $\approx 4.5 \mathrm{~mW} / \mathrm{m}^{2}$ ). Conduction of this heat into the interior of the rotor conductor will establish a temperature gradient, and associated thermal stress. The temperature gradient is set by the heat $f l u x$ and the thermal conductivity of the material, while the overall temperature difference is dependent upon the length through which heat must be conducted. The developed stress is proportional to the developed temperature difference.

The necessity of limiting thermal stress under the anticipated heat loading suggests that the typical length of the heat conduction path be limited to a dimension of $0.9 \mathrm{~cm}(0.35 \mathrm{in})$ or less.

\subsubsection{Heat Transfer}

An efficient method of heat removal has been identified. Pool boiling occurring under the influence of large centripetal accelerations is believed to be adequate to remove the heat flux required. Nucleate boiling heat transfer exceeds natural convection. When nucleate boiling is established in a strong centripetal field, a large increase in the heat transfer coefficient is attained. This is due to establishment of strong convection currents driven by buoyant forces acting on the fluid. 
Heat transfer coefficients are expected to be sufficiently large to keep the wall temperature at the inside radius of the current collector cylinder quenched nearly to the saturation temperature of the coolant used.

This method of cooling is well matched to an air-cored homopolar machine. It relies upon the latent heat of vaporization, which is an efficient use of the cryogenic fluid. The spent coolant is ejected from the rotating pool of coolant towards the axis of the rotor, where it is collected and ejected from the machine.

Operation of a current collectror slip-ring at $200 \mathrm{~m} / \mathrm{s}$ suggests a cylindrical tube construction. The centripetal loading of the current collector will create hoop tension stress of a moderately high value. It is believed that the current collector and armature conductor can be made as a self supporting tube of a high strength, high electrical conductivity material such as chrome copper.

If the armature conductor is not made as a cylinder, alternative configurations must provide significant supporting structure to contain the conductor. It is believed that this results in an unnecessarily complicated, heavy design.

A final source of significant loading to the rotor conductor has been identified as the fluid pressure loading of the coolant fluid circulating in the high centripetal field caused by high speed rotation. Operation utilizing liquid hydrogen as the coolant results in relatively small, manageable stress levels.

The low temperature material properties of candidate conductor materials all tend to be superior to room temperature values. The design criterion being followed is to limit stress to a maximum value of $2 / 3$ the room temperature yield.

\subsection{SHUNT-BRUSH DIFFUSION BOND}

Inherent in the construction of most current collection systems is the utilization of "brushes." These brushes are typically made of graphite formed with various other materials. In the case of high powered homopolars, these brushes are typically metal graphite (greater 
than $90 \%$ metal by weight). The metals usually employed are either copper or silver. These brush materials are normally formed by processes similar to those used in powder metallurgy.

A problem arises when a shunt must be attached to such a composite brush. The graphite present in the material does not allow welding or brazing of copper shunts to the brush, because volatile products are driven off. Typical shunt attachments are executed using special tamping techniques, or riveting a shunt, or soldering. All these techniques appear inadequate to meet the demands imposed by continuous duty, high powered homopolar power supplies.

In order to identify a means of forming a "good" metallurgical bond between a copper "shunt" and a conventional "brush," some sample. joints were attempted using a hot isothermal process. Under this process the brush material and copper test piece were "canned" inside a small container. Pressure and temperature were applied and a good diffusion bond is found to have occurred as shown in micrographs of the test pieces shown as Figures 2.1.2 and 2.1.3.

This addresses a present weakness in current collection design, since many brush designs are limited by the temperature limitations imposed by the shunt attachment, rather than the more basic temperature limitations imposed by the current collection rubbing interface.

A patent disclosure has been prepared to describe this process. 


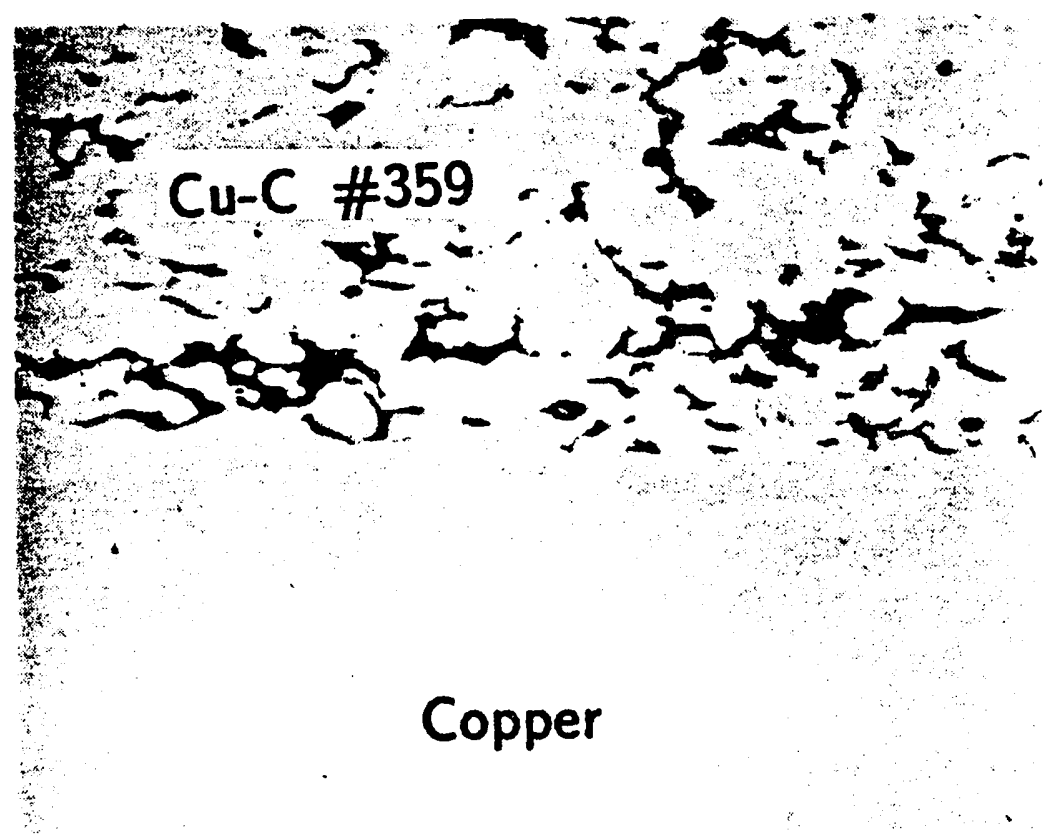

Figure 2.12 - Micrograph of the interface between the \#359 Cu-C and copper. 


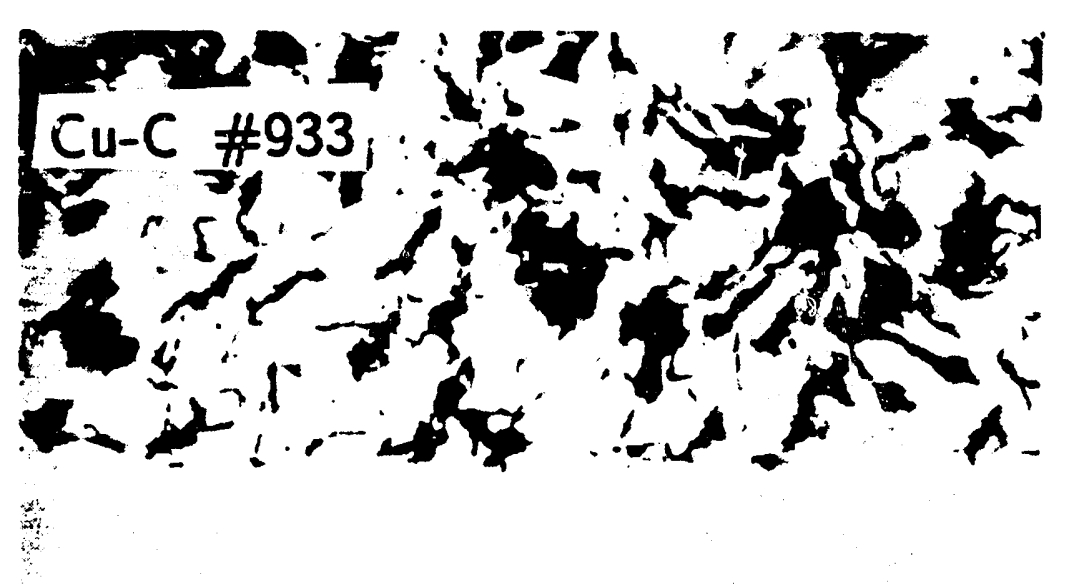

Copper

Figure 2.13 - hicrograph of the interface between the \#933 Cu-C and copner. 


\section{SCHEDULE/STATUS}

All technical program objectives expected in the first year have been met or exceeded. The first-year support allotment was exhausted in late September 1987. Work was halted at this time pending further funding. The only outstanding task was the completion of the first yearly annual report, which is now complete after receiving the next incremental allotment.

\begin{tabular}{|c|c|c|c|c|}
\hline & Task & $\begin{array}{l}\text { Months } \\
6 \quad 12\end{array}$ & $2 \begin{array}{cc}\text { After Start of } \\
2 & 18 \quad 24\end{array}$ & $\begin{array}{cc}f & \text { Contract } \\
30 \quad 36\end{array}$ \\
\hline $\begin{array}{l}1 . \\
2 . \\
3 . \\
4 . \\
5 . \\
6 . \\
7 . \\
8 . \\
9 . \\
10 . \\
11 . \\
12 .\end{array}$ & $\begin{array}{l}\text { Machine Design } \\
\text { Literature Search } \\
\text { Current Collection Data } \\
\text { Analysis } \\
\text { Current Collection Test Rig } \\
\text { Construction } \\
\text { Current Collection Test and } \\
\text { Analysis } \\
\text { Cooling Data Analysis } \\
\text { Cooling Test Rig Construction } \\
\text { Cooling Test and Analysis } \\
\text { Design of Current Collection } \\
\text { System } \\
\text { Prototype System Construction } \\
\text { Prototype System Test and } \\
\text { Analysis } \\
\text { Reports } \\
\text { - Status and Summary } \\
\text { - Annual }\end{array}$ & $\begin{array}{r}-\Delta---- \\
-\Delta-\Delta \\
\Delta- \\
\Delta-\Delta--- \\
\Delta-\end{array}$ & $\begin{array}{l}\int_{\Delta}^{\Delta-\Delta} \Delta \\
-\Delta \\
\Delta-\Delta\end{array}$ & $\begin{array}{l}-\Delta-\Delta \\
\Delta-\Delta \\
\Delta-\Delta\end{array}$ \\
\hline
\end{tabular}

Figure 3.1 - Current Collection Program-Schedule 


\section{FUTURE EFFORTS}

\subsection{TEST PROGRAY}

The cryogenic test rig will be utilized in the next quarter of the yearly period of performance to characterize current collection phenomena in this unexplored low temperature range. Liquid nitrogen will be used as the cryogenic coolant.

These tests represent pioneering efforts in current collection, since no known high current density current collectors are in existence.

The high speed test rig will be assembled and tested in the second quarter. This test rig will be capable of $200 \mathrm{~m} / \mathrm{s}$ peripheral rubbing speed, along with a 0.2 packing factor (ratio of brush area to rotor swept area). This test rig will allow thermal characterization of a current collection system utilizing sufficient rotor coverage to attain meaningful results. This represents a very powerful and unique test device, since the only present test devices accomplishing this goal are full scale, high powered homopolars.

\subsection{DETAILED LOSS ANALYSIS}

The model of the current-induced losses developed this year will be further refined to accommodate analysis of smaller areas of current conduction. This will enable characterization of expected losses occurring at current collection sites with areas of contact predicted by the present theory.

\subsection{DEVELOP DETAILED DESIGN OF BRUSH/COLLECTOR CONCEPT}

The results of the test programs performed on the cryogenic and high speed test rigs will be analyzed. The results of these tests will be used with the estimated losses predicted from the loss analysis to develop a detailed design of the prototype current collection system. 
This work will occur in the 3 rd and 4th quarters of the next yearly period of performance.

\subsection{PROTOTYPE CURRENT COLLECTION SYSTEY - CONSTRUCTION AND TEST}

The third year of the program will be devoted to the construction, test, data analysis, and reporting of the prototype current collection system.

Successful demonstrations of this proposed current collection system will remove a major obstacle to the implementation of homopolar power supplies to SDI space based applications. 


\section{LOSS CALCULATIONS FOR HIGH SPEED, HIGH CURRENT LEVEL CURRENT COLLECTORS}

William F. Hannan III Westinghouse Electric Corporation Research and Development Center 1310 Boulah Road

Pittsburgh, PA 15235

\section{ABSTRACT}

This paper presents a mathematical model describing the controlling aspects of electrical losses found in high speed current collectors. At high speeds, a "skin effect" is predicted to occur in the rotor conductor due to the periodic spacing of brushes. It is shown that the rotor conductor has a boundary condition which can be expressed as a traveling wave. The three dimensional periodic steady state cylindrical wave functions are solved for geometries approximating those found in homopolar rotor conductors. A strong velocity dependence is demonstrated for the losses calculated from predicted currents. Knowledge and understanding of these losses are important to the designer of high power density, advanced homopolar machines. 


\section{INTRODUCTION}

The analysis of electrical contacts has been based predominantly on static contacts. The accepted model to calculate contact resistance is found in Holm's work [1]. This model is based upon calculation of the electrical potential between two remotely located contact points. Due to the small areas of actual contact developed and the relatively enormous distances found between such contacts, it is reasonable to calculate the contact resistance attributed to the current "constriction." This model has assumed that the electric fields develop as though the current diffused into the semi-infinite conductor. This model is very useful in gaining insight into the governing phenomena of contact theory. However, the model will not explain certain apparent variations observed in contact resistance, most notably variations due to high velocities.

The model presented by Holm is one dimensional with no time variation. Such a model is incapable of dealing with time variations that are introduced with high velocity current collectors.

In order to explore the basic governing phenomena of a high speed contact, the field equations for a cylindrical conductor have been presented and solved for a sample case similar to a small, high powered homopolar generator (HPG) recently menufactured by Westinghouse. These equations present a three dimensional, periodic steady state analysis that will allow calculation of the electric and magnetic fields occurring in cylindrical conductors. The solutions of these equations are restricted initially to cases that force current flow into the 
conductor over the entire apparent area of contact between brush and conductor. Future efforts will be directed towards solutions with the conducting areas collapsed to sizes consistent with the present contact theory.

The model presented is useful for conductors that posses a constant relative permeability, such as copper. Ferromagnetic substances will cause the differential equations that result to become nonlinear, and the closed form solution presented will not be appropriate.

This model is developed to allow an understanding of high velocity current transfer. It suggests that the observed variations in apparent contact resistance due to velocity variations can be explained as consequences of Maxwell's equations.

\section{ANALYTICAL MODE}

In order to understand the loss mechanisms operating in HPG devices, it is necessary to examine the basic electromagnetic fields that develop within the rotor conductor. Toward this end, an analytical model has been constructed. This analytical model is derived from the field equations of a cylindrical field. These equations are solved as a boundary value problem ising the radial current injected into the cylindrical surface as the boundary condition to be met. 


\section{EQUATIONS OF A CYLINDRICAL FIELD}

The following description and derivation of the equations of a cylindrical field are found in "Electromagnetic Theory" by Julius Adams Stratton, First Edition, Ch. 6 [2].

An electromagnetic field cannot, in general, be derived from a purely scalar function of space and time; as a consequence, the analysis of electromagnetic fields is inherently more difficult than the study of heat flow or the transmission of acoustic vibrations. The three-dimensional scalar wave equation is separable in 11 distinct coordinate systems, but complete solutions of the vector wave equation in a form directly applicable to the solution of boundary-value problems are at present known only for certain separable systems of cylindrical coordinates and for spherical coordinates. It will be shown that in such systems an electromagnetic field can be resolved into two partial fields, each derivable from a purely scalar function satisfying the wave equation.

Stratton develops the following formulas for the field vectors. in terms of a scalar wave function $\$$.

The scalar wave equation is as follows:

$$
\Delta^{2} \psi-\mu \epsilon \frac{\delta^{2} t}{\delta t^{2}}-\mu \sigma \frac{\delta \psi}{\delta t}=0
$$

In conducting metals, the second term is negligible and will bo dropped. Therefore, the scalar wave equation becomes

$$
\begin{gathered}
\Delta^{2} \psi=\mu \sigma \frac{\delta t}{\delta t}=\frac{1}{h^{2}} \frac{\delta t}{\delta t} ; \\
h^{2}=\frac{1}{\mu \sigma}
\end{gathered}
$$


This equation, transformed into cylindrical coordinates, is:

$$
\Delta^{2} \psi=\frac{1}{\rho} \frac{\delta}{\delta \rho}\left(\rho \frac{\delta \eta}{\delta \rho}\right)+\frac{1}{\rho} \frac{\delta^{2} \psi}{\delta \phi^{2}}+\frac{\delta^{2} \psi}{\delta z^{2}}=\frac{1}{h^{2}} \frac{\delta \psi}{\delta t}
$$

The coordinate system used in this analysis is as shown in Figure 1.

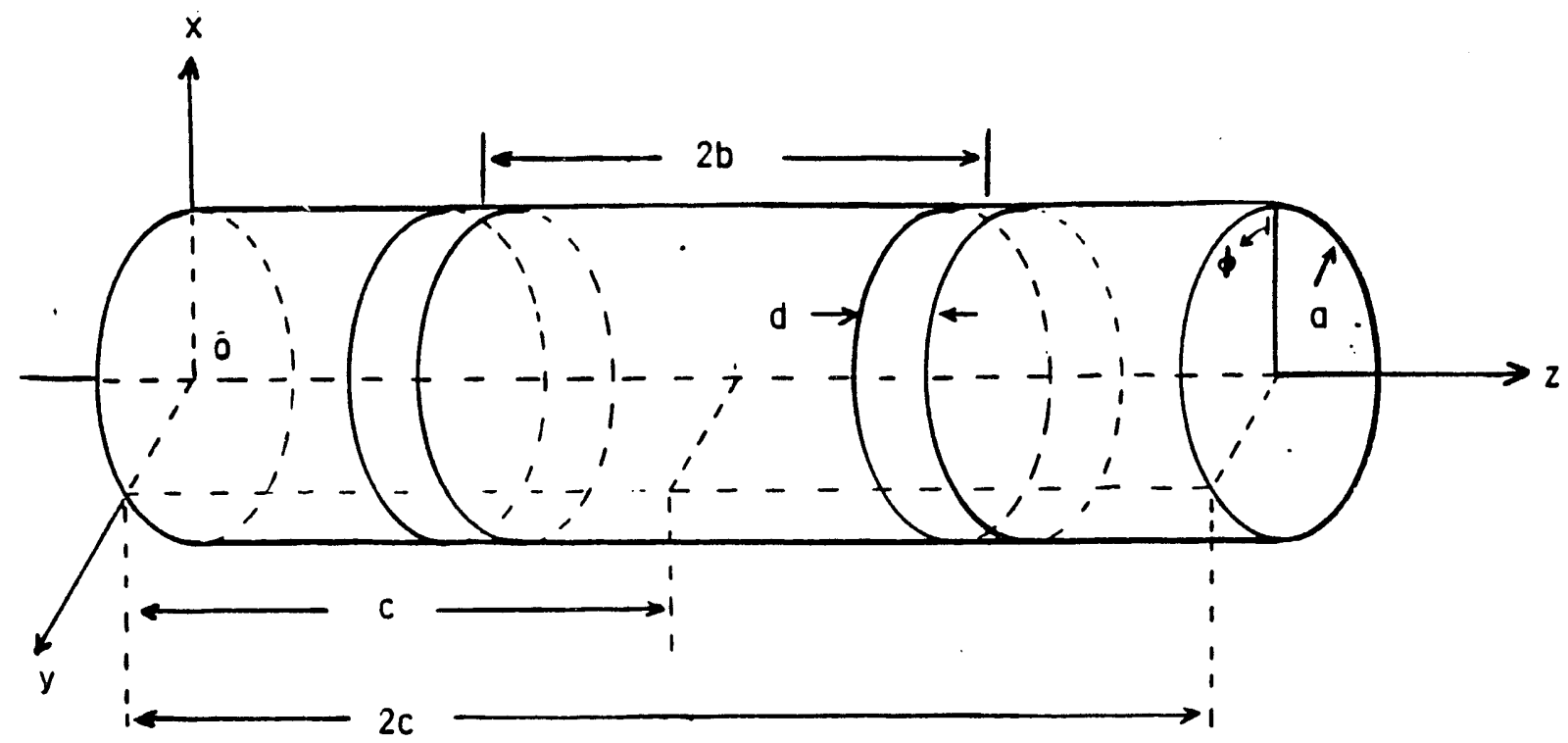

Figure 1 - Conductor Model Under Analysis

SOLUTION OF SCALAR WAVE EQUATION BY SEPARATION OF VARIABLES

Assume a solution as follows:

$$
\phi=R(\rho) P(\phi) Z(z) T(t)
$$


Substitution of the assumed solution into the cylindrical wave equation yields:

$$
\frac{1}{\rho} \frac{\delta}{\delta \rho}\left[\rho \mathrm{PZT} \frac{\delta R}{\delta \rho}\right]+\frac{1}{\rho^{2}} \mathrm{RZT} \frac{\delta^{2} \mathrm{P}}{\delta \phi^{2}}+\mathrm{RPT} \frac{\delta^{2} Z}{\delta z^{2}}=\frac{1}{h^{2}} \mathrm{RPZ} \frac{\delta \mathrm{T}}{\delta t}
$$

Divide Equation (6) by R०P・Z・T to obtain:

$$
\frac{1}{\rho} \frac{\delta}{\delta \rho}\left(\frac{\rho}{R} \frac{\delta R}{\delta \rho}\right)+\frac{1}{\rho^{2}} \frac{1}{\mathrm{P}} \frac{\delta^{2} \mathrm{P}}{2 \phi^{2}}+\frac{1}{Z} \frac{\delta^{2} \mathrm{Z}}{\delta \mathrm{z}^{2}}=\frac{1}{h^{2} \mathrm{~T}} \frac{\delta \mathrm{T}}{\delta \mathrm{t}}
$$

Each term is now a function of a single variable; therefore the equation can be separated by variables. Partial differentials are shown to be total differentials.

Next, assume that the solutions are of exponential type for $P$, $Z$, and $T$.

$$
\text { Assume } \frac{d^{2} p}{d \rho^{2}}=-n^{2} p
$$

Typical solution; $P=A_{1} e^{i n \phi}+A_{2} e^{-i n \phi}$

$$
\text { Assume } \frac{d^{2} z}{d z^{2}}=-m^{2} z
$$

Typical solution; $Z=B_{1} e^{i m z}+B_{2} e^{-i m z}$

$$
\text { Assume } \frac{d T}{d t}=i \omega T
$$


Typical solution; $T=C_{1} e^{i \omega t}$

Put the assumed solutions back into the original equation to produce:

$$
\frac{1}{\rho}\left[\frac{d}{d \rho} \frac{\rho}{R} \frac{d R}{d \rho}\right]-\frac{1}{\rho^{2}} n^{2}-m^{2}+\frac{i \omega}{h^{2}}=0
$$

or

$$
\frac{1}{\rho} \frac{d}{d \rho}\left(\rho \frac{d R}{d \rho}\right)+\left(\left(\frac{i \omega}{h^{2}}-m^{2}\right)-\frac{n^{2}}{p^{2}}\right) R=0
$$

This is a form of Bessel's equation that has the following solutions.

$$
R=D_{1} J_{n}\left(\sqrt{\frac{i \omega}{h^{2}}-m^{2}} \rho\right)+D_{2} H_{n}\left(\sqrt{\frac{i \omega}{h^{2}}-m^{2}} \rho\right)
$$

Where $J_{n}$ is a Bessel function of the first type and $H_{n}$ is a Bessel function of the second type.

For a first pass, analysis was of a solid cylindrical conductor. In this case

$$
H_{n}+\text { at } \rho=0 \text {; therefore } D_{2}=0
$$

The solution of the scalar wave equation can therefore be shown to be of the form 


$$
p=e^{i n \phi} e^{i m z} e^{i \omega t} J_{n}\left(\sqrt{\frac{i \omega}{h^{2}}-m^{2}} \rho\right)
$$

The field equations for such a geometry and potential are given in "Eloctromagnetic Theory," by Julius Stratton, 1st Ed. pp. 360-361 [2].

$$
\begin{gathered}
E_{r}=\operatorname{ihL}_{n} a_{n} \frac{\delta \phi_{n}}{\delta r}-\frac{\mu \omega}{r} \sum_{n} b_{n} \phi_{n} \\
E_{\phi}=-\frac{h}{r} \sum_{n} n a_{n} \phi_{n}-i \mu \sum_{n} b_{n} \frac{\delta \psi_{n}}{\delta r} \\
\therefore E_{z}=\left(k^{2}-h^{2}\right) \sum_{n} a_{n} \phi_{n}
\end{gathered}
$$

where the following substitutions have occurred.

$$
\begin{aligned}
& k^{2}=\frac{i \omega}{h^{2}} \\
& h^{2}=m^{2}
\end{aligned}
$$

From initial conditions prescribed over a given plane or cylindrical surface, a solution is constructed by superposition.

The coefficients $a_{n}$ and $b_{n}$ are determined from boundary corditions imposed upon the cylinder. 


\section{MATCHING BOUNDARY CONDITIONS}

The boundary conditions imposed upon the cylinder are

1) Axial current density is zero at $z=0,2 c$.

2) Radial current density is uniformly injected into cylinder at $r=a$ only in areas defined as those where brush contact is established.

$$
\left.J_{z=0,2 c}=0=\sigma E_{z}=\sigma\left(\frac{i \omega}{h^{2}}-m^{2}\right) a_{n}\right\rangle_{n}
$$

For non-trivial solution,

$$
\phi_{n=0,2 c}^{1}=0=R(\rho) P(\phi) Z(z) T(t)
$$

Since $R(p) P(\phi)$ and $T(t)$ are generally not zero

$$
\left.Z(z)\right|_{Z=0,2 c}=0=B_{1} e^{i m z}+B_{2} e^{-i m z}
$$

An equivalent statement using sin and cos in place of exponential form is

$$
\begin{gathered}
\left.z(z)\right|_{Z=0,2 c}=0=B_{1}^{\prime} \sin m z+B_{2}^{\prime} \cos m z \\
B_{2}^{\prime}=0 \\
0=B_{1}^{\prime} \sin 2 m c
\end{gathered}
$$

This is true if $2 \mathrm{mc}=a \pi$

$$
m_{a}=\frac{a x}{2 c}
$$

The radial current density at $\rho=$ a can be expressed mathematically as; 


$$
\left.J r\right|_{r=a}=\sum_{n} \sum_{a} J_{n, a}\left(\operatorname{Cos}(n(\phi+\omega t)) \operatorname{Cos} m_{a} z\right.
$$

where $J_{n, a}$ are the Fourier coefficients of a traveling wave moving with velocity w.

The values of $J_{n, a}$ are found by considering the Fourier series to be a product of a series in the diroction and a series in the $Z$ direction.

$$
J_{n, a}=F_{n} \cdot G_{a}
$$

Where $F_{n}$ is the $n^{\text {th }}$ Fourier coefficient in the series and $G_{\alpha}$ is the $a^{\text {th }}$ Fourier coefficient in the $Z$ series.

This can best be shown by an example. In the sampie case it is assumed that the current is "on" for one-half of a brush pitch and "off" for the remainder. Consider one brush pitch oqual to $2 \pi$.

Inspection of Figure 2 shows that the match between the ideal waveform and the Fourier approximation with eleven terms is in good agreement. Little error is introduced by not considering higher harmonic terms in the circumferential fourier approximation.

The same stratogy is employed to derive the Fourier coefficients in the axial direction. A figure showing the ideal waveform, and the Fourier approximation which results from using fifteon torms is displayed as Figure 3.

Inspection of the figure shows that consideration of only fifteen Fourier terms will tend to ignore space harmonics of short 


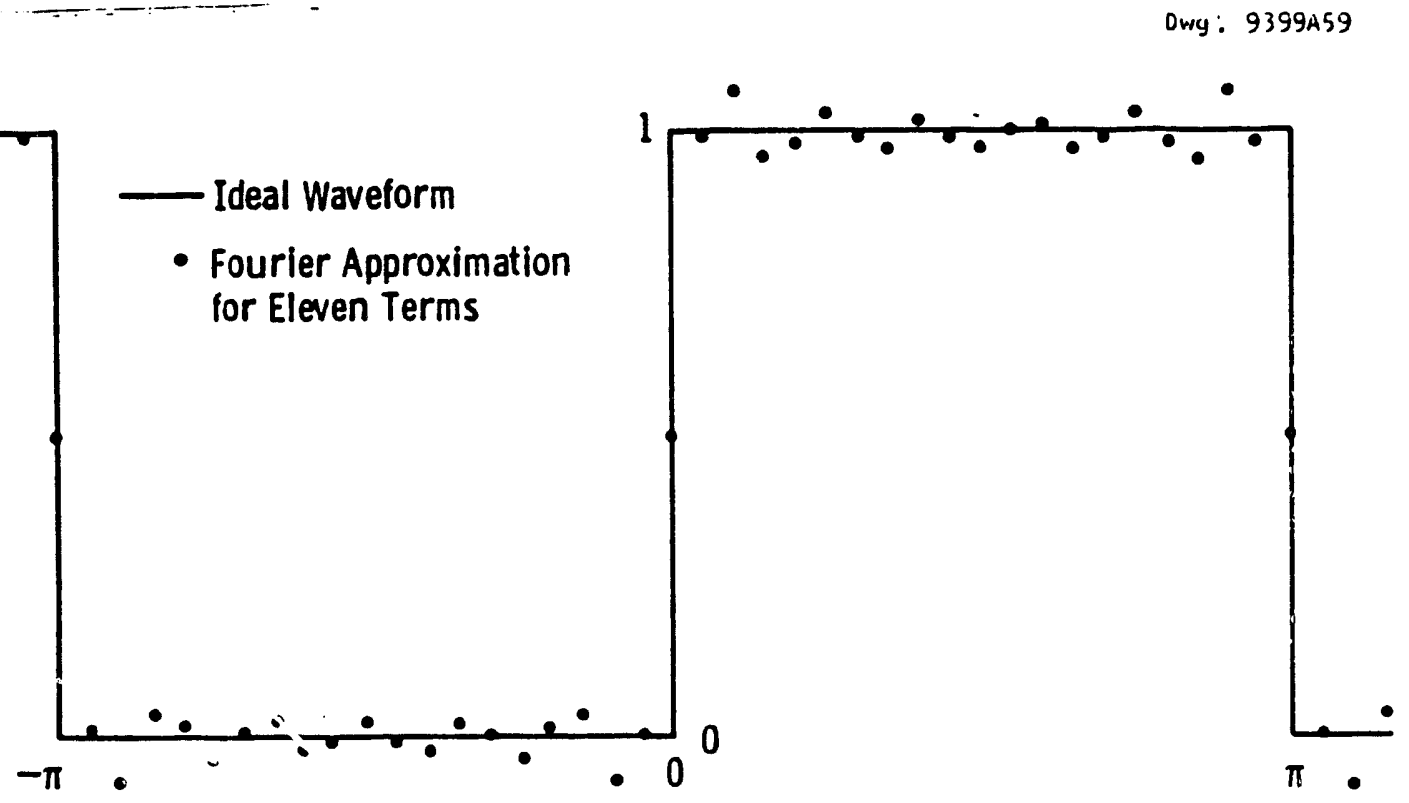

Figure 2 - Circumferential Fourier Series

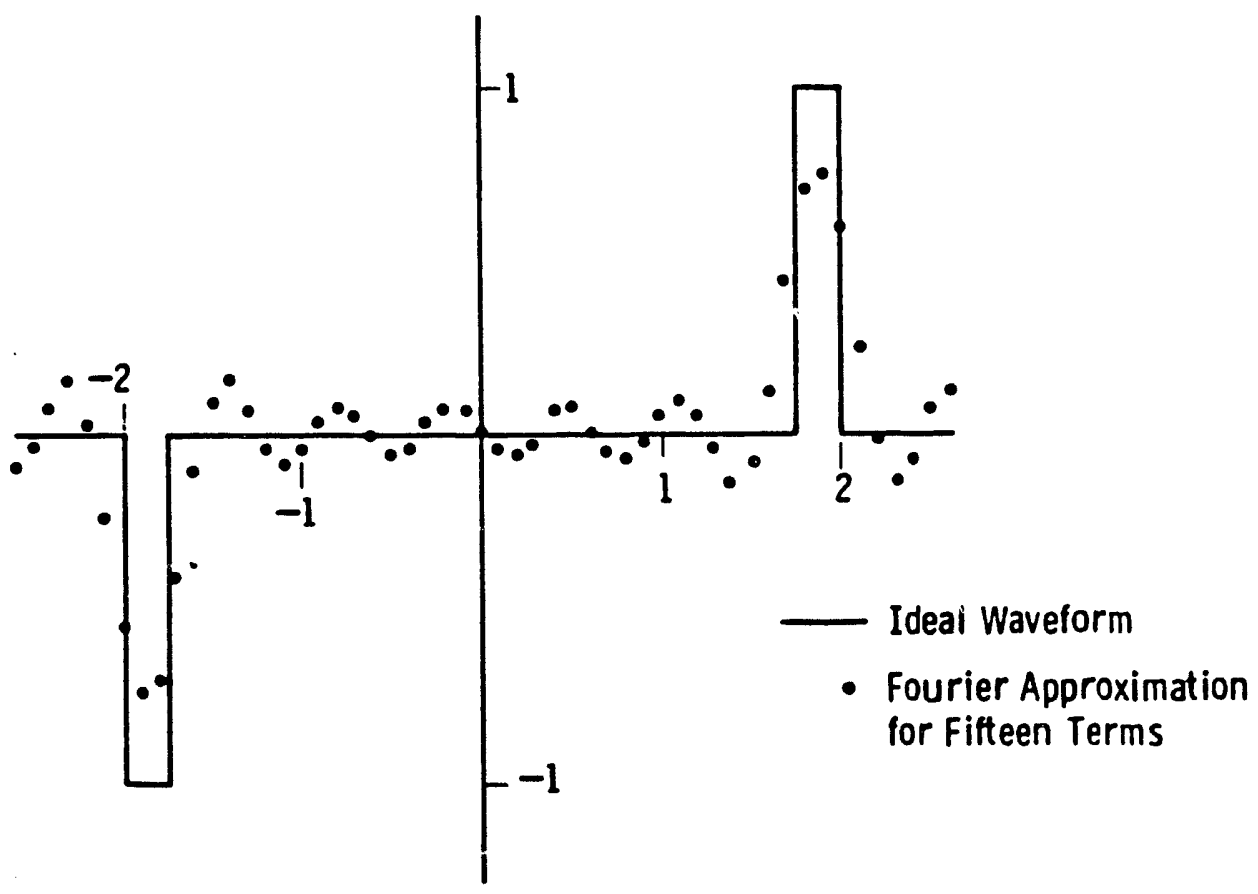

Figure 3 - Axial Fourier Series 
wavelength. It is these high order harmonics which will tend to "square off" the shoulders of the Fourier approximation used in calculation of the field equations.

The basic restraint against using high numbers of Fourier coefficients is that the and the $z$ coefficients are combined as products. Thus, an analysis using 10 terms in the direction and 10 terms in the $Z$ direction actually calculates 100 separate terms in each summation. Doubling the number of terms utilized will quadruple the calculation effort.

The field equations become:

$$
\begin{aligned}
& \frac{J_{r}}{\sigma}=E_{r}=i h \sum \sum_{n, a} \frac{\delta \phi_{n, a}}{\delta r}-\frac{\mu \omega}{r} \sum \sum_{n} n b_{n, a} \phi_{n, a} \\
& \frac{J_{r}}{\phi}=E_{\phi}=-\frac{h}{r} \sum \sum n a_{n, a} \phi_{n, a}-i \mu w \sum \sum_{n, a} \frac{\delta \phi_{n, a}}{\delta r} \\
& \frac{J_{z}}{\sigma}=E_{z}=\left(k^{2}-h^{2}\right) \sum \sum_{n, a} a_{n, a}
\end{aligned}
$$

These equations contain the two partial fields to which Stratton refers. One field is found when considering only the terms conteining $a_{n}$ as a factor, while the other is found to contain only terms having $b_{n}$ as a factor.

The first field referred to above is a field of electric type (transverse magnetic field) while the second is a field of magnetic type (transverse electric field). 
In order to calculate the degree to which each type field is excited for each mode investigated, it is necessary to review how the current injected at the surface excites each mode.

For the sample case, consider excitation of the $a=1, n=1$ mode. Since all the modes except the DC mode $(n=0)$ are forced at frequencies at or above brush passing frequency, a very strong surface offect is experienced. All these higher modes exhibit a strong "skin effect."

Examination of the equations shows that the electric type field establishes very large current flow in the $Z$ direction with virtually no flow in the direction, while the magnetic type field establishes current flow in the direction with absolutely no flow in the $Z$ direction.

This observation will allow an estimation to be made as to how strongly each field will be excited.

Figure 4 represents a segment of the rotor surface that extends to a depth equal to the skin depth "d". The dimensions chosen for the $\phi$ and $Z$ directions correspond to the Fourier wavelengths of the mode under investigation. Since the rotor radius is usually large in comparison to $\lambda_{\phi, a^{\prime}}$ it is reasonable to show this figure in Cartesian rather than cylindrical coordinates.

Since various modes are excited as both $a$ and $n$ vary, the following notation for subscripting will be utilized.

$R_{\phi, a, n}=$ Surface resistance in direction for the $(\alpha, n)^{\text {th }}$ mode $\lambda_{\phi, a}=$ Fourier wavelength in direction for $a^{\text {th }}$ term. 
$\lambda_{z, n}=$ Fourier wavelength in $z$ direction for $n^{\text {th }}$ term

$d_{a, n}=$ "Skin depth" for $(a, n)^{\text {th }}$ mode

$I_{z, a, n}=$ Surface current in $z$ diroction for the $(a, n)^{\text {th }}$ mode

$\delta=$ Eloctrical conductivity of material

Since Figure 4 represents excitation by sine waves of equal amplitude (but differing wavelength) in the and $Z$ direction, an estimate of the division of current flow in each direction is made as follows:

$$
R=\frac{\lambda}{d \sigma}
$$

from "Eloctrodynamics" by Arnold Sommerfeld, pg. 165 [3].

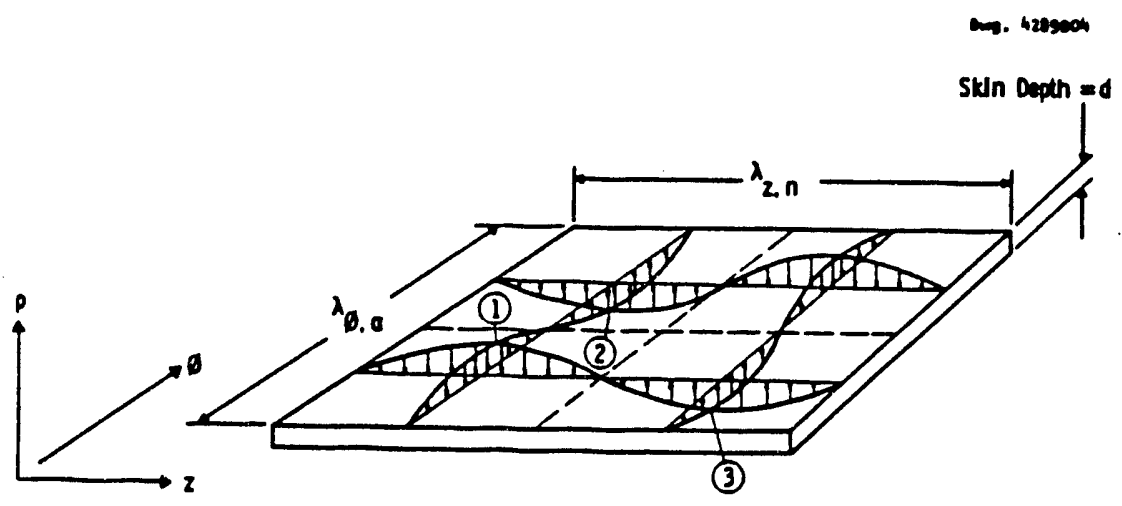

Figure 4 - Representation of excitation of ( $i, i)^{T H}$ mode, assuming skin phenomena can be modelod as restricted to skin depth "d". 


$$
R_{\phi, a, n}=\frac{\lambda_{\phi, a}}{d_{a, n^{\sigma}}} \text { and } R_{y, a, n}=\frac{\lambda_{z, n}}{d_{a, n^{\sigma}}}
$$

If the model is considered to represent a source (located at (1)) and a sink (located at (2)) which causes current to flow in the $\phi$ direction, and also a source (located at (1)) and a sink (located at (3)) causing current to flow in the $Z$ direction, then the following is found to be true.

$$
\Delta V_{12}=\Delta V_{13} \text {, since both are excited by sine waves of equal }
$$

ampl i tude.

$$
\begin{gathered}
\Delta V_{12}=I_{\phi, a, n} R_{\phi, a, n}=I_{\phi, a, n} \frac{\lambda_{\phi, a}}{d_{a, n} \sigma} \\
\Delta V_{13}=I_{z, a, n} R_{z, a, n}=I_{z, a, n} \frac{\lambda_{z, n}}{d_{a, n} \sigma} \\
I_{\phi, a, n} \frac{\lambda_{\phi, a}}{d_{a, n} \sigma}=I_{z, a, n} \frac{\lambda_{z, n}}{d_{a, n} \sigma} \\
\frac{I_{\phi, a, n}}{I_{z, a, n}}=\frac{\lambda_{z, n}}{\lambda_{\phi, a}}
\end{gathered}
$$

This suggests that the ratios of wave length of each separate mode are in inverse proportion to the current flow excited between the two fialds considarad. 
In the sample case for a brush spacing

$\lambda_{\phi, 1} \sim \frac{\pi \cdot D}{\text { brushes in one brush row }}=\frac{\pi \cdot 5 \mathrm{in} .}{16}=0.982 \mathrm{in}$.

$\lambda_{z, 1}=$ Rotor length $\approx 5.2$ in.

Ratio of $\frac{\text { Axial Current }}{\text { Radial Current }}=\frac{0.982}{5.2}=0.19$ for $a=1, n=1$ mode

This shows that an amount of ac current is excited to flow in the axial direction. This current causes significant parasitic losses.

The field equations were programmed using the above estimations, and the results will be discussed in the next section.

\section{SAMPLE ANALYSIS}

The cylindrical field equations were solved for the following geometry and material properties:

Rotor radius $=6.35 \mathrm{~cm}(2.5 \mathrm{in.})=a$

Rotor length $=13.21$ (5.2 in.) $=2 \mathrm{c}$

Axial distance between brushes $=9.14 \mathrm{~cm}(3.6 \mathrm{in})=.2 \mathrm{~b}$

Axial length of brushes $=0.63 \mathrm{~cm}(0.25 \mathrm{in.})$

Circumferential brushes $=16$

Length of brush pitch $=2 \pi a / 16=2.5 \mathrm{~cm}(0.982 \mathrm{in.})$

Brush width $=1.25 \mathrm{~cm}(0.491 \mathrm{in.})$

Rubbing velocities $=50 \mathrm{~m} / \mathrm{s}, 100 \mathrm{~m} / \mathrm{s}, 200 \mathrm{~m} / \mathrm{s}$

Brush passing frequency at $200 \mathrm{~m} / \mathrm{s}=8 \mathrm{kHz}$ 


\author{
Conductivity $=100 \%$ IACS \\ Number of terms in axial direction $=15$ \\ Number of terms in circumferential direction $=11$
}

Boundary conditions were matched using Fourier series of 11 terms to describe the circumferential variation and 15 terms to describe the axial variation. Figures 2, 3, 5 and 6 demonstrate the actual boundary conditions imposed for this analysis. The number of terms used was I imited by computation time and cost. A more accurate estimate will result if the number of Fourier terms is increased. However, the analysis performed appears to adequately represent the problem at hand.

Figures 5 and 6 show the assumed boundary conditions imposed at the rotor surface upon the radial current density. Figures 7 through 13 present the results of this analysis for all three dimensions for a peripheral rubbing velocity of $100 \mathrm{~m} / \mathrm{s}$. Review of the output shows that a "skin effect" is predictod to occur in all components of the current densities. Rapid variations in both the radial and circumferential current densities is predicted to occur within this "skin" in the immediate area of the current collectors. Special note should be taken of the de components present in the radial and axial current densities.

Figures 8 and 9 depict axial current density. These figures show that a large surface current consisting predominantly of ac current with a small de offset is established and persists down the rotor between the current collection areas. It is believed with an increase in the number of Fourier terms considered in this analysis that the 
largest peaks located at $\phi=\pi$ and $2 \pi$ will become slightly larger in magnitude, while the smaller peaks will be reduced.

The variation of this phenomenon with rubbing velocities can be seen by considering Figures 14 through 19, which show the radial variations in current densities occurring at velocities of 50 and 200 $\mathrm{m} / \mathrm{s}$. Comparison with the previous figures $(100 \mathrm{~m} / \mathrm{s})$ shows that the magnitude of the surface density and the skin depth predicted are both highly dependent on the rubbing velocity.

A significant parasitic loss can be driven by these high frequency surface currents. The prediction of the magnitude of these losses requires further analysis, exploring the ramifications of forcing the current transfer to occur across surfaces that will approach the size of "a" spots.

\section{SUMMARY}

An electromagnetic field is established in a homopolar rotor conductor due to the distributed nature and relative peripheral velocity of radially-directed current injected into the rotor surface. This electromagnetic field is determined for the case of a solid cylindrical conductor. The predicted fields consist of a de field superimposed with a time varying (ac) field. The ac field is shown to cause high current densities to occur which are confined to a narrow "skin" at the conductor surface. The estimated magnitudes of the predicted currents show that at high currents and at high velocities, excess loss will occur due to these ac currents. 
An analytical model has been presented to explain such observations as the velocity dependence of contact resistance. This model will allow the estimation of losses occurring in high powered homopolar machines to be performed.

\section{ACKNOMLEDGEMENTS}

This work was supported by the San Francisco Operations Office of the U. S. Department of Energy, under Contract DE-AC03-86SF16518. Thanks are extended to the following people for their assistance and discussions: Mr. D. W. Brown, Mr. O. S. Taylor, Mr. D. Pavlik, Dr. J. H. Parker and Mr. R. S. Schwenk. 


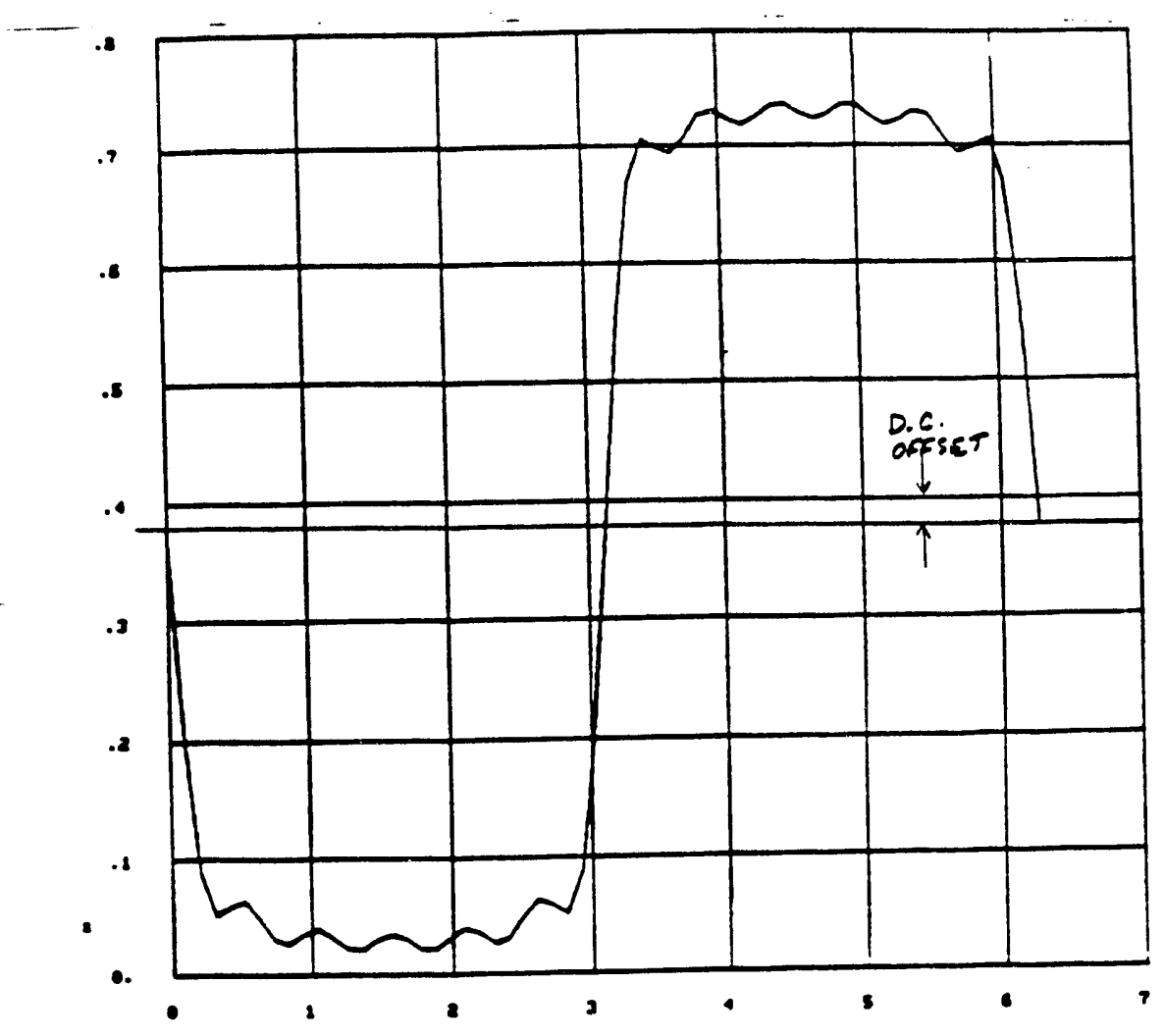

Figure 5 - Variation of Radial Current Density at Rotor Surface Versus Circumferential Location for $Z=0.725$ (Midpoint of Brushtrack). This represents the boundary condition imposed upon the rotor conductor for all peripheral speeds $(50,100,200 \mathrm{~m} / \mathrm{s})$ investigated. Note that the DC offset represents the average radial current entering the cylinder and that a good approximation to a square wave has been attained using 11 Fourier terms for the circumferential representation.

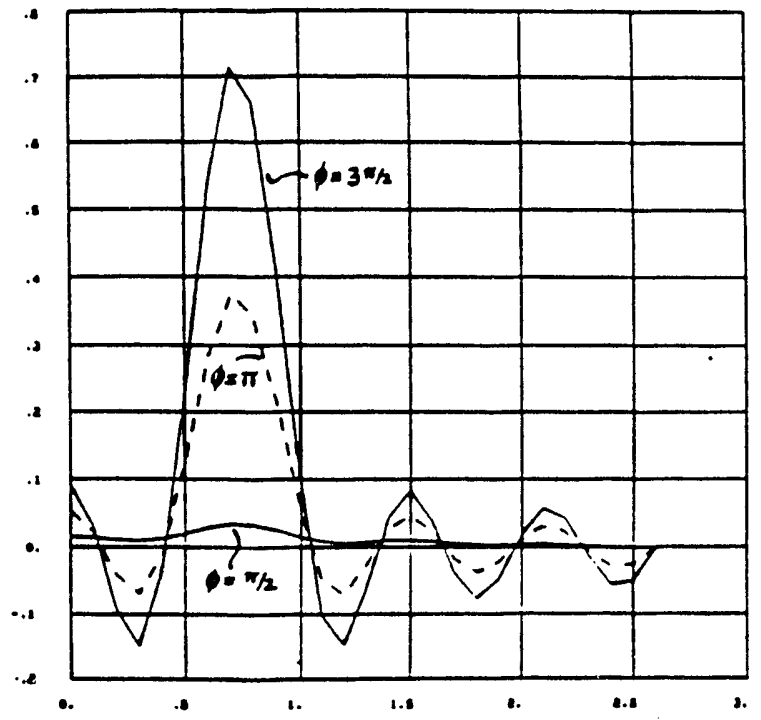

Figure 6 - Variation of Radial Current Density at Rotor Surface Versus Axial Location for $=\pi / 2 ; \pi ; 3 \pi / 2$. This represents the boundary condition imposed upon the rotor conductor for all peripheral speeds $(50,100,200)$ investigated. Note the match to assumed "square" input can be improved through use of more Fourier terms. 
(자)

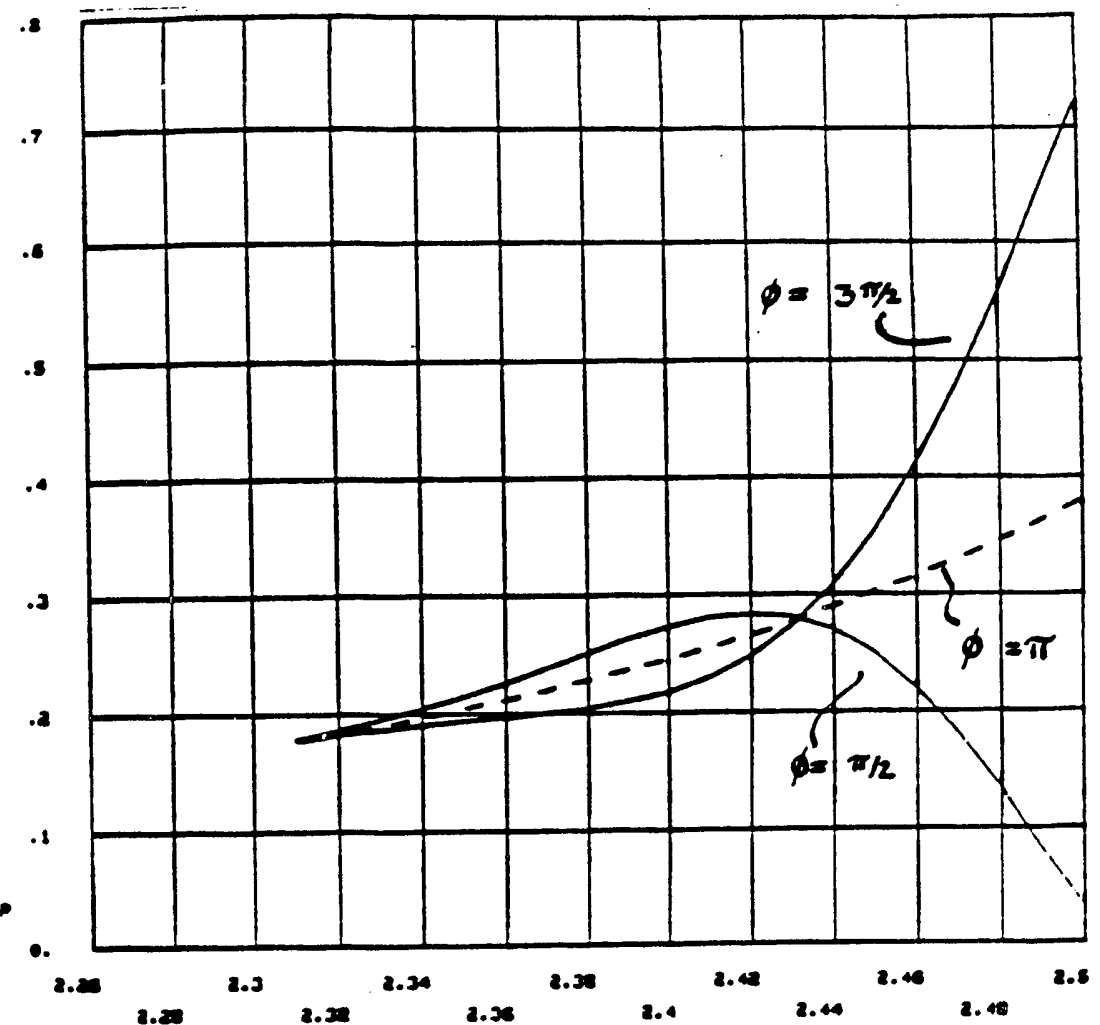

Figure 7 - Variation of Radial Current Density Versus Radius for a Rubbing Velocity of $100 \mathrm{~m} / \mathrm{s}$ and $=\pi / 2 ; \pi ; 3 \pi / 2$. The value of the radial current density at $\phi \pi$ is identical to the $D C$ value which results if current were injected into the rotor through a surface band defined by the brushtrack. The skin depth is apparent in this case and can be compared to similar Figures 14 and 17 which depict different rubbing volocities.

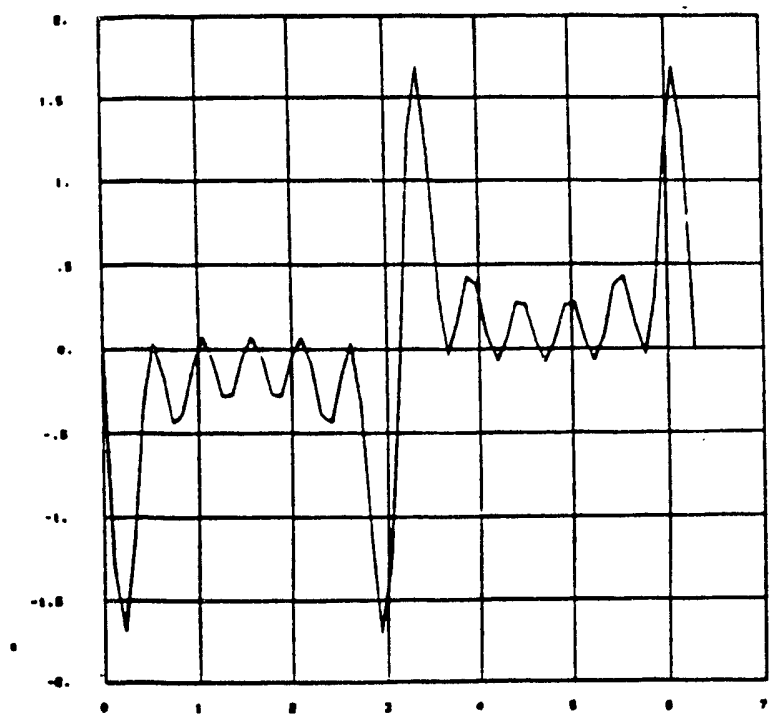

Figure 8 - Variation of Axial Current Density at Rotor Surface Versus Circumferential Location for $Z=.725$ (Midpoint of Brushtrack) and Rubbing Volocity $=100 \mathrm{~m} / \mathrm{s}$. Note the rather pronounced peaks evident about $0, \pi$ and $2 \pi$. These peaks are established about the points of current interruption (current is either made or broken at multiples of ז). 


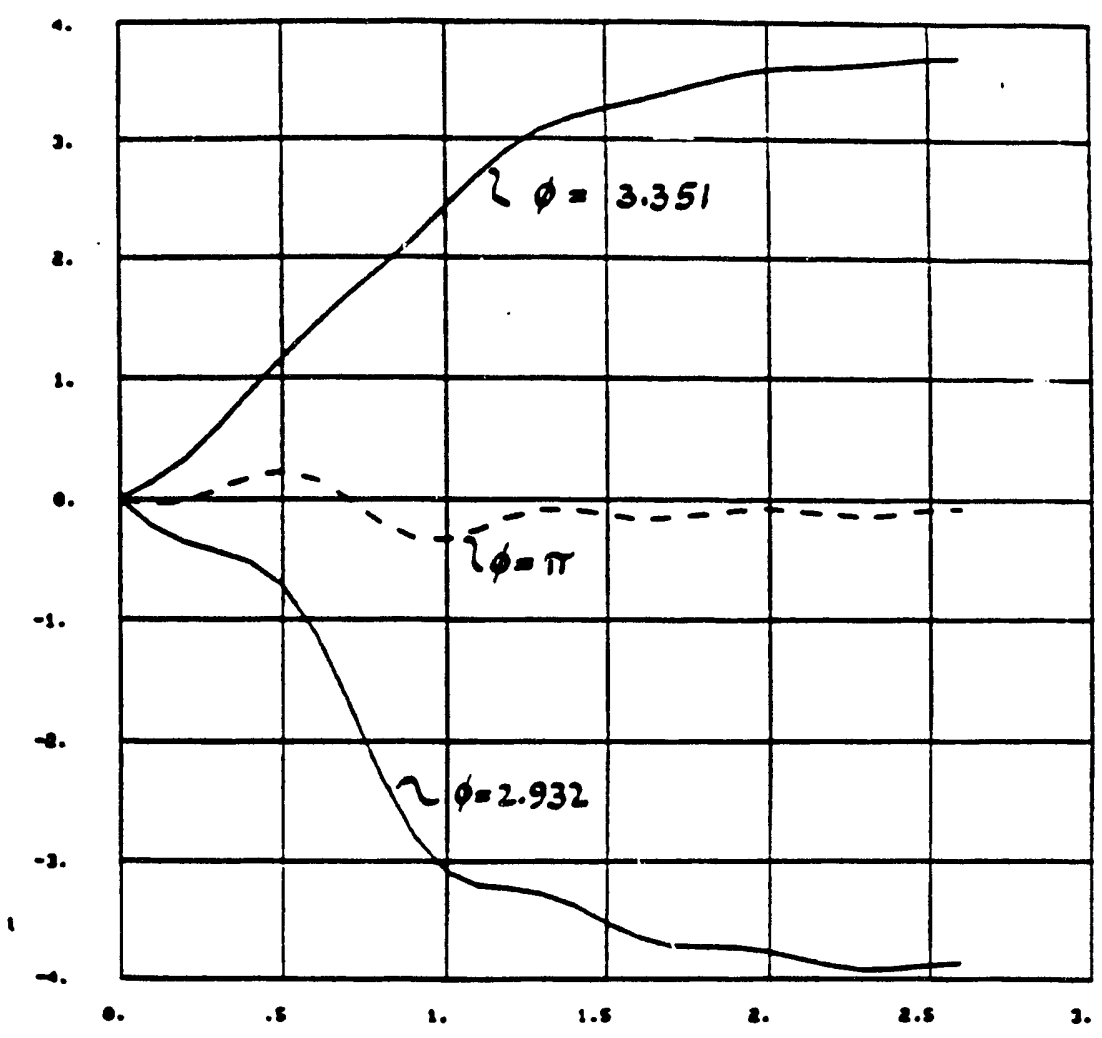

(20)

Figure 9 - Variation of Axial Current Density at Rotor Surface Versus Axial Location for $\phi=2.932, \pi, 3.351$ and Rubbing Volocity $=100 \mathrm{~m} / \mathrm{s}$. This figure shows the axial extent of the $A C$ surface phenomena. The peaks extend virtually unchanged for the length between the current collectors.

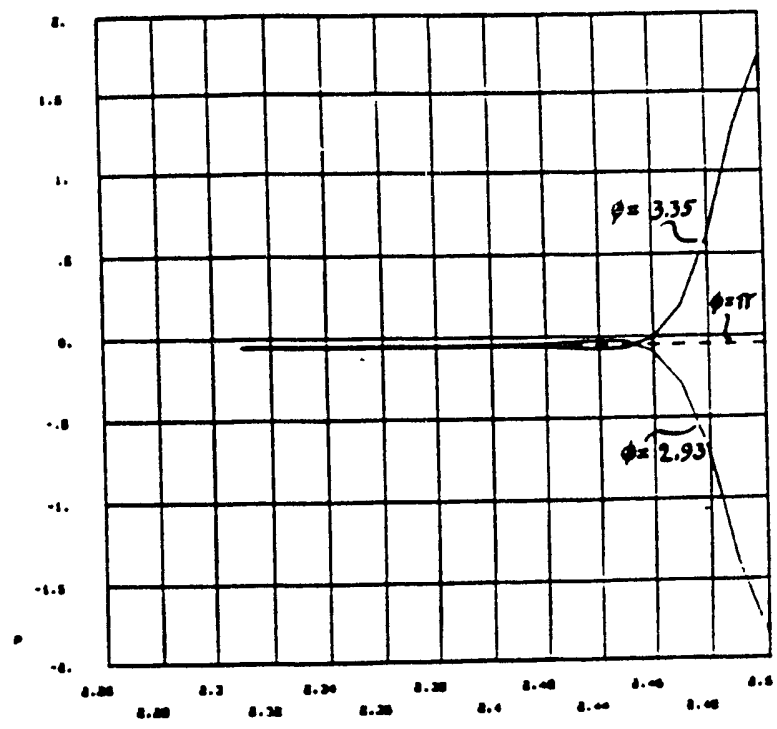

Figure 10 - Variation of Axial Current Density with Radius for $\phi=$ $2.93 ; \pi ; 3.35, Z=0.725$, and Rubbing Velocity $=100 \mathrm{~m} / \mathrm{s}$. The skin depth is apparent in this case and can be compared to similar Figures 15 and 18 which depict different rubbing velocities. 


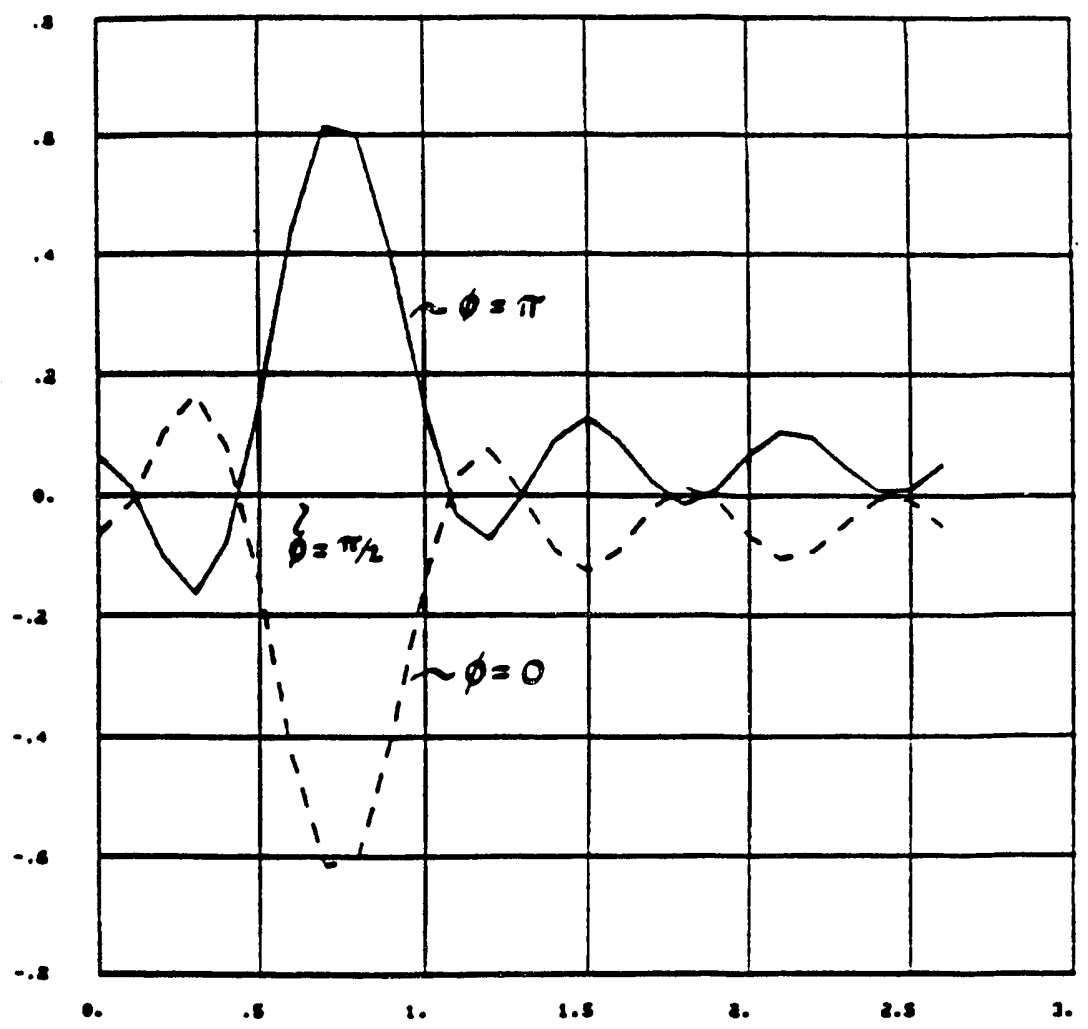

Figure 11 - Variation of Circumferential Current Density at Rotor Surface Versus Axial Location for $\phi=0 ; \pi / 2 ; \pi$ and Rubbing Volocity $=$ $100 \mathrm{~m} / \mathrm{s}$.

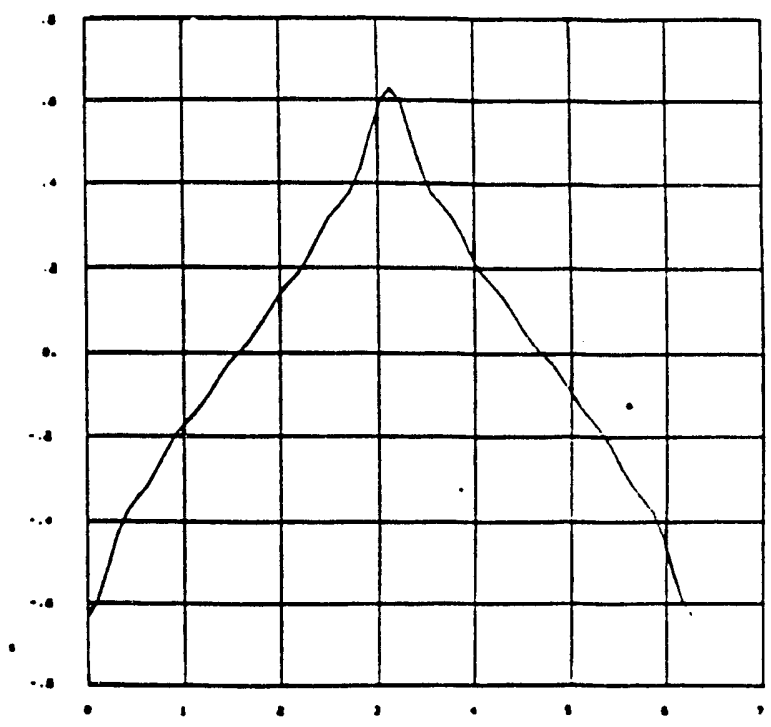

Figure 12 - Variation of Circumferential Current Density at Rotor Surface Versus Circumferential Location for $Z=0.725$ (Midpoint of Brushtrack) and Rubbing Volocity $=100 \mathrm{~m} / \mathrm{s}$. This variation is very pronounced only in the immodiate vicinity of the brush track. 


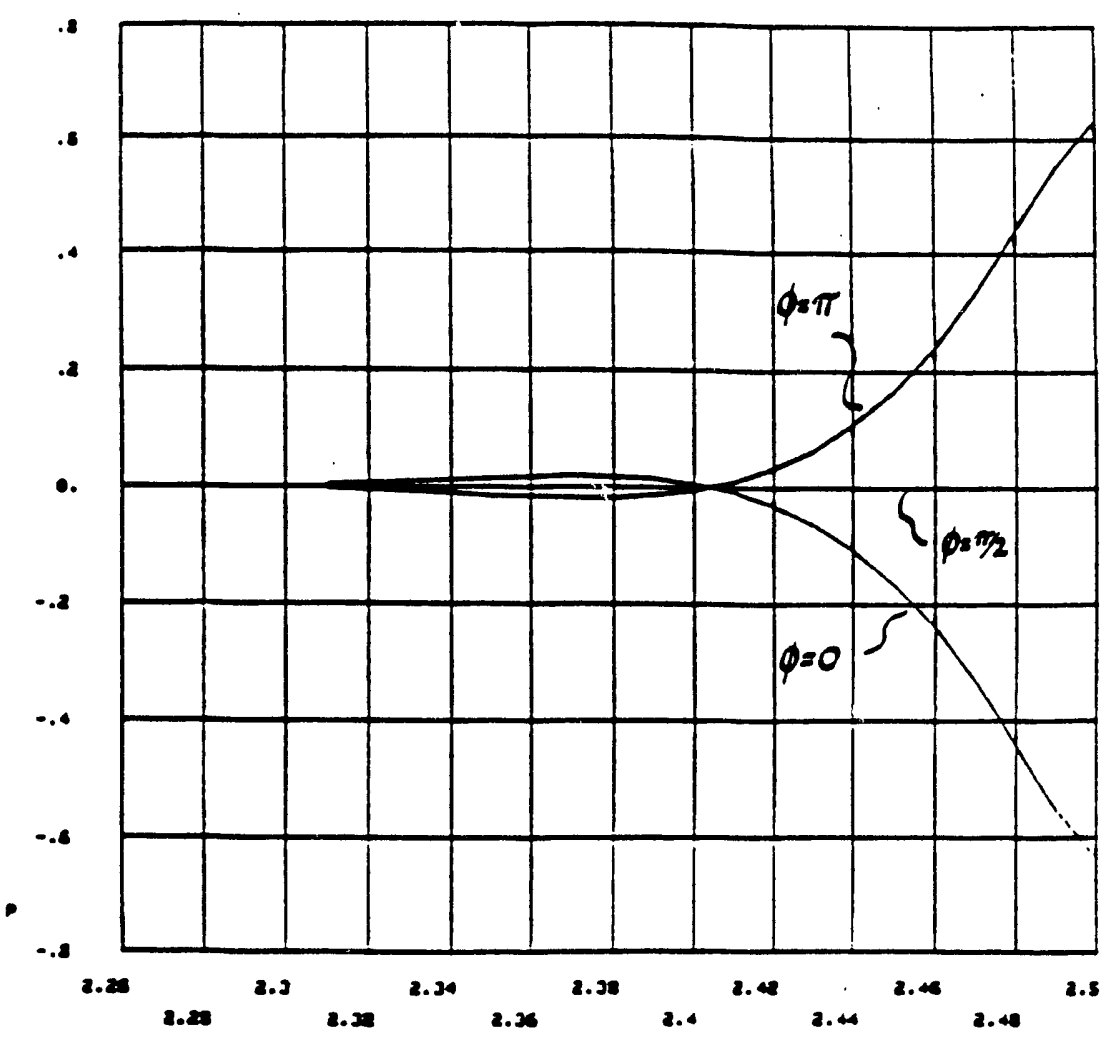

Figure 13 - Variation of Circumferential Current Density with Radius for $\phi=0 ; \pi / 2 ; \pi$ and Rubbing Velocity $=100 \mathrm{~m} / \mathrm{s}$. The skin depth is apparent in this case, and should be compared to similar Figures 16 and 19, which depict different rubbing velocities.

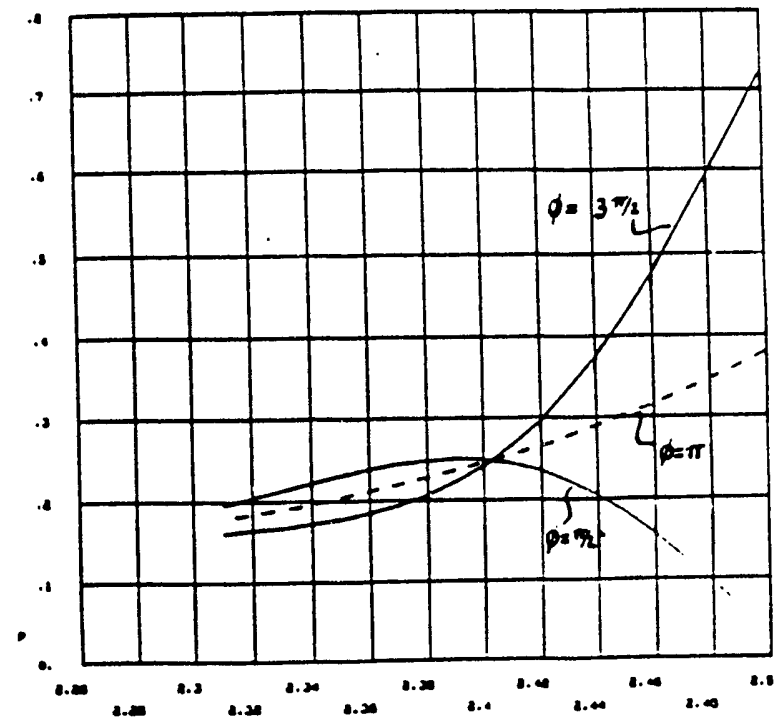

Figure 14 - Variation of Radial Current Density Versus Radiusfor a Rubbing Volocity of $50 \mathrm{~m} / \mathrm{s}$ and for $=\pi / 2 ; \pi ; 3 \pi / 2$ at $Z=0.725$ 


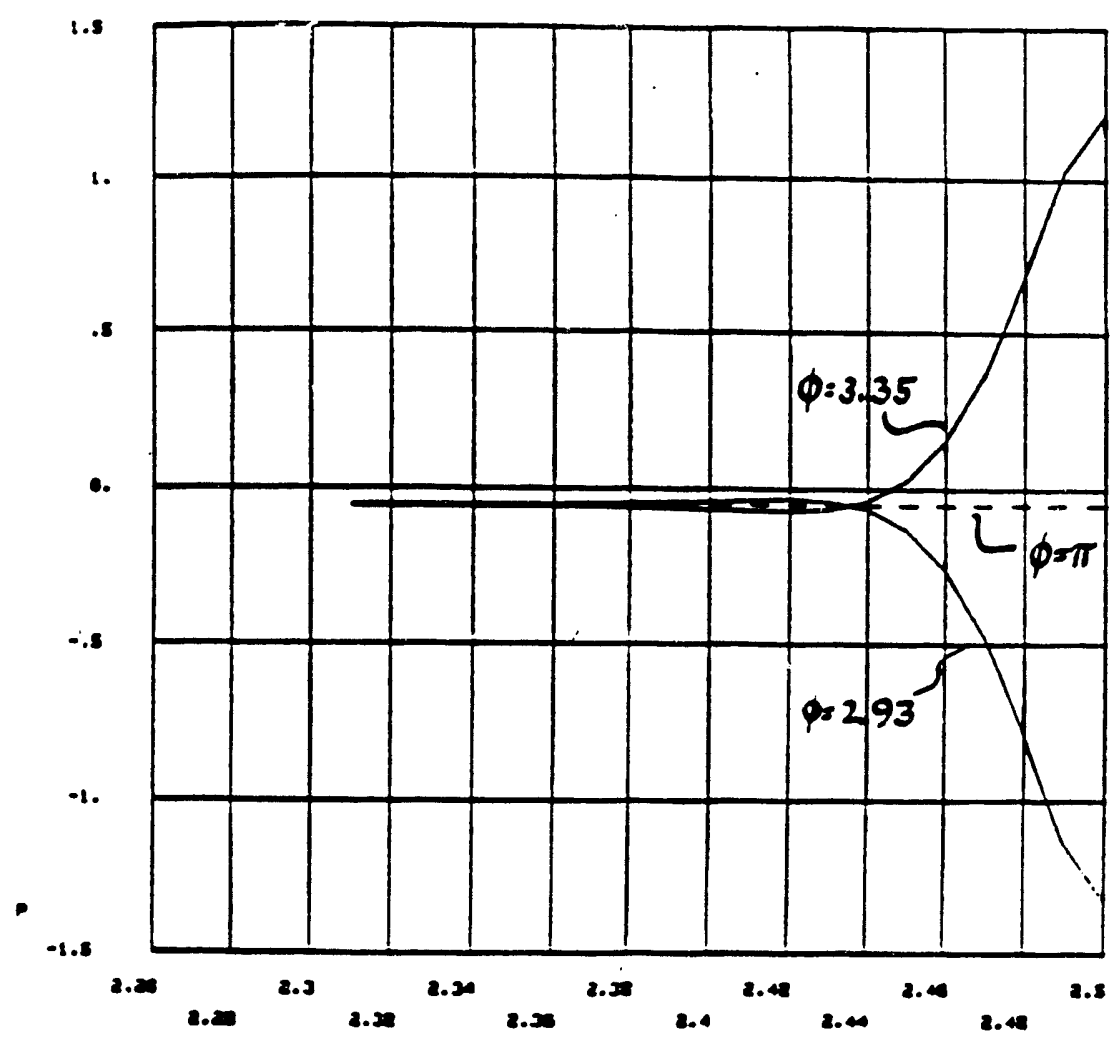

Figure 15 - Variation of Axial Current Density Versus Radius for a Rubbing Velocity of $50 \mathrm{~m} / \mathrm{s}$ and for $=2.93, \pi, 3.351$ at $Z=0.725$

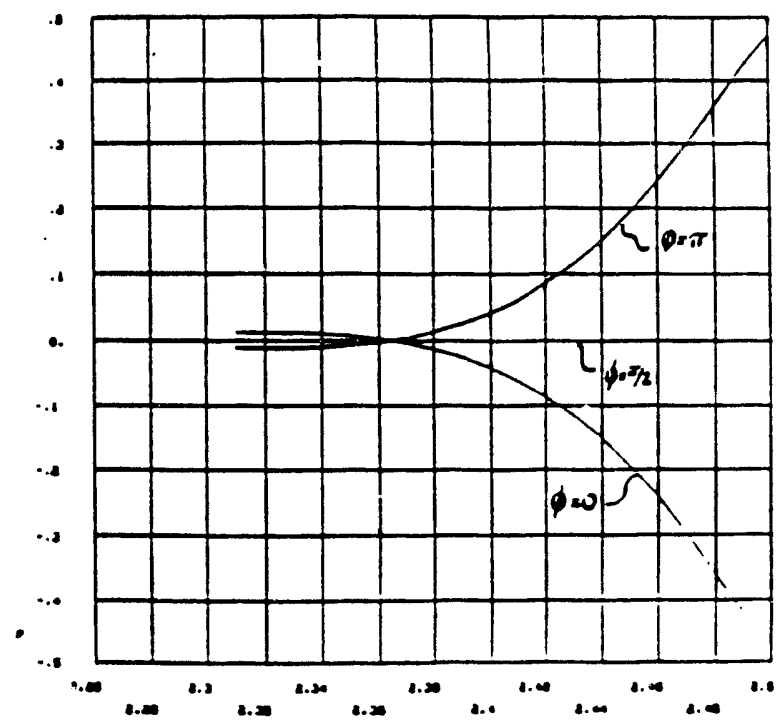

Figure 16 - Variation of Circumferential Current Density Versus Radius for a Rubbing Volocity of $50 \mathrm{~m} / \mathrm{s}$ for $=0 ; \pi / 2 ; \pi$ at $Z=0.725$ 


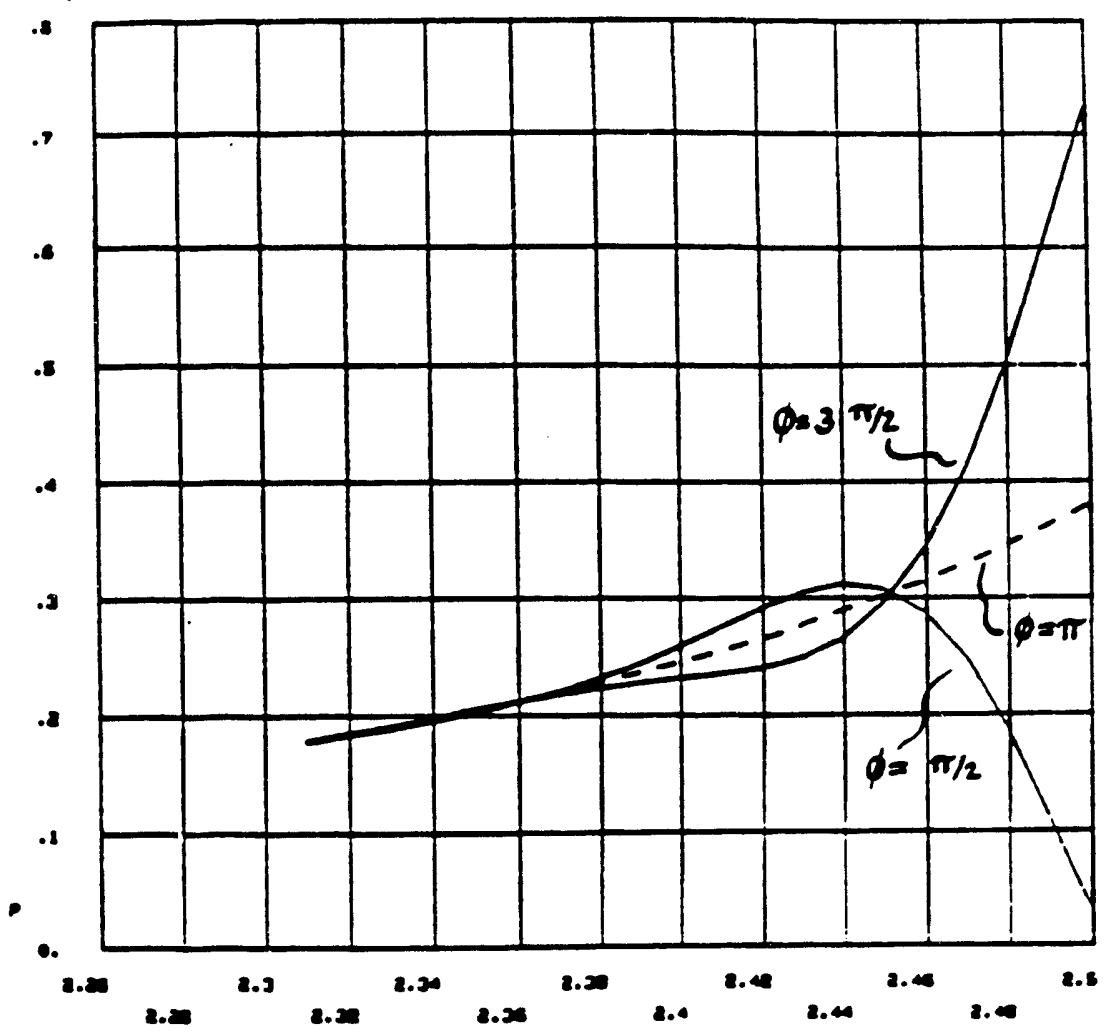

Figure 17 - Variation of Radial Current Density Versus Radius for a Rubbing Velocity of $200 \mathrm{~m} / \mathrm{s}$ and for $\phi=\pi / 2 ; \pi ; 3 \pi / 2$ at $Z=0.725$

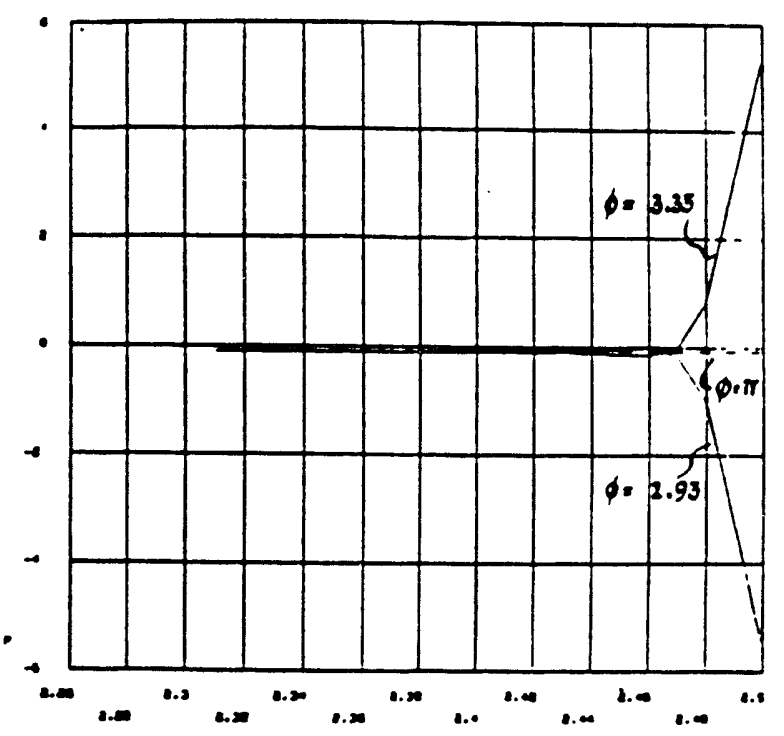

Figure 18 - Variation of Axial Current Density Versus Radius for a Rubbing Velocity of $200 \mathrm{~m} / \mathrm{s}$ and for $=2.93, \pi, 3.35$ at $Z=0.725$ 


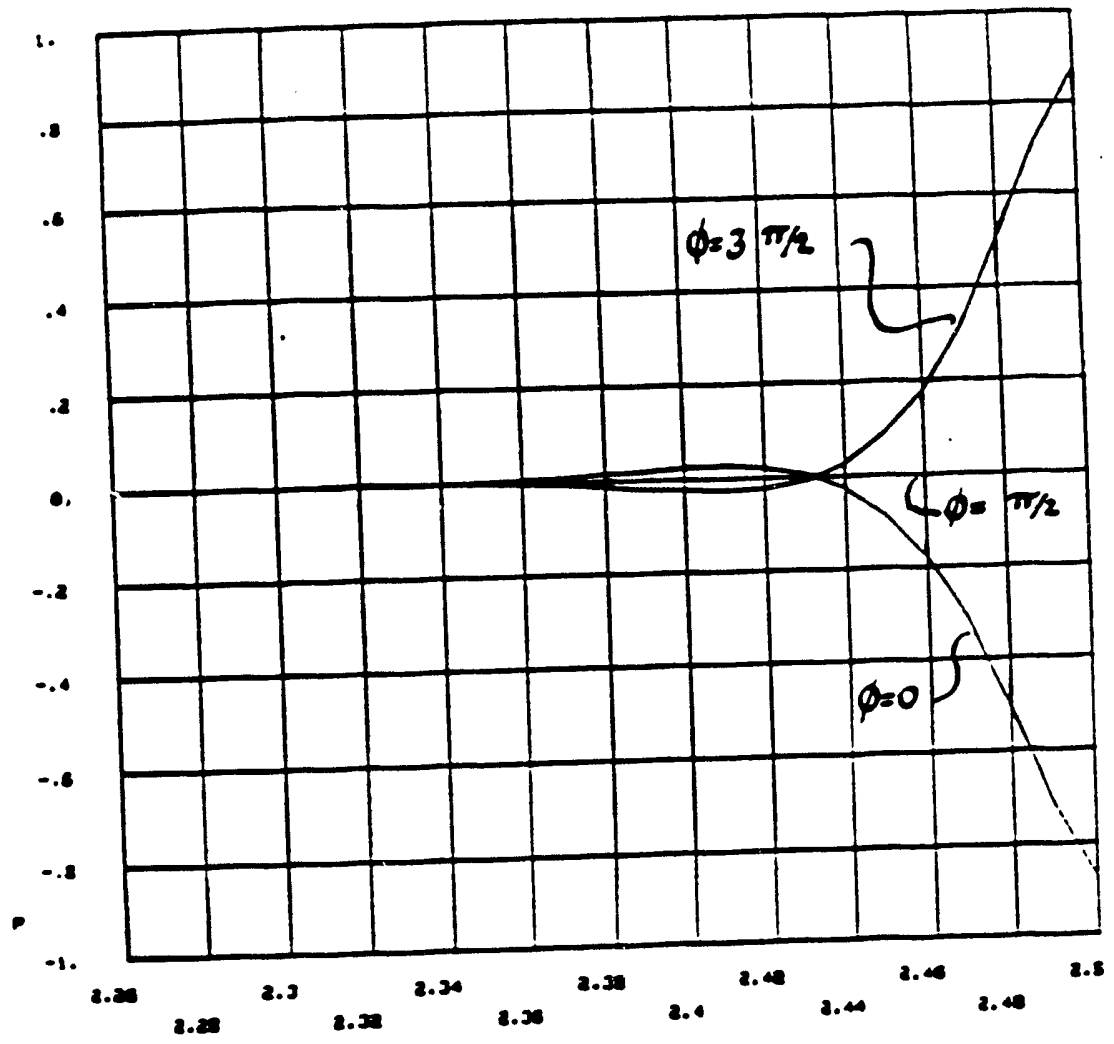

Figure 19 - Variation of Circumferential Current Density Versus Radius for a Rubbing Velocity of $200 \mathrm{~m} / \mathrm{s}$ and for $\phi=0 ; \pi / 2 ; \pi$ at $Z=0.725$

\section{REFERENCES}

1. R. H. Holm, "Electric Contacts, Theory and Application," SpringerVerlag, Now York, Fourth Edition, 1967, pp. 9-26.

2. J. A. Stratton, Electromagnetic Theory, McGraw-Hill, New York and London, First Edition, 1941, Pp. 349-361.

3. A. Sommerfeld, "Electrodynamics," Academic Press, New York and London, First Paperback Edition, 1964, Pp. 163-165. 


\author{
APPENDIX B \\ HOMOPOLAR MACHINE APPLICATION STUDY \\ Dennis Pavlik \\ Westinghouse R\&D Center
}

\title{
B.1 BACKGROUND
}

The objective of the Machine Application Study was to define a homopolar power supply which was suitable for the SDI mission requiring hundreds of megawatts of continuous dc power in the 50- to 400-Volt range. The major operational requirement of the system being that the power density exceed $80 \mathrm{~kW} / \mathrm{kg}$.

To define the operational space and functional design requirements for the current collection system, a baseline homopolar machine concept (which met the operational goals of the SDI mission) was selected. In particular, the selection of a baseline machine quantified the cooling fluids, rubbing speed, current densities, and the thermal and electromagnetic environments for the current collection system.

Two basic homopolar machine concepts were evaluated as part of the selection of a baseline machine. These were the "Iron Core" and "Air Core" machine arrangements. All concepts employed drum type construction (refer to Figure B-1), as previous studies ${ }^{1, a}$ have shown these to have the highest power density and voltage generating capability.

"Iron Core" refers to those machines which are constructed primarily of a ferromagnetic material (i.e., iron or steel). In addition to its structural function the "iron" provides a low reluctance path for the magnetic flux created by the field winding and greatly reduces the excitation requirements on the field winding. Because of the magnetic saturation of ferromagnetic materials, operation of "Iron Core" homopolar machines at flux densities much above 2 tesla is not practical.

"Air Core" refers to those machines which are constructed primarily of nonferromagnetic materials such as stainless steel, 


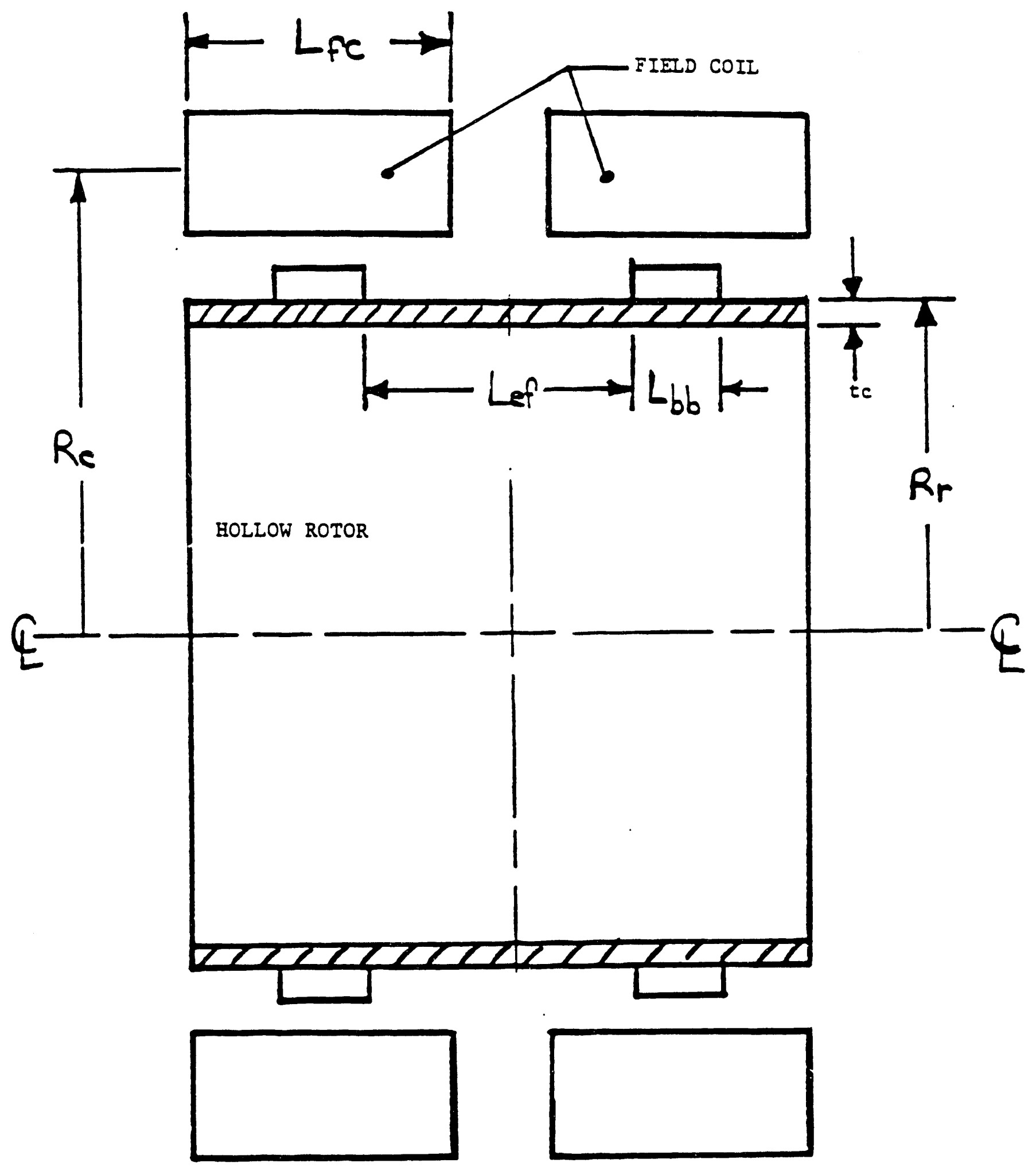

Figure B-1 - Ideal Drum Type Homopolar Motor. 
aluminum, copper, fiber composites, etc. "Air" refers to the fact that the materials used in their construction have roughly the same magnetic permeability as vacuo or air. In these machines there is no low reluctance path for the flux to follow. The flux pattern within the machine is controlled by the shape and placement of the field windings. Because the excitation requirements will in general be very high the field coils are almost always cryogenically cooled.

Previous studies ${ }^{1}$ for high voltage pulsed power systems have shown that "Air Core" machines will have higher power densities than "Iron Core" designs of the same rating. This is because the structural members in "Air Core" machines need only be designed for mechanical strength and not to carry magnetic flux. The savings in the weight of the structural materials more than offsets the added weight of the larger field coil. However, these studies dealt with very high voltage (thousands of volts) homopolar machines which required magnetic field strengths on the order of 4 to 8 tesla. At these high magnetic field strengths there is no advantage to using ferromagnetic materials.

Because low voltage (50 to several hundred volts), high power density, high efficiency machines have not been previously investigated a benchmark assessment of "Iron Core" technology was included as part of the application studies. The results of these studies will now be presented.

\section{B.2 IRON CORE DESIGN STUDIES}

To establish the limits on "Iron Core" technology for continuous duty applications, a series of parametric studies was undertaken. In these studies, the air gap flux density was fixed at 1.7 tesla. Increasing the flux density to 2 tesla will result in higher power densities. However, the practical operational limit for ferromagnetic materials is near the 1.7 tesla value. For these studies the rotor tip speed was fixed at 200 meters/sec (7874 ips) and the packing factor for the brushes was fixed at 0.3 . Two cooling schemes were evaluated: Scheme 1 - Cryogenically cooled field coils with a water cooled current collection system and rotor. Scheme 2 - Water cooled field coils, 
rotor, and current collection system. The basic difference between these techniques is their effect on the operating current densities for the different components. Table B-1 identifies the schemes and the differing operating points.

TABLE B-1

DIFFERING OPERATING PARAMETERS FOR THE IRON CORE SCHEMES

\begin{tabular}{|l||l|l|l|}
\hline SCHEME & 1 & $1 \mathrm{~A}$ & 2 \\
\hline ROTOR TIP SPEED - VEL (m/s) & 200 & 200 & 200 \\
BRUSH CURRENT DENSITY - JBR (MA/sq.m) & 20.0 & 20.0 & 11.6 \\
ROTOR CURRENT DENSITY - JRC (MA/sq.m) & 20.0 & 38.75 & 20.0 \\
FIELD COII CURNT. DEN. - JFC (MA/sq.m) & 77.5 & 77.5 & 20.0 \\
\hline
\end{tabular}

Another scheme that was briefly considered was an all cryogenicully cooled "Iron Core" system. However, the mechanical properties of magnetic steels are significantly degraded at cryogenic temperatures. The problems associated with interfacing a cryogenically cooled rotor conductor with a magnetic steel rotor make that scheme impractical and therefore it was not considered.

Figures B-2, B-3, and B-4 are graphs of the power density, efficiency, rotor speed, and terminal voltage versus machine power for schemes $1,1 \Lambda$, and 2 respectively. As expected, the cryogenically cooled field coil results in an increased power density and efficiency as compared to the all water cooled case.

The maximum power density obtainable at $100 \mathrm{MW}$ is $29 \mathrm{~kW} / \mathrm{kg}$ for the cryogenically cooled field coil (scheme 1A). This scheme operates at a $72 \%$ higher brush current density than scheme 1 .

Although efficiency is increasing with increasing power it seems that the $87 \%$ value is a barrier for the "Iron Core" technology when 


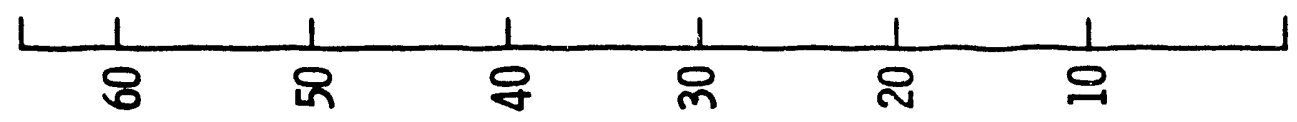

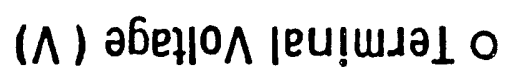

\begin{tabular}{cccccc}
1 & 1 & 1 & 1 & 1 & 1 \\
\hline 8 & 8 & 8 & 8 & 8 & 8 \\
8 & 8 & 8 \\
8 & 8 & 8 & 0 & 0 & 0
\end{tabular}

(Wdd) poəds a 


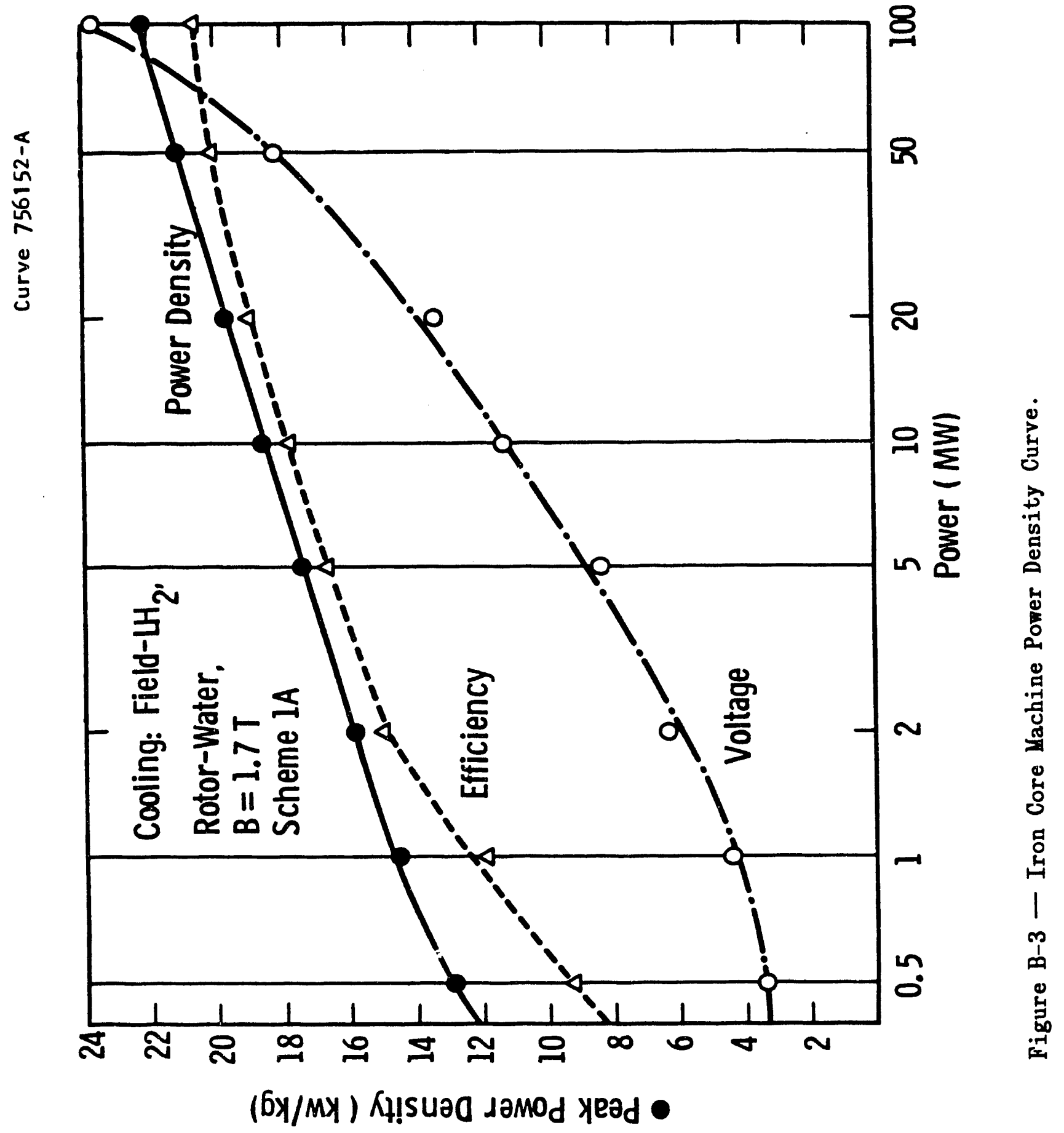

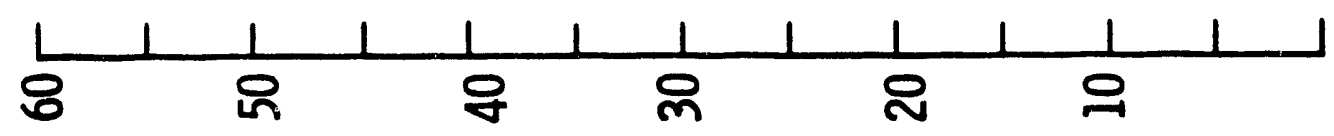

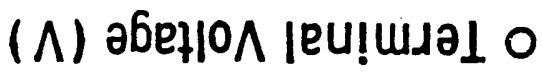

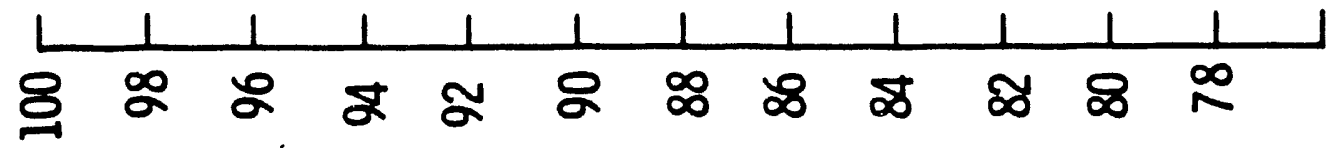

(\%) Кวนจ!ว!กษ $\nabla$ 


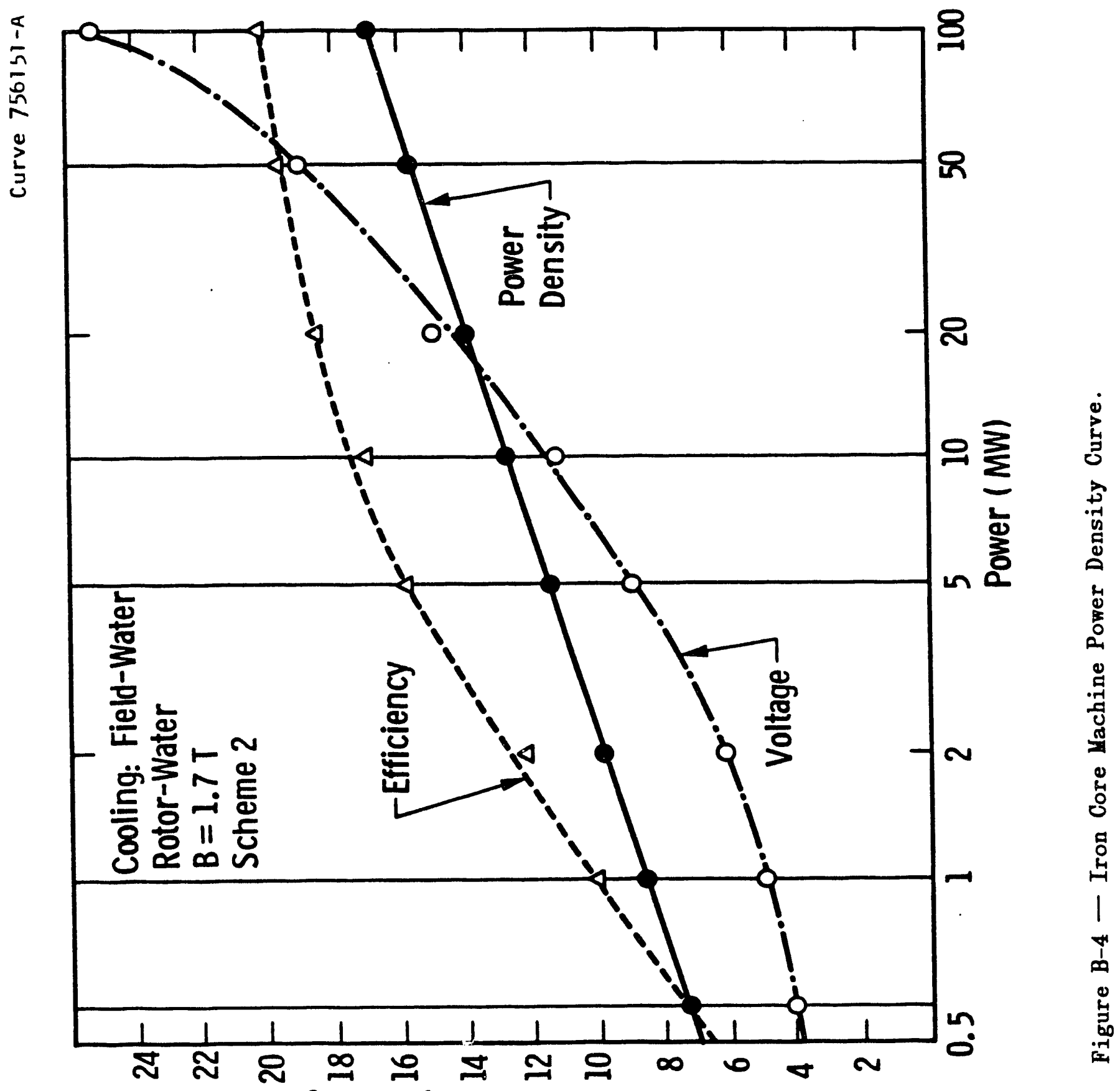

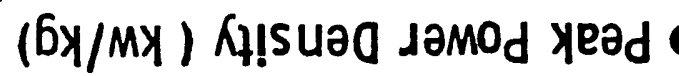

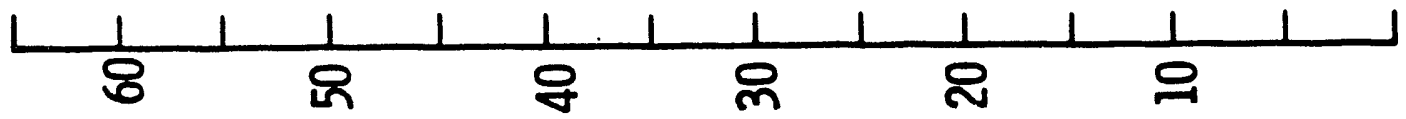

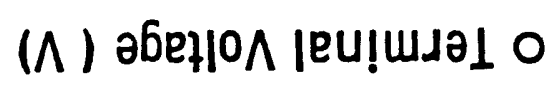

\begin{tabular}{llllllllllll}
1 & 1 & 1 & 1 & 1 & 1 & 1 & 1 & 1 & 1 & 1 & 1 \\
\hline 8 & $\approx$ & $\circ$ & $\&$ & $\approx$ & 8 & $\&$ & $\&$ & $\$$ & $\&$ & $\&$ & $\infty$
\end{tabular}

(\%) Кงบข!ว!Hヨ $\nabla$ 
operating at maximum power density given the present limits on brush current density, contact resistance, friction coefficient, and brush pressure. This is because losses are dominated by the brush friction and contact losses when operating at maximum power density.

Because the brush friction and contact loss are proportional to the load current, raising the operating voltage results in increased efficiency. However, for a fixed rotor velocity this also implies an increase in machine size and the field coil losses become significant and the efficiency begins to drop.

The work completed to date suggests that a continuous duty "Iron Core" based homopolar machine will not meet the $80 \mathrm{~kW} / \mathrm{kg}$ power density requirements for the SDI low voltage (50 to 100 volts) multimegawatt mission.

Although inadequate for the SDI mission, the power densitics which are obtainable using "Iron Core" technology are quite impressive when compared to conventional rotating electrical machinery. The benchmark studies have shown that at power levels below $2 \mathrm{MW}$ the "Iron Core" machines are competitive in terms of efficiency and power density with "Air Core" designs!

Increasing the rotor tip speed and brush current density does not address the question of low efficiency. Unless the efficiency can be increased, the cooling fluid requirements for a $100 \mathrm{MW}$ machine become too large. To meet the efficiency requirements the present friction coefficient and contact resistance limits must be reduced significantly.

Given the present limits on brush current density and rotor tip speed, the maximum obtainable power density approaches $30 \mathrm{~kW} / \mathrm{kg}$ at an efficiency of $96 \%$ which is significantly below the SDI mission requirements. Further increases in power density for this technology can only be achieved by dramatically increasing the rotor tip speed and/or brush current density. 


\section{B.3 AIR CORE DESIGN STUDIES}

B.3.1 Development of a Design Algorithm and Optimization Criteria

In general, "Air Core" homopolar machines have been designed on a case by case basis to meet a specific set of performance requirements. To make a systematic evaluation of the general performance characteristics and to identify the operational parameter space for "Air Core" designs it was necessary to develop an optimization criteria and design algorithm for these machines.

The two key differences between the "Air Core" and "Iron Core" designs are:

1) In an "Iron Core" machine the magnetic circuit and operating flux density defines the machine performance and all major dimensions such as the rotor diameter and weights. In "Air Core" machines the rotor diameter is the key independent physical parameter and it determines the magnetic circuit and operating flux density in addition to establishing the basic machine dimensions, weight, rpm (for a fixed tip speed), and power density.

2) In the "Air Core" algorithm the magnetic circuit equations are formulated in terms of the magnetic vector potential. The operational magnetic vector potential is simply the required internal voltage divided by the rotor tip speed (rolt-sec/meter $=$ webers $/$ meter $)$.

By formulating the magnetic field and voltage equations for the homopolar machine in terms of the magnetic vector potential, a unique optimum power density machine can be configured for a specified rotor diameter. This assumes that the limits on rotor tip speed, current densities in the brushes, rotor conductor, and field coils are specified along with a shape factor on the field coil as is done with "Iron Core" design algorithms.

Using the magnetic vector potential formulation and an idealized machine configuration based on infinitesimal current sources for the field winding, it was shown that the machine power density $(\mathrm{kW} / \mathrm{kg})$ depends on the difference in magnetic vector potential between the sets 
of brushes, divided by their spacing. This is equal to the average radial flux density in the active region, which means that the power density will be maximized when the average flux density in the active region is maximized. Assuming, of course, that the rotor tip speed, rotor radius and load current are fixed.

Figure B-5 shows a plot of the magnetic vector potential (for a single coil) and the average flux density versus brush spacing at a fixed radius. Bavg and power density (PDEN) peak when the brushes are spaced so that the internal voltage of the machine (E) is $50 \%$ of the maximum possible value that can be obtained.

The model was expanded to include finite dimensions and weights for the field coil. Subsequent studies which included the field coil weight and dimensions indicated that a machine designed using the $50 \%$ voltag iteria still produced the highest power density machine.

The rotor size is set by how much heat is generated (brush friction, rotor resistance, $I^{2} R$ ) and the area needed to manage the coolant fluids. The coil size is set by the field coil current density limit (fill factor and coolant management). The brush axial spacing, $L$, is set by the $50 \%$ voltage criteria for maximum power density; it is a function of the ratio of the rotor radius to the radius at the the magnetic centroid of the field coil.

The simplified model and analysis confirmed that a complete "Air Core" machine can be formulated using the same constraints as the "Iron Core" algorithm (i.e., rotor tip speed, current densities, packing factors, etc.), and two added constraints; a field coil shape and aspect ratio constraint, and a fixed rotor diameter. Furthermore, if the 50\% voltage criteria is used this machine will operate at the maximum power density.

The magnetic vector potential approach was verified using an idealized homopolar machine model. It was then incorporated into a more comprehensive design code which considered all major machine components. Several machines were configured using the design optimization algorithm. The code was then verified by comparing its results to a 
Curve 756148-A

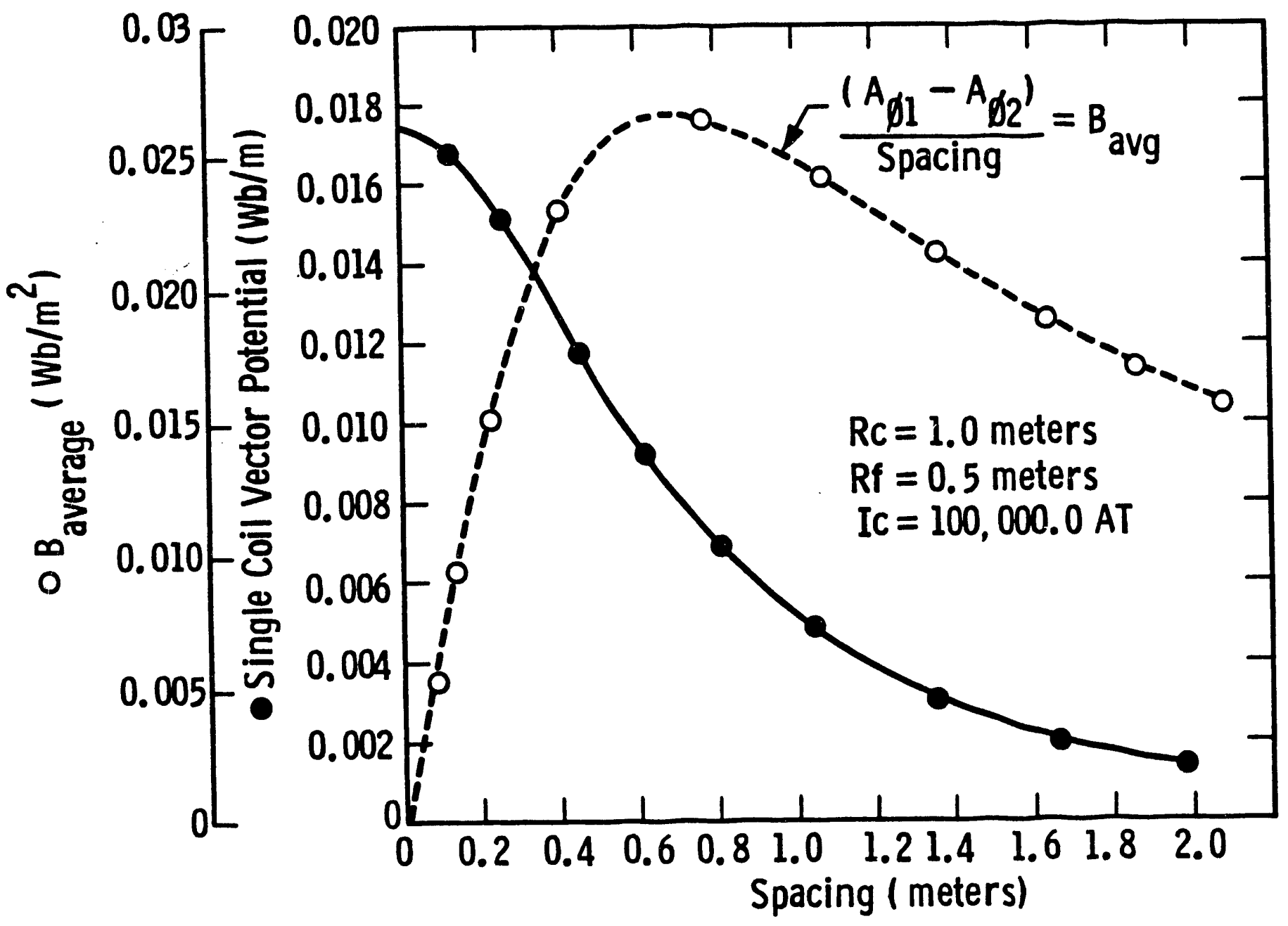

Figure B-5 - Variation in Vector Potential and Average Flux Density as a Function of Brush Spacing 
finite element model of the magnetic circuit and hand calculations for the structural and thermal performance.

\section{B.3.2 Parametric Studies}

The objectives of the parametric studies were two fold. The first was to verify the optimization criteria and investigate different machine configurations. The second was to establish the performance criteria and design requirements for the current collection systen.

One element of the initial parametric studies was an attempt to maximize the average $f l u x$ density in the active region (Bavg), as this is directly proportional to the machine power density. However, as previously mentioned, the studies showed that Bavg is not arbitrarily selectable if the machine is to be operated at maximum power density.

Bavg is not an arbitrarily selectable quantity becaus. the useful flux through the rotor depends on the ratio of the rotor radius to that of the field coil centroid and the ampere turns in the coil. Any increase in the field coil's excitation level must result in an increase in coil cross sectional area due to thermal constraints. This can be accomplished by changing the coil radial thickness, axial length, or a combination of the two.

Changing the radial coil thicknese will result in a lower flux density, and hence, lower porer density machine. This is because the machine flux increases linearly with excitation level but elliptically with changes in the ratio of rotor to coil radius. This means that the decrease in useful flux due to changing Rrot/Rcoil is much greater than the increase due to greater excitation.

Increasing the axial length of the coil to get extra ampere turis works to some extent, but eventually the coil length results in a brush spacing greater than the $50 \%$ voltage criteria would establish and further increases actually decrease Bavg and fower density.

A rectangular coil cross section (with the long dimension along the axis) ras selected for all fieid coil designs for the following reasons: 
1) A rectangular shape maximizes the ratio of Rrot/Rc which in turn increases the useful flux per ampere (this is not the same as maximizing the inductance of the coil).

2) It has the minimum volume for a fixed ampere turn excitation, which in turn gives the lowest loss and lightest weight.

3) The field coil must also be used to shape the flux profile in the current collection region to prevent excessive radial flux and hence circulating currents. To accomplish this requires a coil of a generally rectangular cross section which is at least twice as long as the brush box.

For the range of parameters investigated a coil which is twice as long as the radial thickness (aspect ratio of 2) seems to be a good compromise, although some further investigation is appropriate.

The selection of the hollow rotor design concept and the field coil geometrical constraints completed the set of design rules for "Air Core" continuous duty machines. The next phase of the parametric studies were used to define the current collector design specifications and parameter space. Table B-2 gives the design parameters used in the those studies.

Figure B-6 shows a typical power density (PDEN) versus voltage curve for a $50 \mathrm{MW}$ homopolar using the design constraints of Table B-2. Observe, that just as with iron core designs, there is a voltage where PDEN peaks. For the $50 \mathrm{MW}$ machine PDEN peaks at $80 \mathrm{~kW} / \mathrm{kg}$ between 50 and 53 volts. The efficiency is $96.2 \%$, but can be improved upon by changes in the current collector as will be discussed in more detail in the next section. 


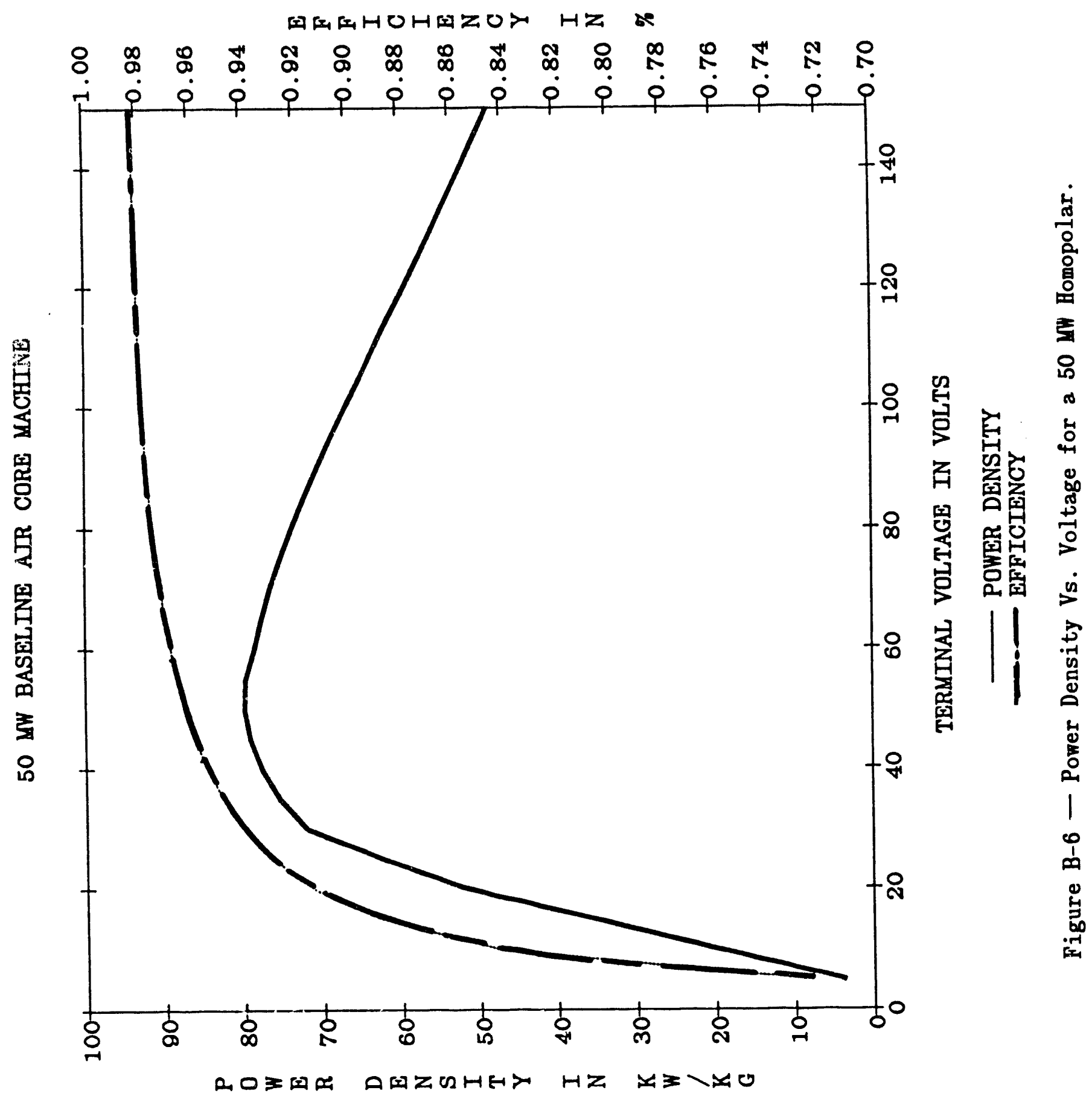




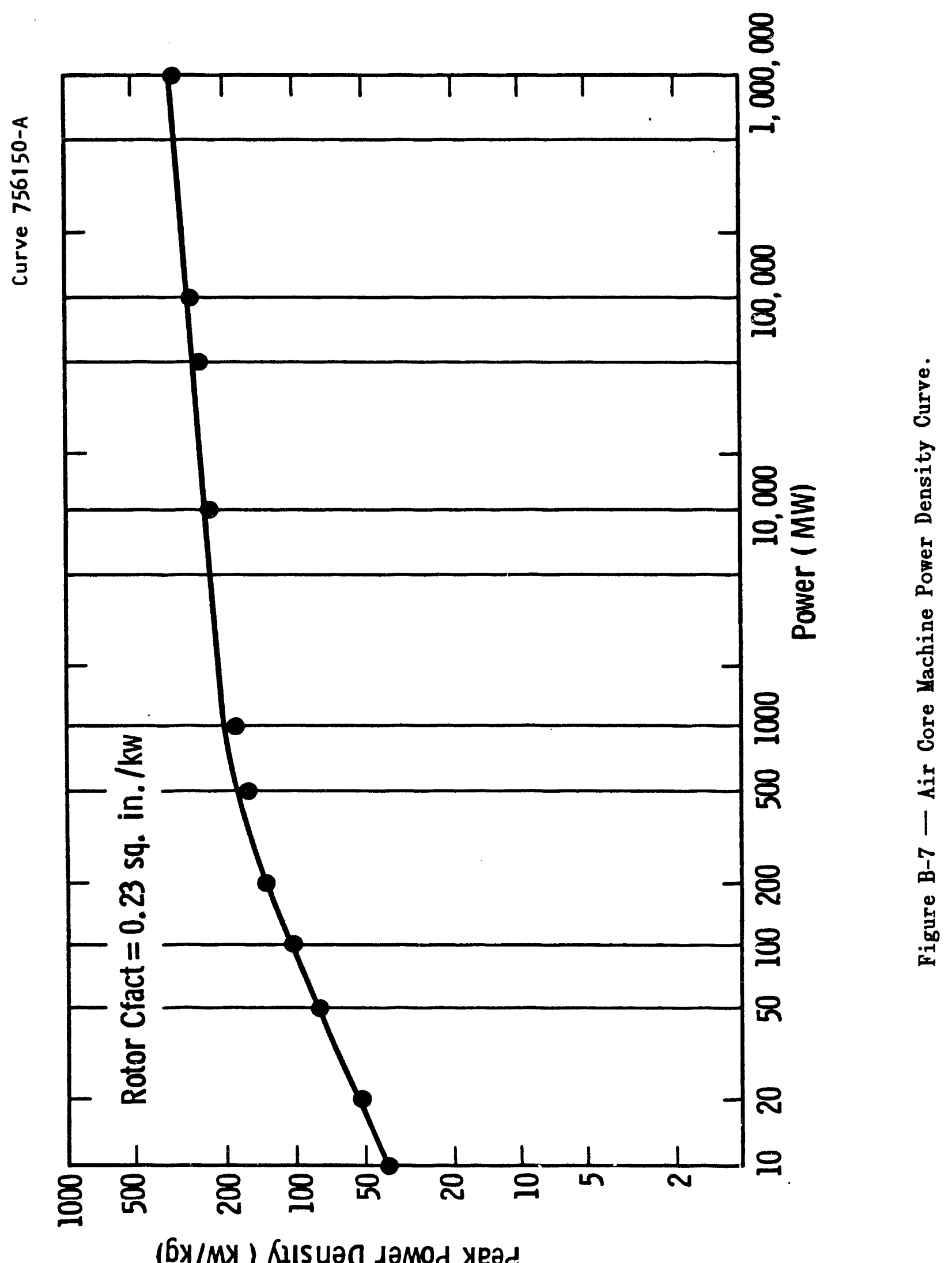

B-15 


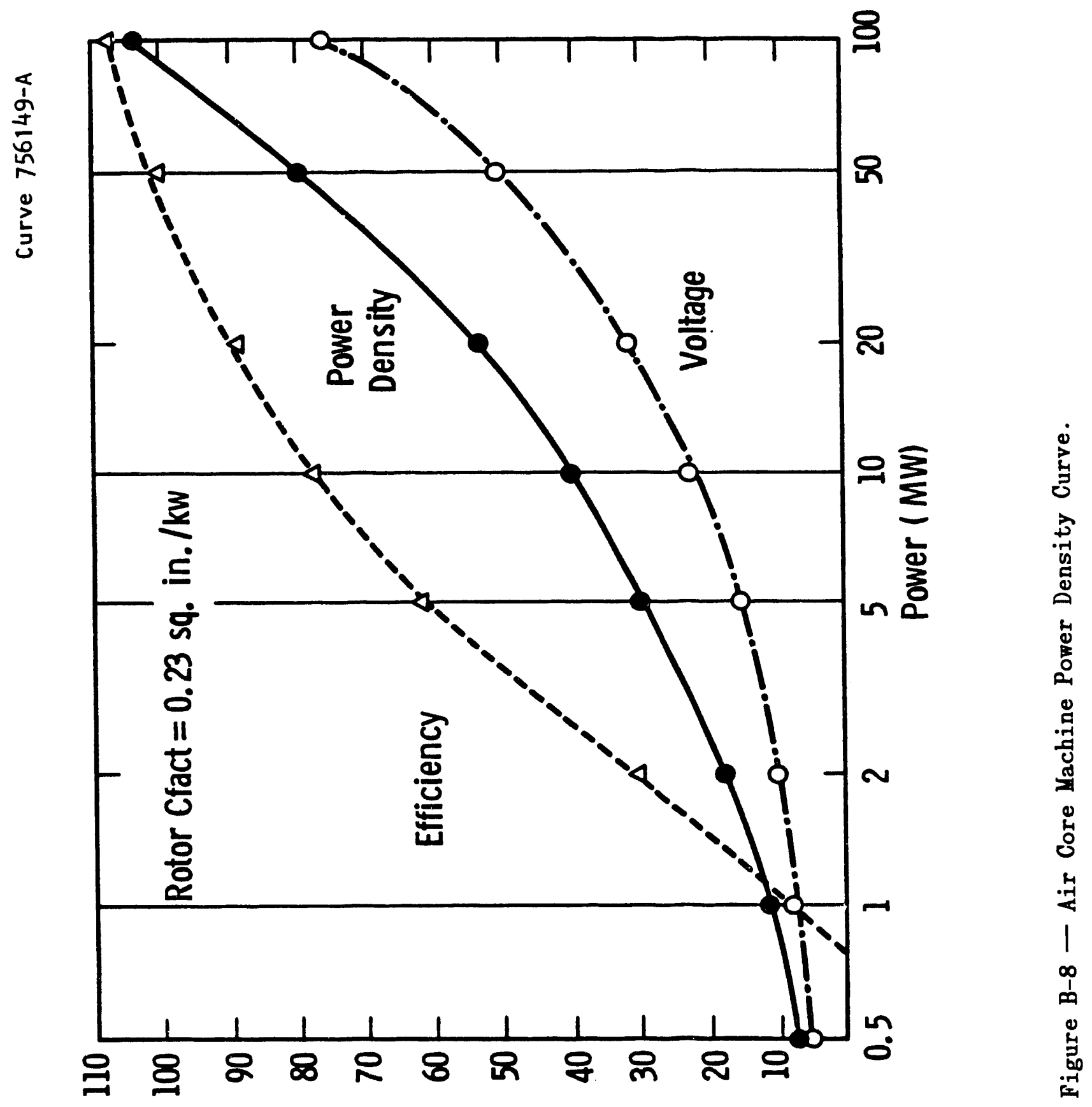

(БX/My) Kł!suәO дәм0д Yеәd

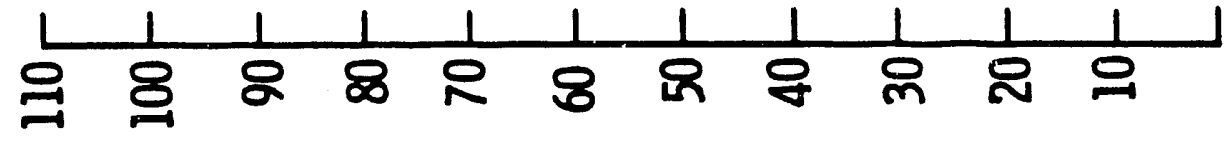

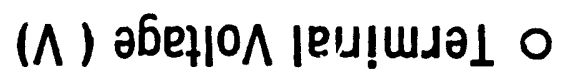

离

(\%) Кวบว!ว!มื $\nabla$ 
TABLE B-2

AIR CORE DESIGN CONSTRAINTS

\begin{tabular}{|lll|}
\hline \multicolumn{1}{|c|}{ PARAMETER } & VALUE & \multicolumn{1}{c|}{ UNITS } \\
\hline & & \\
FIELD COIL COOLING & LH2 & HYPERCONDUCTING \\
ROTOR COOLING & LH2 & HYPERCONDUCTING \\
ROTOR TIP SPEED & 200. & meters/sec. \\
BRUSH CURRENT DENSITY & $20.0(0.3)$ & $\mathrm{kA} / \mathrm{cm}^{2}$ (packing fraction) \\
FIELD CURRENT DENSITY & $77.5(0.4)$ & $\mathrm{kA} / \mathrm{cm}^{2}$ (packing fraction) \\
ROTOR CURRENT DENSITY & $77.5(1.0)$ & $\mathrm{kA} / \mathrm{cm}^{2}$ (packing fraction) \\
ROTOR RESISTIVITY & 0.021 & $\mu-0 \mathrm{hm}-\mathrm{cm}$ \\
FIELD COIL RESISTIVITY & 0.021 & $\mu-0 \mathrm{hm}-\mathrm{cm}$ \\
BRUSH RESISTANCE (cm2) & 0.001 & $0 \mathrm{hms} / \mathrm{brush}^{2}$ \\
FRICTION COEFICIENT & 0.10 & ------ \\
ROTOR COOLING FACTOR & 1.484 & $\mathrm{~kW} / \mathrm{cm}^{2}$ \\
\hline
\end{tabular}

A set of power density vs voltage curves was made for output powers ranging from $0.5 \mathrm{~mW}$ to $10,000 \mathrm{MW}$. These curves were compiled into a composite curve showing peak power density vs power as shown in Figure B-7. A more detailed set of data showing not only power density but also machine voltage and efficiency vs power for the $0.5 \mathrm{M}$ to 100 MW power range is shown in Figure B-8.

In Figure B-8 the efficiency curve peaks at about $87 \%$. This can be improved by changing the operating current density of the brushes. In a current collector the minimum loss condition occurs when the friction loss and $I^{2} \mathrm{~B}$ contact loss are equal. In the systems considered, the friction losses are only $10 \%$ of the total losses and the $I^{2} R$ contact losses are $81 \%$ of the total. Therefore, machine efficiency can be increased by lowering the brush current density and increasing the number of brushes.

An investigation of the impact of varying the current collector defining parameters is planned for 1988 . 


\section{B.3.3 Baseline Machine Selection}

In the final segment of the application study a $50 \mathrm{MW}$ "Air Core" homopolar machine was configured to serve as a baseline. The $50 \mathrm{MW}$ rating was selected because it was large enough to be useful in the SDI mission scenario and small enough so that it could be built and tested.

As shown in Figure B-5, the machine had a power density of 80 $\mathrm{kW} / \mathrm{kg}$ using the current collector design goals and the hollow rotor concept. The efficiency was $96.2 \%$, but this can be increased by relaxing the brush current density goal of $2 \mathrm{kA} / \mathrm{cm}^{2}$. The basic physical dimensions are shown in Figure B-8. Figure B-9 shows a breakdown of the weight and loss for the major machine components.

The most surprising finding was that the average magnetic field, Bavg, was only 1.04 tesla and that the peak field in the system was below $2.3 \mathrm{~T}$. This is clearly within demonstrated limits of operating current collectors (iron core experience).

\section{B.4 CONCLUSIONS AND RECOMMENDATIONS}

The work complated to date suggests that rather impressive power densities are obtainable using "Iron Core" technology. However, given the present limits on brush current density and rotor tip speed, the maximum obtainable power density approaches $30 \mathrm{~kW} / \mathrm{kg}$ at an efficiency of $96 \%$, which is short of the SDI requirements. Further increases in energy density for this technology can only be achieved by dramatically increasing the rotor tip speed and/or brush current density. It does not appear that sufficient breakthroughs in this technology can be made to make it viable for the low voltage (50 to 100 volts) SDI application. "Iron Core" homopolar machines are not suited for the SDI mission requiring multimegawatt, low de voltage, continuous operation, for the following reasons:

1) To meet. the SDI mission requirements the machine will require cryogenic cooling. The physical properties of magnetic steels are significantly degraded at these temperatures, and interfaces between the magnetir. steel 
rotor and stator with the cryogenic components would require significant developments in the state of the art.

2) To achieve the power density increases necessary to meet SDI goals, the brush current density and rotor tip speed limits will have to be significantly increased. Since any developments in this area apply equally well to "Air Core" technology, which already has significantly higher power densities, this work should be directed toward those machines as the benefits will be greater.

3) The minimum efficiency requirement keeps the cooling requirement in line with fuel consumption. To achieve this minimum efficiency means that the friction coefficient and contact resistance will have to be significantly lowered. It also means that the homopolar machine will have to operate at less than the maximum power density point. The higher tip speed is also working against the efficiency requirement. Again, since an "Air Core" technology-based machine has an inherent advantage in terms of power density, it can more readily be operated at "off peak" conditions and appears to be more attractive.

Previous work has indicated that "Air Core" homopolar machines are viable for the medium voltage (several thousand volts), multimegawatt pulsed duty SDI application. The application study conducted for this program shows that they are also applicable for the low voltage continuous duty application as well. The major problem in the low voltage application will be to maintain a high power density at high efficiency. The critical fiactors are rotor tip speed, contact resistance, brush friction, and operating current density.

The most significant findings of the study are:

1) The average magnetic field in the active region of "Air Core" homopolar machines (operating at maximum power density) is not an arbitrary quantity, but depends on the rotor diameter and the thermal properties and cooling technique employed in the desigñ. 
2) Power densities of $80 \mathrm{~kW} / \mathrm{kg}$ can be achieved with average flux densities in the active region of about 1 tesla, and peak values anywhere in the magnetic circuit under 2.3 tesla.

It is recommended that the application studies be continued to determine the interrelationships between the various parameters which define the current collection system (i.e., trade off between friction coeficient, cooling scheme, operating current density). Further studies of alternate design concepts such as the inside out machine (field coil on the inside of the rotor), the impact of dimensional clearances, and field coil shaping should also be undertaken. 


\section{REFERENCES}

1. K. I. Thomassen, et.al. "Conceptual Engineering Design of a One-GJ Fast Discharging Homopolar Machine for the Reference Theta-Pinch Fusion Reactor," EPRI report ER-246, Semi Annual Report August 1976 .

2. D. W. Ohst and D. Pavlik, "Self-Excited Air Core (SEAC) Homopolar Generator Concept Design," Final Report to the U S Army Armament Research and Development Command (AARADCON) Contract DAAA21-85-C0214, Sept 1986. 

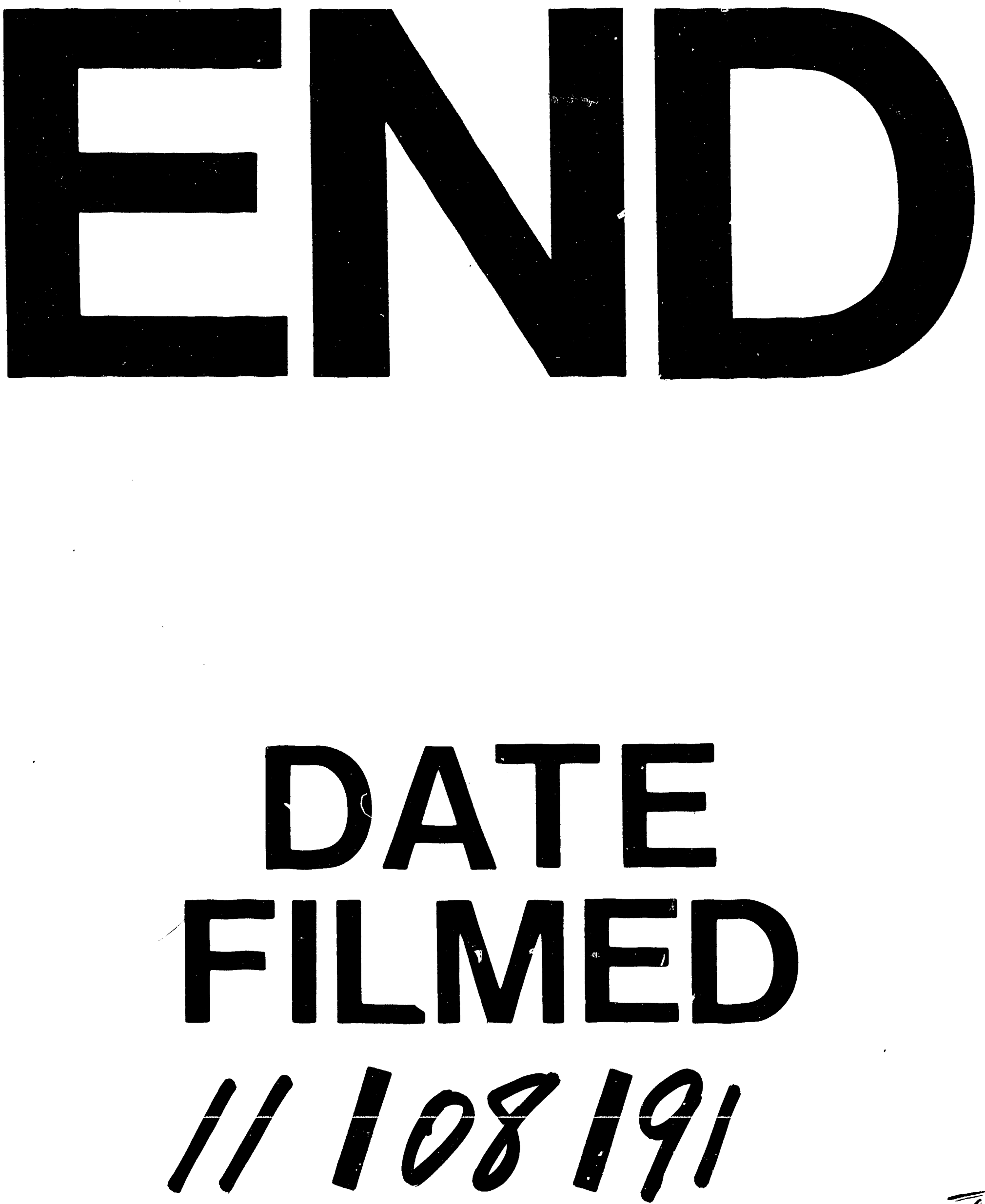

$\bar{Z}$ 
